UNIVERSIDADE DE SÃO PAULO

FFCLRP - DEPARTAMENTO DE FÍSICA

GUSTAVO SANTO PEDRO PAMPLONA

Conectividade funcional no cérebro: Uma análise das associações com desempenho intelectual e atenção sustentada usando imagens por ressonância magnética

Ribeirão Preto - SP

2014 


\title{
Conectividade funcional no cérebro: Uma análise das associações com desempenho intelectual e atenção sustentada usando imagens por ressonância magnética
}

\begin{abstract}
Dissertação apresentada à Faculdade de Filosofia, Ciências e Letras de Ribeirão Preto da Universidade de São Paulo como parte das exigências para a obtenção do título de Mestre em Ciências.
\end{abstract}

Área de concentração

Física Aplicada a Medicina e Biologia.

Orientador:

Prof. Dr. Carlos Ernesto Garrido Salmon

$$
\text { Ribeirão Preto - SP }
$$


Autorizo a reprodução e divulgação total ou parcial deste trabalho, por qualquer meio convencional ou eletrônico, para fins de estudo e pesquisa, desde que citada a fonte.

\section{FICHA CATALOGRÁFICA}

Pamplona, Gustavo Santo Pedro

Conectividade funcional no cérebro: Uma análise das associações com desempenho intelectual e atenção sustentada usando imagens por ressonância magnética / Gustavo Santo Pedro Pamplona; Carlos Ernesto Garrido Salmon. Ribeirão Preto - SP, 2014.

$105 p$.

Dissertação (Mestrado - Programa de Pós-Graduação em Física Aplicada a Medicina e Biologia) - Faculdade de Filosofia, Ciências e Letras de Ribeirão Preto da Universidade de Ribeirão Preto, 2014.

1. Conectividade funcional. 2. Redes complexas. 3. Atenção sustentada. 4. Inteligência. 5. fMRI. 
Nome: PAMPLONA, Gustavo Santo Pedro

Título: Conectividade funcional no cérebro: Uma análise das associações com desempenho intelectual e atenção sustentada usando imagens por ressonância magnética

Dissertação apresentada à Faculdade de Filosofia, Ciências e Letras de Ribeirão Preto da Universidade de São Paulo como parte das exigências para a obtenção do título de Mestre em Ciências.

Aprovado em

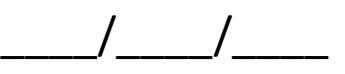

\section{Banca examinadora}

Prof. Dr. Instituição:

Julgamento: Assinatura:

Prof. Dr. Instituição:

Julgamento: Assinatura:

Prof. Dr. Instituição:

Julgamento: Assinatura: 


\section{Agradecimentos}

A Deus e ao destino por haverem me trazido até aqui e ter me reservado algo realmente prazeroso e digno de ser estudado.

Àquela que me trouxe o fôlego, coragem, persistência e refúgio sempre que era preciso. Por ter apoiado minhas escolhas, pela companhia inseparável mesmo à distância, por ser o caminho e a chegada. Meu muito obrigado a você, Vanessa, chegamos aqui juntos.

A toda minha adorável e muito amada família que contava comigo de Rio Claro. A meu correto e inteligente pai, a minha querida e zelosa mãe, a minha tão graciosa e carinhosa irmã, ao melhor amigo que é meu irmão.

Ao Prof. Dr. Garrido, guia justo, conselheiro profissional e orientador constante no melhor sentido da palavra. Seu rigor e disciplina exigidos nortearam o trabalho do princípio ao fim. "Mas vem cá... " Muito obrigado!

Ao professor Baxter Rogers, dono de um cérebro repleto de ideias para o estudo dos próprios cérebros e de uma paciência impagável, ao professor John Gore pela indicação à visita e à toda a equipe do VUIIS, em Nashville (TN-EUA), que me recebeu tão cordialmente.

Àqueles que suportaram a tarefa árdua de dividir comigo o ambiente de trabalho e que foram copiosos em compartilhar o conhecimento. À plêiade de pesquisadores e amigos que é o laboratório InBrain. A todos vocês, sem exceção!

Pela contribuição intelectual e apoio emocional que trouxeram os amigos Jeam (Mineiro) e Antônio Carlos (Bizu). Aos amigos e irmãos de longa data Rodrigo (Barba), Pedro (Jesus) e Ricardo (Killer). Aos bons momentos com o Fabio Vaz, o Henrique Dutra, o Gustavo (Sotoma), o Tiago (Costa) e o Mark Worley.

Ao Gérson Santos Neto, indicado pela Dra. Sara Rosset, pela aplicação e correção pontuais e meticulosas dos testes de avaliação intelectual.

A todos os voluntários interessados que prontamente se dispuseram a tomar parte desse trabalho, os quais foram parte crucial do projeto.

Aos técnicos operadores, secretárias e enfermeiros do setor de ressonância magnética do HCFMRP pelo suporte prático e pela ajuda na solução de problemas.

Ao suporte financeiro oferecido pela CAPES, pelo custeio da visita ao exterior concedida pela SBF, à estrutura e suporte educacional oferecido pela FFCLRP e ao CCIFM pelo uso das instalações do tomógrafo de ressonância magnética. 


\section{Resumo}

PAMPLONA, G. S. P. Conectividade funcional no cérebro: Uma análise das associações com desempenho intelectual e atenção sustentada usando imagens por ressonância magnética. 2014. 105p. Dissertação (Mestrado - Programa de Pós-graduação em Física Aplicada a Medicina e Biologia) - Faculdade de Filosofia, Ciências e Letras de Ribeirão Preto, Universidade de São Paulo, Ribeirão Preto - SP, 2014.

Sabe-se que diversas regiões do cérebro humano trabalham em sincronia, mesmo anatomicamente separadas, sugerindo conexões funcionais e estruturais. Dessa forma, nosso cérebro pode ser considerado uma rede que pode ser estudada para diferenças entre indivíduos e entre tarefas, em que os nodos podem ser diferentes regiões e as arestas podem ser medidas de conectividade funcional entre séries temporais de um sinal de ressonância magnética de cada região. Neste estudo, propomos analisar como conectividade funcional e parâmetros de rede cerebral se relacionam com desempenho intelectual e um estado de atenção sustentada. Foram adquiridas imagens de ressonância magnética de 30 indivíduos saudáveis jovens em estado de repouso e de atenção sustentada, a partir delas foram calculadas as conexões funcionais entre 90 regiões cerebrais usando o coeficiente de correlação entre pares de series temporais. Destes sujeitos foram estimados sete índices de inteligência a partir da aplicação do teste WAIS-III. As matrizes de conectividade evidenciariam um comportamento de rede complexa de mundo pequeno para limiares entre 0,2 e 0,5. Não foram encontradas associações entre parâmetros globais das redes ponderadas em estado de repouso e os índices de inteligência. Conectividade funcional e alguns parâmetros de rede locais evidenciaram correlações com pontuações de inteligência, principalmente nas regiões frontal, pré-central, parietal e occipital, giro fusiforme e supramarginal e caudado. Embora o p-valor não-corrigido seja bem pequeno e/ou haja 
simetria entre hemisférios em alguns resultados, ao ser considerado o efeito de múltiplas comparações para análise inteira não foram encontradas associações estatisticamente significativas, por isso as análises foram corrigidas para cada região ( $p$-valor corrigido pelo FDR $<0,05)$. Ainda assim, possivelmente um aumento do número de sujeitos levaria a resultados mais conclusivos. Não foram encontrados resultados que confirmassem a hipótese de que, para indivíduos normais, haveria uma maior anti-correlação de redes extrínsecas e intrínsecas como um todo para o estado de atenção focada em relação ao estado de repouso. Entretanto, durante o estado de atenção sustentada, foram encontradas algumas diferenças estatisticamente significantes nas conexões locais dentro das redes positivas e negativas à tarefa, evidenciadas por um aumento na magnitude das correlações positivas ou negativas durante a atenção sustentada, além de uma tendência de anticorrelação em conexões entre regiões positivas e negativas à tarefa.

Palavras-chave: 1. Conectividade funcional. 2. Redes complexas. 3. Atenção sustentada. 4. Inteligência. 5. fMRI. 


\section{Abstract}

PAMPLONA, G. S. P. Functional connectivity of the brain: Analyzing the associations with intellectual performance and sustained attention using magnetic resonance imaging. 2014. 105p. Dissertation (MSc. - Postgraduate Program in Physics Applied to Medicine and Biology) - Faculty of Philosophy, Sciences and Literature, University of São Paulo, Ribeirão Preto - SP, 2014.

It's known that some regions of the human brain work synchronously, even if they are anatomically separated, suggesting functional and structural connections. In this way, our brain can be considered a network that can be studied for individual or task differences and in which nodes can be the different regions and edges can be the measurements of functional connectivity between blood oxygen level-dependent signal time series from each region. In this study, we aim to analyze how functional connectivity and brain network parameters relate to intellectual performance and to sustained attention state. Resonance Magnetic images were acquired in 30 healthy young volunteers in resting and attentional state. The functional connections between 90 brain regions were computed from them using correlation coefficient between pairs of temporal series. Seven intelligence indices were estimated from these subjects through WAIS-III test application and associations between functional connectivity values or brain network parameters were sought. Connectivity matrices evidenced a small-world complex network behavior for thresholds between 0.2 and 0.5. No associations between global parameters using weighted networks were found. Functional connectivity and network parameters have evidenced some correlations with intelligence scores, mainly in frontal, pre-central, parietal, occipital regions, fusiform and supramarginal gyrus and caudate nucleus. Even that the uncorrected $p$-value was small and/or there was symmetry between hemispheres in several results, statistical significant 
associations were not found considering multiple comparisons correction for the entire analysis, therefore the analysis were corrected for each region (FDR corrected p-value $<0.05)$. Even, increasing the number of subjects possibly would get more conclusive results. Results corroborant to the initial hypothesis of greater anti-correlation between default mode network and task-positive regions were not found for the sustained attention state. However, during sustained attention state, some statistically significant differences in local connections within task-positive and negative regions were found, evidenced by the increase of the strength of positive and negative correlations, besides of a trend of anti-correlation in connections between task-positive and negative regions.

Key-words: 1. Functional connectivity. 2. Complex networks. 3. Sustained attention. 4. Intelligence. 5. fMRI. 


\section{Lista de Figuras}

Figura 1. Relação entre ativação no cérebro e imagem funcional. Extraída de Gusnard, 2001.

Figura 2. Mapas quantitativos de fluxo sanguíneo (primeira linha) e consumo de oxigênio (segunda linha) para sujeitos no repouso com olhos abertos. Há grande variação de fluxo sanguíneo e consumo de oxigênio entre as regiões do cérebro, principalmente entre substância branca e cinzenta. Mesmo assim, fluxo sanguíneo e consumo de oxigênio se correspondem, como é refletido na OEF, mostrado nos mapas da terceira e quarta linhas. Extraída de Raichle et al., 2001.

Figura 3. Esquematização de como é realizado o estudo de conectividade funcional no repouso para o método da semente. Baseada em van den Heuvel e Pol, 2010

Figura 4. Diferentes padrões no repouso estimados por análise de componentes independentes: (a) regiões corticais visuais mediais, (b)regiões corticais visuais laterais, (c) sistema auditório, (d) sistema sensório-motor, (e) sistema visuo-espacial, (f) controle executivo, (g) sistema visual dorsal direito e (h) sistema visual dorsal esquerdo. Vistas sagital, coronal e axial de diferentes mapas espaciais associados com padrões de repouso de baixa frequência estimados de um grupo de 10 sujeitos. As coordenadas referem-se às distâncias em milímetros da comissura anterior. Extraída de Beckmann et al., 2005

Figura 5. Regiões mostrando diferenças em ativação durante o desempenho da tarefa RVIP e da tarefa controle. Fatias axiais são mostradas a cada $9 \mathrm{~mm}$ de $-21 \mathrm{~mm}$ (inferior) a $51 \mathrm{~mm}$ (superior). Cores quentes indicam ativação durante a tarefa RVIP e cores frias indicam desativação. Regiões: (1) cerebelo esquerdo, (2) cerebelo médio, (3) cerebelo direito, (4) giro occipital esquerdo, (5) giro fusiforme direito, (6) giro parahipocampal esquerdo, (7) ínsula anterior direita, (8) córtex cingulado anterior, (9) córtex frontal medial esquerdo, (10) ínsula anterior esquerda, (11) ínsula média esquerda, (12) ínsula média direita, (13) tálamo/núcleo caudado, (14) córtex cingulado médio/posterior, (15) giro frontal médio/inferior esquerdo, (16) giro frontal médio/inferior direito, (17) giro frontal médio/superior direito, (18) giro temporal médio esquerdo, (19) pré-SMA (área motora suplementar), (20) giro parietal esquerdo, (21) giro parietal direito, (22) giro frontal médio esquerdo, (23) giro frontal médio direito. Extraída de Lawrence et al., 2003.

Figura 6. Modelagem de uma rede funcional cerebral. Adaptado de van den Heuvel e Pol, 2010

Figura 7. Rede complexa (a) com algumas características gráficas como: (b) grau de um nodo, (c) coeficiente de clusterização do nodo, (d) modularidade, (e) comprimento de caminho característico e (f) centralidade. Adaptado de van den Heuvel e Pol, 2010.

Figura 8. Classificação de topologias de rede. Adaptado de van den Heuvel e Pol, 2010.

Figura 9. Correlações intrínsecas dentro de uma região semente no PCC e todos os outros voxels no cérebro para um único sujeito durante o repouso. Acima são mostradas distribuição dos coeficientes de correlação; as regiões em cores quentes mostram correlações positivas e as regiões em cores frias mostram correlações negativas. Abaixo, são mostradas as séries temporais para a região semente no 
PCC (em amarelo) positivamente correlacionadas com a região semente no córtex pré-frontal medial (em laranja) e negativamente correlacionados com a região semente no sulco intraparietal. Extraído de Fox et al., 2005.

Figura 10. Tomógrafo de MRI de 3 Tesla localizado no Hospital das Clínicas de Ribeirão Preto (SP)........56

Figura 11. Interface do toolbox CONN, implementado para MatLab, versão 13.m................................59

Figura 12. Extração de séries temporais de sinal BOLD de cada região do atlas AAL. .............................60

Figura 13. Construção de redes cerebrais e cálculo de parâmetros de rede. .64

Figura 14. No gráfico da esquerda, são mostrados os resultados para o comprimento de caminho característico médio para redes cerebrais (vermelho) e para redes aleatórias (azul) para limiares entre 0,05 e 0,5 . No gráfico da direita, são mostrados os resultados para o coeficiente de clusterização médio para redes cerebrais (vermelho) e para redes aleatórias (azul) para o mesmo intervalo de limiares. As linhas de maior espessura ligam os pontos resultantes dos cálculos, enquanto que as linhas de menor espessura representam a adição e subtração do desvio-padrão.

Figura 15. Para todos os limiares usados, são mostrados os gráficos de lambda e gama. As linhas de maior espessura ligam os pontos resultantes dos cálculos, enquanto que as linhas de menor espessura representam a adição e subtração do desvio-padrão.

Figura 16. Comprimento de caminho característico normalizado (lambda) (gráfico à esquerda) negativamente correlacionado com QIT no estudo de van den Heuvel et al. (2009). No mesmo estudo, não foi encontrada correlação entre o coeficiente de clusterização normalizado (gama) e o QIT. Foram utilizadas redes binárias dentro da escala de mundo-pequeno (limiar de 0,45), em que os nodos eram cada um dos voxels. Extraída de van den Heuvel et al., 2009.

Figura 17. Comprimento de caminho característico normalizado (lambda) (gráfico à esquerda) e coeficiente de clusterização normalizado (gama) (gráfico à direita) sem correlação significante com o QIT, utilizando os dados do nosso estudo. Foram utilizadas redes binárias dentro da escala de mundo-pequeno (limiar de 0,45 ), em que os nodos eram cada uma das regiões do atlas AAL.

Figura 18. Visões axial, coronal e axial das regiões com associação significante entre coeficiente de clusterização e/ou eficiência local para a rede cerebral e QIE. Os números correspondem à classificação mostrada na tabela 5 .

Figura 19. Visões axial, coronal e axial das regiões com associação significante entre coeficiente de clusterização e/ou eficiência local para a rede cerebral e QIT.

Figura 20. Visões axial, coronal e sagital das regiões com associação significante entre coeficiente de clusterização e/ou eficiência local para a rede cerebral e ICV. Os números correspondem à classificação mostrada na tabela 7.

Figura 21. Visões axial, coronal e axial das regiões com associação significante entre coeficiente de clusterização e/ou eficiência local para a rede cerebral e IOP. Os números correspondem à classificação mostrada na tabela 8.

Figura 22. Visões axial, coronal e axial das região com associação significante entre coeficiente de clusterização e/ou eficiência local para a rede cerebral e IMT. .... 
Figura 23. Visões axial, coronal e axial das regiões com associação significante entre coeficiente de clusterização e/ou eficiência local para a rede cerebral e IVP. Os números correspondem à classificação mostrada na tabela 10.

Figura 24. Visões axial, coronal e axial de pares de regiões conectadas funcionalmente com associação significante com QIV para um p-valor corrigido pelo FDR menor que 0,1. As conexões em vermelho representam correlações positivas. Os números correspondem às classificações mostradas na tabela 11

Figura 25. Visões axial, coronal e axial de pares de regiões conectadas funcionalmente com associação significante com QIE para um p-valor corrigido pelo FDR menor que 0,1. As conexões em vermelho representam correlações positivas. Os números correspondem às classificações mostradas na tabela 12.

Figura 26. Visões axial, coronal e axial de pares de regiões conectadas funcionalmente com associação significante com QIT para um p-valor corrigido pelo FDR menor que 0,1. As conexões em vermelho representam correlações positivas. Os números correspondem às classificações mostradas na tabela 13.

Figura 27. Visões axial, coronal e sagital de pares de regiões conectadas funcionalmente com associação significante com ICV para um p-valor corrigido pelo FDR menor que 0,1 . As conexões em vermelho representam correlações positivas e a conexão em azul representa uma correlação negativa. Os números correspondem às classificações mostradas na tabela 14.

Figura 28. Visões axial, coronal e axial de pares de regiões conectadas funcionalmente com associação significante com IOP para um p-valor corrigido pelo FDR menor que 0,1 . As conexões em vermelho representam correlações positivas. Os números correspondem às classificações mostradas na tabela 15.

Figura 29. Visões axial, coronal e axial de pares de regiões conectadas funcionalmente com associação significante com IMT para um p-valor corrigido pelo FDR menor que 0,1 . As conexões em azul representam correlações positivas. Os números correspondem às classificações mostradas na tabela 16.

Figura 30. Médias de correlação de todos os participantes dentro de algumas redes funcionais e entre elas. Foram definidas três redes: DMN, RNA (rede negativa à atenção) e RPA (rede positiva à atenção). As barras azuis representam as médias de correlação das ROls tomadas durante o estado de atenção e as barras laranjas durante o estado de repouso. Os intervalos de confiança também são indicados para um nível de significância de 0,05.

Figura 31. Médias de correlação de todos os participantes para as ROls definidas na tabela 2 com diferença significante para um nível de significância de 0,05. As abreviaturas das ROls mostradas no eixo horizontal são explicadas segundo a tabela 2. Regiões que fazem parte da rede que responde positivamente à tarefa de atenção sustentada iniciam-se com a letra "P" e regiões que constituem a rede que responde negativamente à tarefa iniciam-se com a letra " $\mathrm{N}$. As barras azuis representam as médias de correlação das ROIs tomadas durante o estado de atenção e as barras laranjas durante o estado de repouso. Os intervalos de confiança também e os p-valores não corrigidos pelo FDR são mostrados 


\section{Lista de Tabelas}

Tabela 1. Dados demográficos e de pontuações de inteligência. Idade e pontuações de inteligência são mostrados como média \pm desvio-padrão

Tabela 2. Coordenadas no espaço MNI $(\mathrm{mm})$ onde as ROls (acompanhadas pelas abreviaturas usadas nesse trabalho) estão centradas e as redes que contém essas coordenadas. Essas coordenadas foram utilizadas para o estudo de atenção.

Tabela 3. Correlações entre pontuações de inteligência. Valores em negrito são significantes para $\alpha<0,01$.

Tabela 4. Valores de correlação entre parâmetros globais de rede cerebral e índices de inteligência, p-valores não-corrigidos e intervalos de confiança.

Tabela 5. Valores de correlação, p-valores não-corrigidos, $p$-valores corrigidos pelo FDR e intervalos de confiança para associações significativas para $p$-valores não corrigidos menores que 0,05 entre coeficiente de clusterização e/ou eficiência local para a rede cerebral e QIE.

Tabela 6. Valores de correlação, $p$-valores não-corrigidos, $p$-valores corrigidos pelo FDR e intervalos de confiança para associações significativas para p-valores não corrigidos menores que 0,05 entre coeficiente de clusterização e/ou eficiência local para a rede cerebral e QIT.

Tabela 7. Valores de correlação, $p$-valores não-corrigidos, $p$-valores corrigidos pelo FDR e intervalos de confiança para associações significativas para $p$-valores não corrigidos menores que 0,05 entre coeficiente de clusterização e/ou eficiência local para a rede cerebral e ICV.

Tabela 8. Valores de correlação, $p$-valores não-corrigidos, $p$-valores corrigidos pelo FDR e intervalos de confiança para associações significativas para $p$-valores não corrigidos menores que 0,05 entre coeficiente de clusterização e/ou eficiência local para a rede cerebral e IOP.

Tabela 9. Valores de correlação, $p$-valores não-corrigidos, $p$-valores corrigidos pelo FDR e intervalos de confiança para associações significativas para $p$-valores não corrigidos menores que 0,05 entre coeficiente de clusterização e/ou eficiência local para a de rede cerebral e IMT. O valores da última coluna, embora sem significância estatística pelo p-valor não corrigido ou pelo p-valor corrigido, são mostrados para comparação com os resultados de Cole et al., 2012.

Tabela 10. Valores de correlação, p-valores não-corrigidos, p-valores corrigidos pelo FDR e intervalos de confiança para associações significativas para $p$-valores não corrigidos menores que 0,05 entre coeficiente de clusterização e/ou eficiência local para a de rede cerebral e IVP.

Tabela 11. Valores de correlação, p-valores não-corrigidos, p-valores corrigidos pelo FDR e intervalos de confiança ordenados em ordem decrescente para os valores de correlação para associações entre conectividade entre duas regiões e QIV. 
Tabela 12. Valores de correlação, p-valores não-corrigidos, p-valores corrigidos pelo FDR e intervalos de confiança ordenados em ordem decrescente para os valores de correlação para associações entre conectividade entre duas regiões e QIE.

Tabela 13. Valores de correlação, $p$-valores não-corrigidos, p-valores corrigidos pelo FDR e intervalos de confiança ordenados em ordem decrescente para os valores de correlação para associações entre conectividade entre duas regiões e QIT.

Tabela 14. Valores de correlação, p-valores não-corrigidos, p-valores corrigidos pelo FDR e intervalos de confiança ordenados em ordem decrescente para os valores de correlação para associações entre conectividade entre duas regiões e ICV. Regiões marcadas com $\left(^{*}\right)$ estão em concordância com Gläscher et al., 2009.

Tabela 15. Valores de correlação, $p$-valores não-corrigidos, p-valores corrigidos pelo FDR e intervalos de confiança ordenados em ordem decrescente para os valores de correlação para associações entre conectividade entre duas regiões e IOP. Regiões marcadas com (*) estão em concordância com Gläscher et al., 2009.

Tabela 16. Valores de correlação, $p$-valores não-corrigidos, $p$-valores corrigidos pelo FDR e intervalos de confiança ordenados em ordem decrescente para os valores de correlação para associações entre conectividade entre duas regiões e IMT. Regiões marcadas com $\left(^{*}\right)$ estão em concordância com Gläscher et al., 2009.

Tabela 17. Valores de correlação, p-valores não-corrigidos, p-valores corrigidos pelo FDR e intervalos de confiança ordenados em ordem decrescente para os valores de correlação para associações entre conectividade entre duas regiões e IVP. Regiões marcadas com $\left(^{*}\right)$ estão em concordância com Gläscher et al., 2009. 


\section{Lista de Abreviaturas}

AAL Automated Anatomical Labeling. Disorder).

ADHD Transtorno do Déficit de Atenção com Hiperatividade (Attention Deficit Hyperactivity

BOLD Nível de Dependência de Oxigenação do Sangue (Blood Oxigenation Level Dependence).

DMN Rede de Modo Padrão (Default Mode Network).

DTI Imagem de Tensor de Difusão (Diffusion Tensor Imaging).

EPI Echo-Planar Imaging.

fcMap Mapa de Conectividade Funcional (Functional Connectivity Map).

FDR False Discovery Rate.

fMRI Imagem por Ressonância Magnética Funcional (functional Magnetic Resonance Imaging).

ICA Análise de Componentes Independentes (Independent Component Analysis).

ICV Índice de Compreensão Verbal.

IMT Índice de Memória de Trabalho.

IOP Índice de Organização Perceptual.

IVP Índice de Velocidade de Processamento.

MNI Montreal Neurological Institute.

OEF Fração de Extração de Oxigênio (Oxygen Extraction Fraction).

PCA Análise da Componente Principal (Principal Component Analysis).

PCC Córtex Cingulado Posterior (Posterior Cingulate Cortex).

PET Tomografia por Emissão de Pósitrons (Positron Emission Tomography).

QIE Quociente de Inteligência Executivo.

QIT Quociente de Inteligência Total.

QIV Quociente de Inteligência Verbal.

RM Ressonância Magnética.

RNA Rede Negativa à Tarefa.

ROI Região de Interesse (Region Of Interest).

RPA Rede Positiva à Tarefa.

RVIP Teste de Processamento Rápido de Informação Visual (Rapid Visual Information Processing).

WAIS Wechsler Adult Intelligence Scale. 


\section{Sumário}

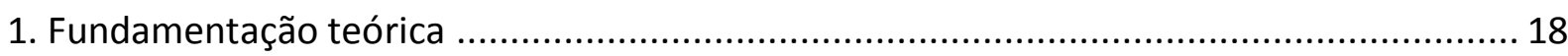

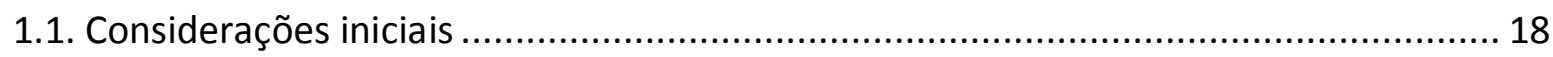

1.2. Imagem funcional por ressonância magnética do cérebro em repouso.................... 19

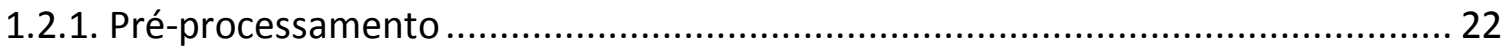

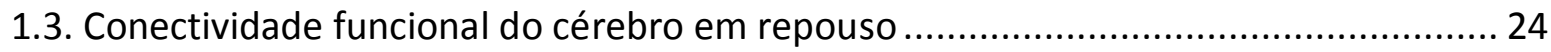

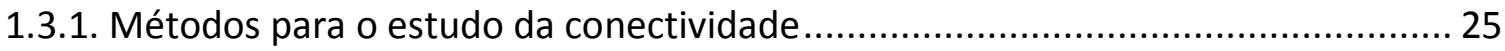

1.3.1.1. Métodos dependentes do modelo: método da semente........................... 29

1.3.1.2. Métodos livres de modelo .................................................................... 31

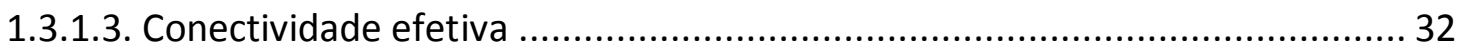

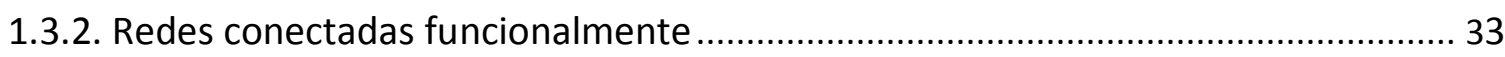

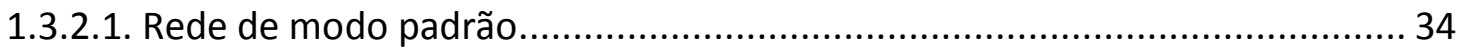

1.3.2.1. Rede neural mediando atenção sustentada .......................................... 36

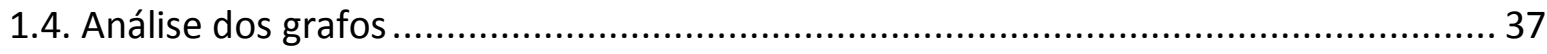

1.5. Desempenho intelectual e conectividade funcional no cérebro .............................. 48

1.6. Diferenças neurais entre estado de repouso e atenção focada ................................ 50

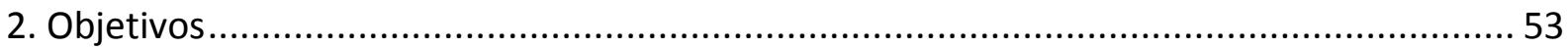

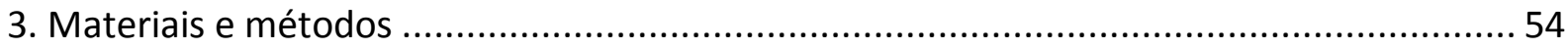

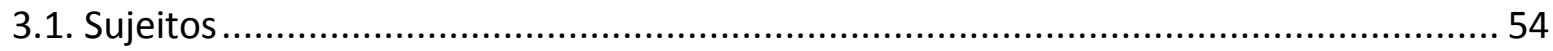

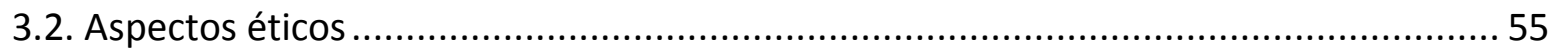

3.3. Estimativa do nível de inteligência individual ..................................................... 55

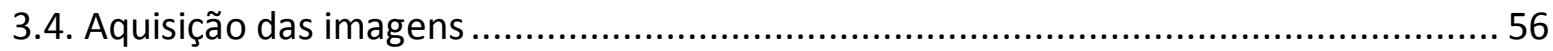


3.5. Protocolo do experimento

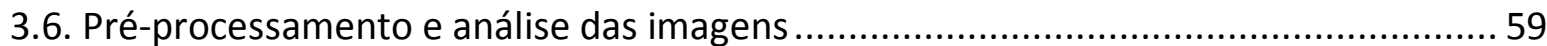

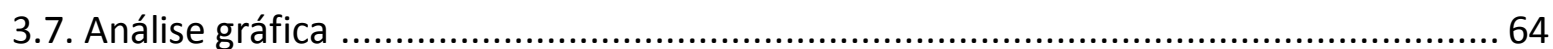

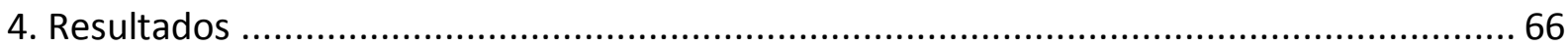

4.1. Associações entre parâmetros de rede/conectividade funcional e desempenho intelectual 68

4.2. Diferenças de conectividade funcional entre atenção sustentada e estado de repouso

5. Discussão

5.1. Associações entre parâmetros de rede/conectividade funcional e desempenho intelectual

5.2. Diferenças de conectividade funcional entre atenção sustentada e estado de repouso 95

6. Conclusões 99

7. Referências 


\section{Capítulo 1}

\section{Fundamentação teórica}

\section{1. Considerações iniciais}

No fim do século passado, as imagens funcionais de Ressonância Magnética (RM) ganharam espaço nas clínicas e nos laboratórios de pesquisa. Por ser uma técnica não-invasiva, com resolução da ordem de milímetros e por trazer informação da fisiologia e da funcionalidade do cérebro, chamou a atenção de pesquisadores de diversas áreas. Através do conceito de ativação e desativação de áreas do cérebro que dependem da tarefa envolvida no experimento e de sua metodologia, é possível inferir como este órgão se comporta em situações específicas.

O conceito de conectividade funcional e estrutural é ainda mais recente. O estudo de áreas separadas anatomicamente trabalhando em sincronia durante um experimento que exige a execução de uma tarefa planejada ou durante um estado passivo do sujeito - chamado estado de repouso - pode trazer uma ótica positiva para a resolução de numerosas perguntas feitas sobre o cérebro. Além disso, a descoberta de que as conexões intrínsecas do cérebro obedecem a um comportamento de rede complexa trouxe a possibilidade de estudo de vários parâmetros que podem diferir entre características individuais dos sujeitos estudados.

Visto que as conexões entre regiões funcionalmente ativas do cérebro são organizadas para refletir uma arquitetura ótima, em que a informação seria processada por redes altamente interconectadas e eficientemente comunicantes, foi pensado que haveria diferenças na conformação das redes no repouso entre grupos de indivíduos de inteligência superior e de inteligência mediana, como de fato foi observado (Song et al., 2009; van den Heuvel et al., 2008, van den Heuvel et al., 2009). Também foram reportadas diferenças de ativação e 
conectividade entre indivíduos mais capazes de sustentar a atenção durante certo tempo e diferenças quando o indivíduo está em repouso e quando mantém atenção focada em um objeto (Brefczynski-Lewis et al., 2007; Brewer et al., 2011; Hasenkamp e Barsalou, 2012; Jang et al., 2011; Josipovic et al., 2012; Kilpatrick et al., 2011; Pagnoni, 2012).

Nesse trabalho, pretende-se aprofundar alguns conceitos como conectividade funcional cerebral, parâmetros de rede neural, inteligência e atenção sustentada, visando apresentar o estado da arte de cada um desses tópicos relacionados entre si. Propõe-se analisar as correlações entre desempenho intelectual e capacidade de sustentar a atenção, no que diz respeito à conectividade no cérebro pela perspectiva das redes complexas.

\section{2. Imagem funcional por ressonância magnética do cérebro em repouso}

A imagem por ressonância magnética funcional ( $f M R l$, do inglês Functional Magnetic Resonance Imaging) é uma técnica não-invasiva e por meio dela pode-se distinguir entre diferentes níveis de oxigenação sanguínea no cérebro. A atividade neural corresponde a um consumo energético que demanda oxigênio para o tecido e é acompanhado por um aumento no fluxo sanguíneo, no diâmetro do calibre dos vasos e na concentração de oxigênio na região. 0 aumento na atividade neural é expresso como o aumento relativo de oxiemoglobina presente no sangue comparado à desoxiemoglobina. A diminuição na proporção de desoxiemoglobina, que tem efeito paramagnético, pode ser detectada como um pequeno aumento no sinal de ressonância em imagens ponderadas em T2*, também chamado de efeito BOLD (do inglês, Blood Oxygenation Level Dependent). Dessa forma, há uma resposta hemodinâmica associada a uma atividade neural em determinada região relacionada, de forma indireta, com intensidade do pixel nas imagens de fMRI.

Experimentos de fMRI e também de PET (do inglês, Positron Emission Tomography) revelaram aumentos esperados na atividade de certas regiões do cérebro durante comportamentos dirigidos a um objetivo. Eles são geralmente específicos para uma dada tarefa, ou seja, a localização do aumento de atividade depende fortemente do tipo de tarefa que está sendo realizada. Entretanto, também foram encontrados decréscimos induzidos pela tarefa cujas redes (conforme explicado na seção 1.3) podem ser detectadas mesmo 
quando o sujeito examinado está em um estado de repouso, seja com olhos fechados, seja olhando passivamente para um estímulo. A localização desses decréscimos é mais independente, não é tão específica do tipo da tarefa requisitada (Shulman et al., 1997). Quando comparados com estudos de fMRI baseados em uma determinada tarefa, aquisições feitas durante o estado de repouso são mais fáceis de executar - pois o planejamento do experimento é mais simples e não é necessário o treinamento dos sujeitos - e comparáveis entre grupos de diferentes pacientes (Tian et al., 2006).

Para que se compare uma condição de interesse em um estudo funcional em neurociências, seria fundamental a definição de uma linha de base a partir da
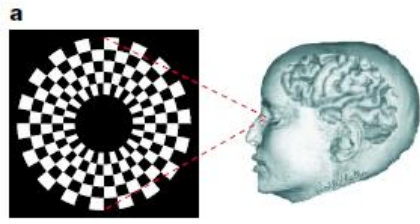

c Activation

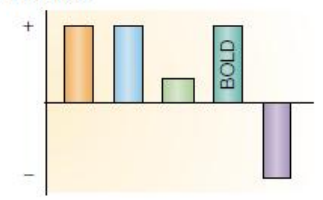

qual se poderia verificar as ativações e desativações. Supondo-se, por exemplo, uma determinada tarefa visual a um indivíduo, verifica-se que a mesma produz mudanças fisiológicas em regiões do cérebro específicas para a visão (figura 1.a). Essas mudanças, conforme já foi dito, consistem principalmente de um aumento no fluxo sanguíneo e utilização de glicose, mas pouco ou nenhum aumento na utilização de oxigênio. A quantidade de oxigênio disponível na região aumenta e é
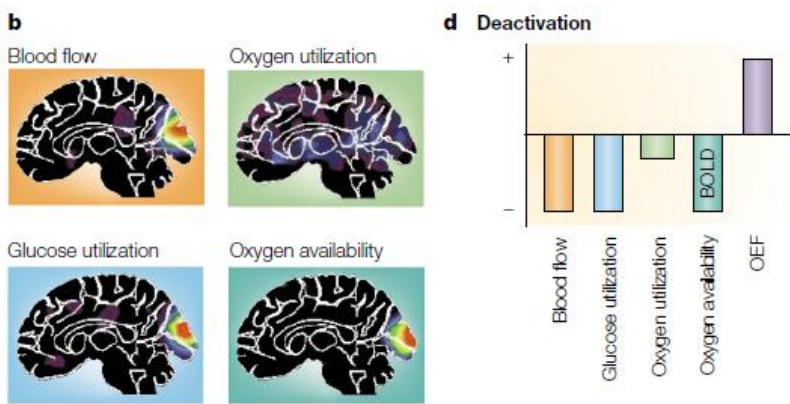

Figura 1. Relação entre ativação no cérebro e imagem funcional, que pode ser produzida, por exemplo, através de um estímulo visual (a). Quando comparado com a visualização de uma tela branca, produz variações relacionadas à atividade em imagem por RM funcional ou PET (b), que consistem no aumento de fluxo de sangue, utilização de glicose, mas pouco ou nenhum aumento na utilização de oxigênio, resultando num aumento da quantidade de oxigênio disponível na área de ativação. (c) e (d) mostram a relação entre fluxo de sangue, utilização de glicose, utilização de oxigênio e disponibilidade de oxigênio com a OEF durante a ativação e desativação, respectivamente. Extraída de Gusnard e Raichle, 2001. ela que mais influencia para o sinal BOLD (figura 1.b). Como a quantidade de oxigênio disponível aumenta com o fluxo e a utilização do oxigênio é constante ou tem um aumento relativamente menor, a fração de extração de oxigênio (ou OEF - Oxygen Extraction Fraction) diminui (figura 1.c). É essa variação negativa na OEF que define a ativação. De forma exatamente antagônica, quando há diminuição da quantidade de oxigênio disponível e a utilização do oxigênio é constante ou tem uma diminuição relativamente menor, a OEF aumenta (figura 1.d) e, dessa forma, a desativação pode ser definida. 


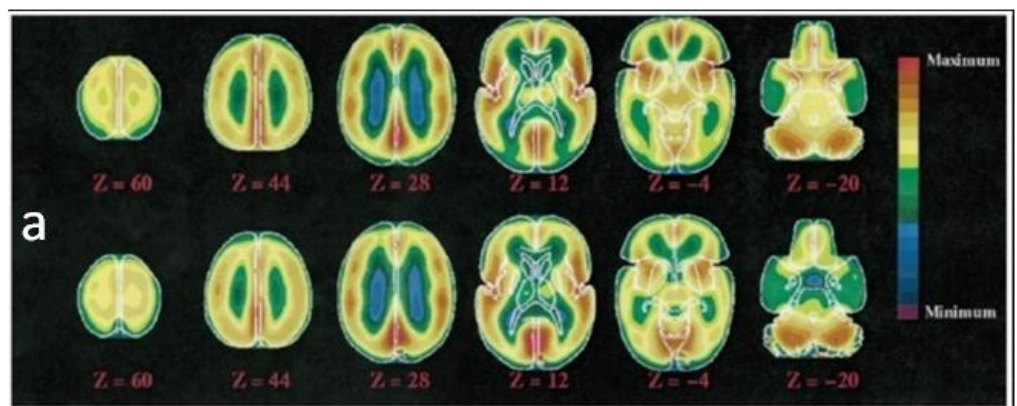

Utilizando imagens de PET, pode-se verificar uma sensível variação do fluxo sanguíneo e do consumo de oxigênio entre regiões do cérebro, principalmente

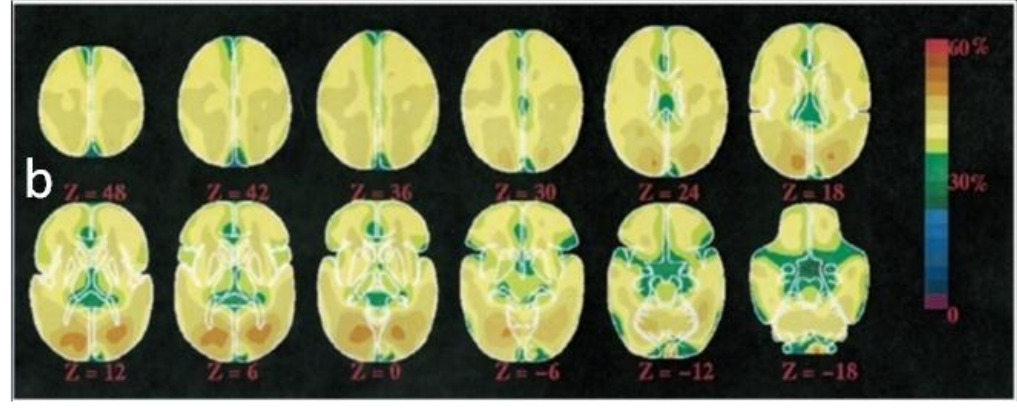
entre substância branca e cinzenta, como é mostrado na figura 2.a. No entanto, variações de fluxo sanguíneo e consumo de oxigênio são

Figura 2. Mapas quantitativos de fluxo sanguíneo e consumo de oxigênio para sujeitos em repouso com olhos abertos (a). Há grande variação de fluxo sanguíneo (acima) e consumo de oxigênio (abaixo) entre as regiões do cérebro, principalmente entre substância branca e cinzenta. Mesmo assim, fluxo sanguíneo e consumo de oxigênio se correspondem, como é refletido na OEF, mostrado no mapa em (b). Extraída de Raichle et al., 2001.

aproximadamente similares anatomicamente. Isso faz com que a OEF no repouso seja aproximadamente

uniforme (figura 2.b) e indica que o equilíbrio foi alcançado entre os requisitos metabólicos e o fluxo de sangue naquela região. Por causa dessa uniformidade, foi proposto que esse equilíbrio na OEF fosse a definição da linha de base para a atividade neural (Gusnard e Raichle, 2001). A partir dos decréscimos observados na OEF durante o estado de repouso, surgiu a hipótese de que haveria um modo organizado de função cerebral que se apresentasse como estado padrão e que fosse suspenso durante comportamentos específicos dirigidos a um objetivo (Raichle et al., 2001).

É importante lembrar que algumas variações que podem ser confundidas com ativações ou desativações surgem apenas no modo como controle e tarefa são manipuladas na estratégia de estudo. Nesse caso, as variações estão relacionadas apenas com a forma como os dados são analisados, não com a fisiologia cerebral. Já outras formas de explicar ativações e desativações verdadeiramente vêm da fisiologia, considerando a significância funcional. Foi postulado que alguns dos decréscimos que são observados em regiões distantes de ativações poderiam refletir a supressão ou modulação de processamento de informação em regiões não envolvidas com desempenho de tarefa. É considerado que essa modulação 
facilita o processamento de informação com significância funcional filtrando outros sinais de entrada, como sinais sensoriais (Gusnard e Raichle, 2001).

Visto que a fMRI é uma importante ferramenta para investigação dos mecanismos neurais, é preciso que haja uma definição adequada da linha de base do estado de repouso cerebral para que alguns conceitos quantitativos decorrentes da análise de fMRI sejam bem estabelecidos. Entretanto, a linha de base do estado de repouso em si é um conceito mal compreendido e que tem suas limitações (Beckmann et al., 2005). De fato, o estado da linha de base do cérebro não significa um estado inativo, dada a sua dinamicidade, exibindo lentas flutuações no sinal BOLD e coerentes entre regiões (Damoiseaux et al., 2006).

Uma alternativa seria o estudo de determinadas flutuações de baixa frequência da hemodinâmica cerebral que exibem estrutura espacial complexa e que lembram os mapas de ativação de $\mathrm{fMRI}$. Os dados dessas flutuações podem ser tomados tanto durante o repouso (Beckmann et al., 2005) quanto durante uma tarefa em estado constante (Newton et al., 2011). Vários pesquisadores sugeriram que essas variações de sinal, temporalmente correlacionadas, são de origem neuronal e correspondem a redes de repouso funcionais que juntamente caracterizam a linha de base do cérebro humano na ausência de atividade deliberada ou externamente estimulada e podem refletir redes distintas funcionalmente (Beckmann et al., 2005).

Embora a técnica de $\mathrm{fMRI}$ seja poderosa para identificar variações do sinal BOLD em regiões do cérebro e extrair informações sobre a funcionalidade do mesmo, seu uso exige um tratamento adequado e requer uma série de etapas e cuidados para remoção da variabilidade dos dados que não interessam ao estudo em questão e preparar as imagens para a análise estatística.

\section{2. 1. Pré-processamento}

- Correção de tempo-fatia: Essa etapa corrige a diferença no tempo de aquisição de imagem entre fatias, ou seja, as séries temporais para uma determinada fatia são deslocadas no tempo proporcionalmente à diferença temporal em relação a uma fatia de referência. Depois dessa etapa, as fatias correspondentes a um mesmo 
volume ficam com a mesma referência temporal e é como se o volume todo fosse medido num mesmo instante de tempo. O deslocamento temporal depende da ordem em que as fatias foram obtidas (ascendente, descendente ou intercalada).

- Correção de movimento tridimensional: O movimento que o participante do estudo não pode evitar é um dos problemas mais severos em estudos de fMRI. Portanto, a correção para movimento de cabeça é imprescindível para remoção dos artefatos de movimento. Nessa etapa, a estimação do movimento é baseada em um volume de referência e alguns parâmetros de movimento são aplicados para alinhar as séries temporais das imagens cerebrais adquiridas para um mesmo sujeito para referência. É geralmente feito através do método de mínimos quadrados. Padronizadamente, seis parâmetros de movimento de corpo rígido são usados - três de translação e três de rotação.

- Filtragem temporal: Dados de séries temporais em fMRI costumam exibir desvios de baixa frequência (entre 0,01 e 0,1 Hz), que pode ser causado por ruídos de ordem física ou fisiológica. Esse passo é crucial, pois fontes de ruído fisiológico (e de movimento) podem induzir falsas correlações entre voxels distantes, aumentando a chance de falsos positivos e confundindo a interpretação dos resultados de conectividade funcional (Whitfield-Gabrieli e Nieto-Castanon, 2012). Todavia, é recomendada cautela em seu uso, pois, se mal aplicada, pode eliminar variações de sinal relacionadas ao objeto de estudo.

- Suavização espacial: Esse passo de pré-processamento suaviza (ou convolui) volumes de imagens com um núcleo gaussiano de uma largura especificada. É utilizado para reduzir ruído e efeitos devidos às diferenças residuais durante a promediação entre sujeitos. É justificado pelo fato de que os dados de fMRI inerentemente mostram altas correlações espaciais devido a similaridades funcionais de regiões adjacentes que são pouco afetadas por essa etapa de pré-processamento, mas evita com eficácia o borramento de fontes de ruído fisiológico de tecidos adjacentes. Os consequentes benefícios dessa aplicação são a melhora da razão sinal-ruído, a melhora da validade dos testes estatísticos tornando a distribuição de erros mais normal e a acomodação de variações anatômicas e funcionais entre os sujeitos. Contudo, alguns inconvenientes devem ser considerados, como redução da resolução 
espacial dos dados, aparecimento de artefatos de borda, fusão de picos de ativação, extinção de pequenas ativações e deslocamento de picos de ativação.

- Co-registro: Essa etapa move uma ou várias imagens para uma dada outra dita estacionária, procurando ajustar voxel por voxel e definindo um determinado espaço.

- Segmentação: A segmentação pode separar, em imagens, diferentes classes de tecidos: a substância cinzenta, a substância branca e/ou o fluido cérebro-espinhal. A motivação histórica foi reduzir os efeitos confundidores da variabilidade de estruturas não cerebrais.

- Normalização: Calcula a deformação que melhor co-registra uma imagem para se ajustar a uma outra dada imagem estática, fazendo com que uma localização no cérebro de um indivíduo corresponda à mesma localização no cérebro de outro.

A maioria dos estudos funcionais realizados antes de 2000 eram orientados a tarefa. Após as etapas de pré-processamento aqui comentadas, era aplicada também uma técnica de regressão linear para estimar os voxels cujo sinal estava mais correlacionado com a dinâmica temporal da tarefa em questão, resultando em mapas de associações entre ambas as dinâmicas, buscando por significância estatística. Mais recentemente uma abordagem de experimentos sem tarefa específica tem levado à exploração de inter-correlações entre os sinais temporais dos voxels, o chamado estudo sobre a conectividade funcional em repouso.

\section{3. Conectividade funcional do cérebro em repouso}

Nosso cérebro pode ser considerado uma rede de regiões com tarefas e funções específicas, havendo um compartilhamento de informações entre estas regiões. Recentes avanços em neuroimagem funcional proveram novas ferramentas para medir e analisar as interações entre funções cerebrais, catalisando o estudo de conectividade funcional no cérebro (van den Heuvel e Pol, 2010). A conectividade temporal é definida como a dependência temporal dos padrões de atividade neural, manifestos pelo sinal BOLD, de regiões cerebrais separadas anatomicamente (Biswal et al., 1995).

O estudo da conectividade cerebral tem sido bastante explorado em indivíduos saudáveis e pode trazer informações sobre o comportamento humano e como essa organização é 
alterada para determinadas diferenças individuais. Desta forma, diversos estudos têm sido reportados avaliando a influência na conectividade de diferentes variáveis como sexo (Wang et al., 2008; Gong et al., 2009; Yan et al., 2011; Tian et al., 2011), idade (Gong et al., 2009; Wu et al., 2013; Andrews-Hanna et al., 2007), inteligência (Song et al., 2008; Song et al., 2009; van den Heuvel et al., 2009), ingestão de psicoativos (Fontes, 2008), estados meditativos (Brefczynski-Lewis et al., 2007; Brewer et al., 2011; Hasenkamp e Barsalou, 2012; Jang et al., 2011; Josipovic et al., 2012; Kilpatrick et al., 2011), entre outros. Embora estes trabalhos tenham muitos aspectos em comum, diferentes métodos tem sido empregados, como métodos que dependem de um modelo de série temporal, métodos que não usam nenhum modelo a priori e métodos que estimam a conectividade efetiva. Recentes técnicas e métodos de análise possibilitaram o estudo da conectividade através do nível de correlação entre as séries temporais funcionais de regiões durante o repouso.

\section{3. 1. Métodos para o estudo de conectividade}

A compreensão de como as regiões cerebrais ou, em um nível mais detalhado, os neurônios se intercomunicam pode elucidar processos cognitivos complexos. Alguns pesquisadores examinaram a possibilidade de medir conectividade funcional através do nível de correlação das séries temporais de $\mathrm{fMRI}$ espontâneas durante o repouso. Biswal foi o primeiro a demonstrar que durante o repouso as regiões dos hemisférios direito e esquerdo do córtex motor primário não estão silentes, antes mostram uma alta correlação entre suas séries temporais de sinal com contraste BOLD. Em seu estudo pioneiro, séries de tempo para voxels contidos em regiões cerebrais motoras definidas previamente foram altamente correlacionadas dentro e entre essas regiões durante o estado de repouso (Biswal et al., 1995).

Durante um experimento em estado de repouso, os sujeitos são colocados no tomógrafo de RM e, geralmente, é pedido para que não pensem em nada em particular sem dormir. Assim como no experimento em que se dá uma tarefa ao sujeito e seu mapa de significância estatística funcional é extraída, o mesmo é feito para o estado de repouso. 
Os protocolos de fMRI têm resolução temporal que pode ser considerada alta - sendo um volume de imagens a cada 1 ou 2 segundos -, porém, oscilações cardíacas e respiratórias interferem nos sinais detectados no estado de repouso e podem introduzir correlações artificiais. As flutuações BOLD que produzem correlações mais consistentes com redes funcionais ocorrem dentro de uma escala de 0,01 a $0,08 \mathrm{~Hz}$. Portanto, os sinais de interesse estão no espectro das baixas frequências e a aplicação de um filtro passa-baixa como um passo de pré-processamento é necessário para remover frequências mais altas. Enquanto os efeitos da respiração ocorrem com uma frequência de aproximadamente $0,3 \mathrm{~Hz}$ e são possivelmente removidos pelo filtro passa-banda, variações da taxa de respiração ocorrem em frequências muito mais lentas (em torno de $0,03 \mathrm{~Hz}$ ). Essas fontes de ruído podem ter um efeito no cérebro inteiro e distorcem as correlações estimadas se não forem propriamente analisadas. Uma forma de minimizar a variação não desejada de sinal BOLD é o préprocessamento para isolar sinais cardíacos e respiratórios e incorporá-los como regressores nulos a fim de retirá-los dos dados temporais (Van Dijk et al., 2010). Para estudos de ativação, o risco de apenas remover parcialmente as fontes de ruído de sinal BOLD levaria a falsos negativos enquanto que, em estudos de conectividade, se poderia chegar a resultados com falsos positivos, portanto cautela é necessária para a escolha de uma técnica cuidadosa para controlar os efeitos de fontes de ruído de sinal BOLD (Whitfield-Gabrieli e NietoCastanon, 2012).

Os sinais extraídos dos ventrículos e da substância branca contêm uma proporção relativamente alta de influência dos ciclos cardíacos e respiratórios. Além disso, assume-se que os ruídos fisiológicos causam o mesmo padrão de atividade ao longo do tempo em todos os voxels afetados do cérebro. Uma forma de neutralizar esses efeitos globais é pela regressão do sinal de cérebro inteiro (Van Dijk et al., 2010).

No entanto, foi questionado se a regressão do sinal de cérebro inteiro facilitaria ou impediria a observação de relações neuralmente significativas. A conectividade funcional de alguns sistemas córtico-talâmicos foram avaliados e discutiu-se que a remoção de sinal de cérebro inteiro realmente melhorava a sobreposição dos resultados de conectividade funcional em sistemas conhecidos (Fox et al., 2009). Weissenbacher et al. (2009) demonstrou que, depois da regressão de sinal de cérebro inteiro, a especificidade dos fcMap do sistema motor aumentou e correlações espúrias entre os sistemas visual e motor diminuíram. É digno de 
nota que ambos Fox et al. (2009) e Weissenbacher et al. (2009) encontraram somente melhoras (nunca decréscimos) devidas à regressão de cérebro inteiro para sistemas em que seriam esperados aparecerem correlações positivas, levando Weissenbacher e colaboradores a concluírem que a regressão de sinal de cérebro inteiro é um passo de préprocessamento viável, mas deve-se evitar a interpretação de correlações negativas. Porém, o pré-processamento que inclui a normalização de sinal de cérebro inteiro troca a distribuição das correlações. Anticorrelações robustas são presentes depois da normalização, mas não antes (Van Dijk et al., 2010).

O método CompCor de redução de ruído, que não usa regressão de sinal de cérebro inteiro ou monitoramento fisiológico, também resulta em anticorrelações, suportando uma base biológica para sua existência, e as correlações positivas têm maior sensibilidade e especificidade que a regressão de sinal de cérebro inteiro. Acredita-se que o método CompCor, implementado no toolbox CONN para MatLab, produz anticorrelações válidas entre redes cerebrais de larga escala (Whitfield-Gabrieli e Nieto-Castanon, 2012).

Tem estado em discussão se esses sinais resultam de processos fisiológicos ou de ativações neurais correlacionadas e espontâneas. Para uma base neural de sinais de fMRI no repouso, há respaldo oriundo da observação de que a maioria dos padrões no estado de repouso tendem a ocorrer entre regiões cerebrais que se sobrepõem em função e neuroanatomia. Isso sugere que regiões que têm que trabalhar juntas formam uma rede funcional durante 0 repouso (van den Heuvel e Pol, 2010).

A técnica de conectividade funcional em imagens de RM detecta correlações que são limitadas pela anatomia cerebral e podem ser usadas para auxiliar do mapeamento da arquitetura conectiva (Van Dijk et al., 2010). Uma outra forma de medir a conectividade faz uso do imageamento por tensor de difusão (Diffusion Tensor Imaging - DTI) - técnica de imagem de RM que usa o princípio da difusão restrita da água através das fibras nervosas mielinizadas - e através da tractografia, a reconstrução computacional do caminho feito pelas moléculas, oferece uma visão geral da anatomia cerebral, incluindo o grau de conectividade (então chamada conectividade estrutural) entre diferentes regiões do cérebro. 
Como definição, pode-se dizer que enquanto a conectividade funcional mede características dinâmico-estocásticas (correlação, coerência, causalidade) entre sinais de diferentes regiões durante o processamento da informação cerebral, a conectividade estrutural é o conjunto de ligações sinápticas e processos biofísicos de transmissão de sinal (axônios, neurotransmissores etc) presentes na anatomia cerebral (Nucifora et al., 2007). Uma vez detectada funcionalmente uma comunicação entre duas regiões, supõe-se que deveria haver uma estrutura de conexões formadas por fibras axonais na substância branca embasando essa conexão, sugerindo associação entre conectividade funcional e estrutural (van den Heuvel e Pol, 2010).

Tanto as redes cerebrais funcionais quanto as estruturais podem ser exploradas através dos quatro passos a seguir (Bullmore e Sporns, 2009):

- Definição dos nós da rede - através de eletroencefalograma, fMRI, DTI ou de cortes histológicos.

- Estimação de uma medida contínua de associação entre os nós - através de coerência espectral, causalidade de Granger, probabilidade de conexão entre duas regiões de uma DTI, correlações inter-regionais na espessura cortical ou outras medidas anatômicas a partir de imagens de RM.

- Gerar uma matriz de associação compilando todas as associações entre os nós e aplicar um limite inferior para cada elemento dessa matriz.

- Calcular os parâmetros de rede e compará-los com uma população de uma rede aleatória.

No processo de estimação de uma medida de associação, diferentes abordagens têm sido utilizadas. Dentre as mais comuns, podemos citar: o método da semente, a análise da componente principal (PCA, do inglês Principal Component Analysis), a decomposição do valor singular, a análise de componentes independentes (ICA, do inglês Independent Component Analysis) e o algoritmo de agrupamento ou clustering. Uma classificação mais específica destes métodos de estimativa de conectividade seria considerar se o método envolve ou não um determinado modelo. 


\section{3. 1. 1. Métodos dependentes do modelo: método da semente}

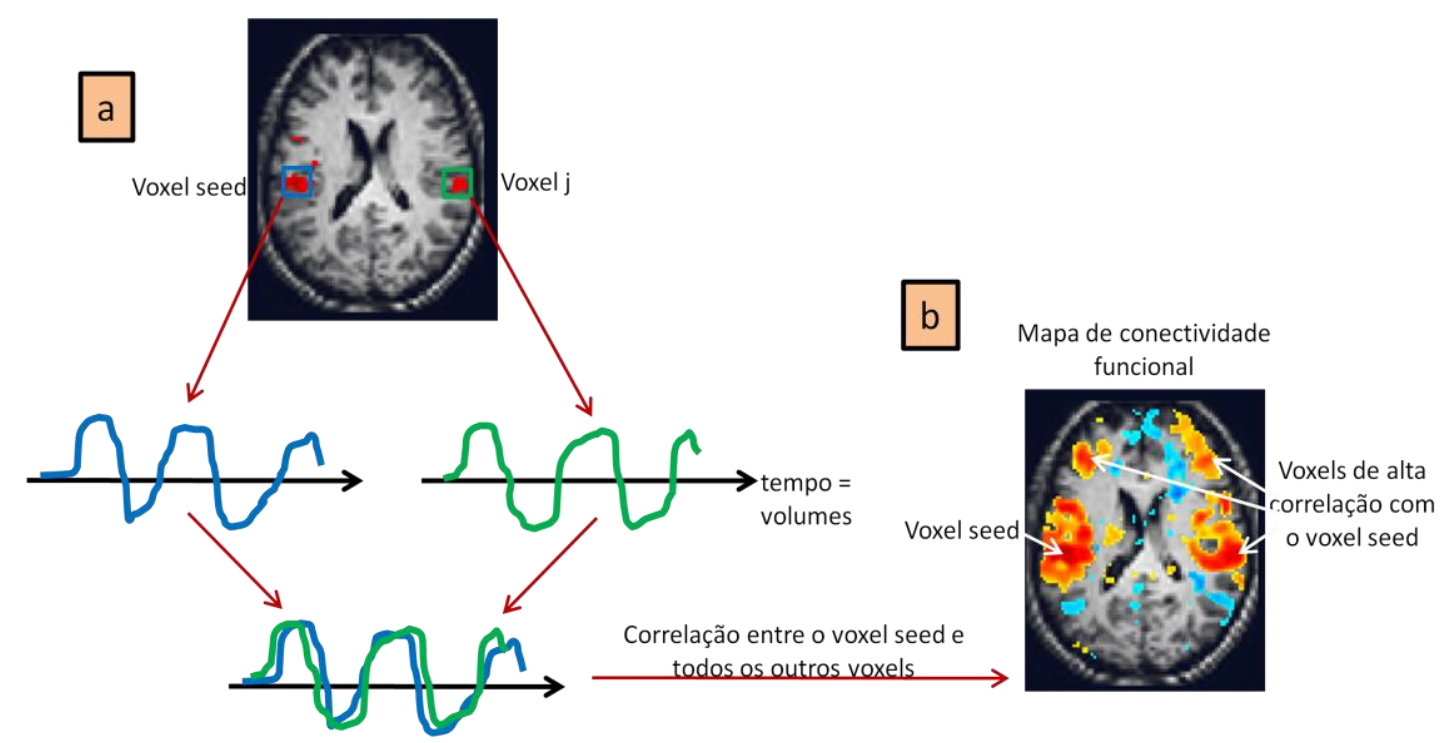

Figura 3. Esquematização de como é realizado o estudo de conectividade funcional no repouso para o método da semente. Baseada em van den Heuvel e Pol, 2010.

Um dos métodos para análise da conectividade funcional é o chamado método da semente. A figura 3 mostra uma esquematização de como se deve proceder nesse método para o estudo do estado de repouso. A primeira etapa deste método é a definição da semente. Muitas vezes para a definição da região semente é utilizada uma aquisição de fMRI convencional com uma tarefa de ativação envolvida, como por exemplo, movimento de dedos. A partir do processamento destes dados orientados à tarefa é definida como semente uma região de interesse (ROI, do inglês Region Of Interest). Posteriormente é calculada uma medida de conectividade. Uma medida comumente usada, devido a sua simplicidade, é o coeficiente de correlação de Pearson calculado entre a série temporal extraída de um voxel ou de um conjunto de voxels definindo uma ROI semente e a série temporal de um voxel j arbitrário para analisar o nível de conectividade funcional entre as duas regiões (figura 3.a). O coeficiente de correlação de Pearson, para um par de séries temporais $\left(x_{i}\right.$ e $\left.y_{i}\right)$ é dado por:

$$
r=\frac{C_{x, y}}{S_{x} S_{y}}
$$

em que $C_{x, y}$ é a covariância ou variância conjunta das variáveis x e y e $S_{x}$ e $S_{y}$ são os desviospadrão das variáveis $x$ e $y$, respectivamente. A covariância é definida como uma medida de como ambas as variáveis variam conjuntamente. A fórmula acima pode também ser escrita em termos de suas somatórias ao longo dos $\mathrm{n}$ pontos temporais e se torna: 


$$
r=\frac{\sum_{i=1}^{n}\left(x_{i}-\bar{x}\right)\left(y_{i}-\bar{y}\right)}{\sqrt{\sum_{i=1}^{n}\left(x_{i}-\bar{x}\right)^{2} \sum_{i=1}^{n}\left(y_{i}-\bar{y}\right)^{2}}}
$$

Um alto nível de correlação entre as séries temporais de duas regiões significa que as duas regiões possuem um alto grau de conectividade funcional. Finalmente, as séries temporais de todos os outros voxels do cérebro são correlacionadas com a região definida como semente, resultando num mapa de conectividade funcional (fcMap) (figura 3.b), refletindo as regiões que mostram um alto nível de conectividade com a região semente (van den Heuvel e Pol, 2010). Os coeficientes de correlação são geralmente convertidos para valores distribuídos em uma curva normal (Whitfield-Gabrieli e Nieto-Castanon, 2012), usando a transformada-z de Fisher para permitir a análise de grupo, fazendo com que a variância de $z$ seja aproximadamente constante para todos os valores de coeficiente de correlação $r$ da população. Tal transformada é dada por

$$
z=\frac{1}{2} \ln \left(\frac{1+r}{1-r}\right)
$$

As informações de um fcMap, estimado dessa forma, são limitadas às conexões funcionais da região semente, tornando difícil o exame dos padrões de conexões funcionais do cérebro como um todo (van den Heuvel e Pol, 2010). A aplicabilidade do método da semente é limitada, pois se apoia na série temporal da localização de uma região que representa bem os voxels correlacionados. Como consequência, esse método é restrito a casos em que as regiões semente podem ser inferidas acurada e robustamente de estudos de ativação embasados muitas vezes em uma hipótese a priori. Além disso, a escolha da região semente é um tanto arbitrária, como é, de fato, selecionada a exata localização do pico de ativação estatisticamente significante, e pode ser influenciada por diferentes fontes de ruído de fMRI (Beckmann et al., 2005).

Muitos dos estudos em conectividade funcional usando imagens de RM focaram-se na conectividade inter-regional, fixando um número de regiões do cérebro e definindo-as como os nodos de uma rede (Farb et al., 2007; Jang et al., 2011; Josipovic et al., 2012; Brewer et al., 2011; Castellanos et al., 2008). No entanto, análise semelhante pode ser feita para o nível de resolução do voxel, o que poderia trazer informações adicionais das características de um cérebro funcionalmente conectado (van den Heuvel et al., 2008; van den Heuvel et al., 2009). No entanto, esse tipo de análise é computacionalmente demorado. 


\section{3. 1. 2. Métodos livres de modelo}

Uma importante vantagem dos métodos livres de modelo em relação àqueles baseados em hipóteses é a habilidade de identificar flutuações de sinais sem a necessidade de especificar de antemão um modelo temporal explícito e explorar o volume de imagem voxel-a-voxel sem excessivo custo computacional. Dessa forma, procura por padrões de ativação, artefatos e componentes geradas fisiologicamente, incluindo redes de repouso (Beckmann et al., 2005).

Um desses métodos é o ICA, que decompõe uma matriz de dados bidimensionais (tempo $\mathrm{x}$ voxels) em um conjunto de componentes espacialmente independentes com séries temporais e com distribuições espaciais associadas. O objetivo da técnica é encontrar a matriz $\mathrm{S}_{\mathrm{q} \times n}$ da equação

$$
x_{p X n}=A_{p X q} S_{q X n}+\eta_{p X n},
$$

em que $x_{p X n}$ são as medidas individuais na localização de cada voxel (os dados obtidos), $S_{q X n}$ são as fontes de sinal - as componentes maximamente independentes umas das outras - $A_{p X q}$ é a matriz de mistura - a qual será estimada a partir dos dados - e $\eta_{p X n}$ é o ruído gaussiano. Os sub-índices indicam que $n$ é o número total de voxels, $p$ é o número de pontos temporais e $q$ é o número de componentes independentes.

O método de ICA pode ser aplicado em uma análise de cérebro inteiro, sem ser preciso selecionar regiões arbitrárias. As regiões maximamente independentes determinadas por esse método podem ser utilizadas para análises a posteriori, como, por exemplo, a investigação da conectividade funcional pelo método da semente. As redes detectadas não são afetadas por ciclos cardíacos ou respiratórios e as flutuações são bem definidas na substância cinzenta (Beckmann et al., 2005). A desvantagem desse método é que gera mapas mais difíceis de interpretar que o método de semente por ter uma representação mais complexa dos dados. Além disso, o ICA pode indicar apenas uma rede cerebral quando, na realidade, várias redes estão compreendidas. Isso acontece porque o método captura somente a variância comum e perde as diferenças sutis da conectividade funcional (Uddin et al., 2008). 
Outro método livre de modelo que pode ser citado é o de agrupamento ou clustering, em inglês. O mesmo agrupa os pontos de dados em alta ou baixa similaridade, maximizando-a. Porém, enquanto o ICA tem a forte vantagem de permitir a comparação entre grupos de sujeitos, o clustering precisa de informações adicionais sobre uma ROI.

É importante dizer que resultados produzidos tanto por técnicas baseadas na semente quanto por ICA são similares (Van Dijk et al., 2010).

\section{3. 1. 3. Conectividade efetiva}

Além da análise de conectividade funcional não-direcionada, outros métodos foram desenvolvidos, como modelos matemáticos de conectividade efetiva (modelagem da equação, modelagem da dinâmica causal e causalidade de Granger), para estimar a influência causal que cada elemento de um sistema exerce no comportamento de outros (Bullmore e Sporns, 2009). A causalidade de Granger entre duas regiões, por exemplo, pode ser definida como a extensão com que os dados de uma região em um ponto no tempo melhoram a predição de outros dados em outra região para um ponto posterior. Usa-se essa diferença para avaliar influências causais entre redes medindo a extensão com que as variações de sinal em uma região confiavelmente precedem aquelas em outras regiões num determinado instante de tempo, permitindo a caracterização da intensidade e direção da influência entre regiões do cérebro (Uddin et al., 2008). 


\section{3. 2. Redes conectadas funcionalmente}
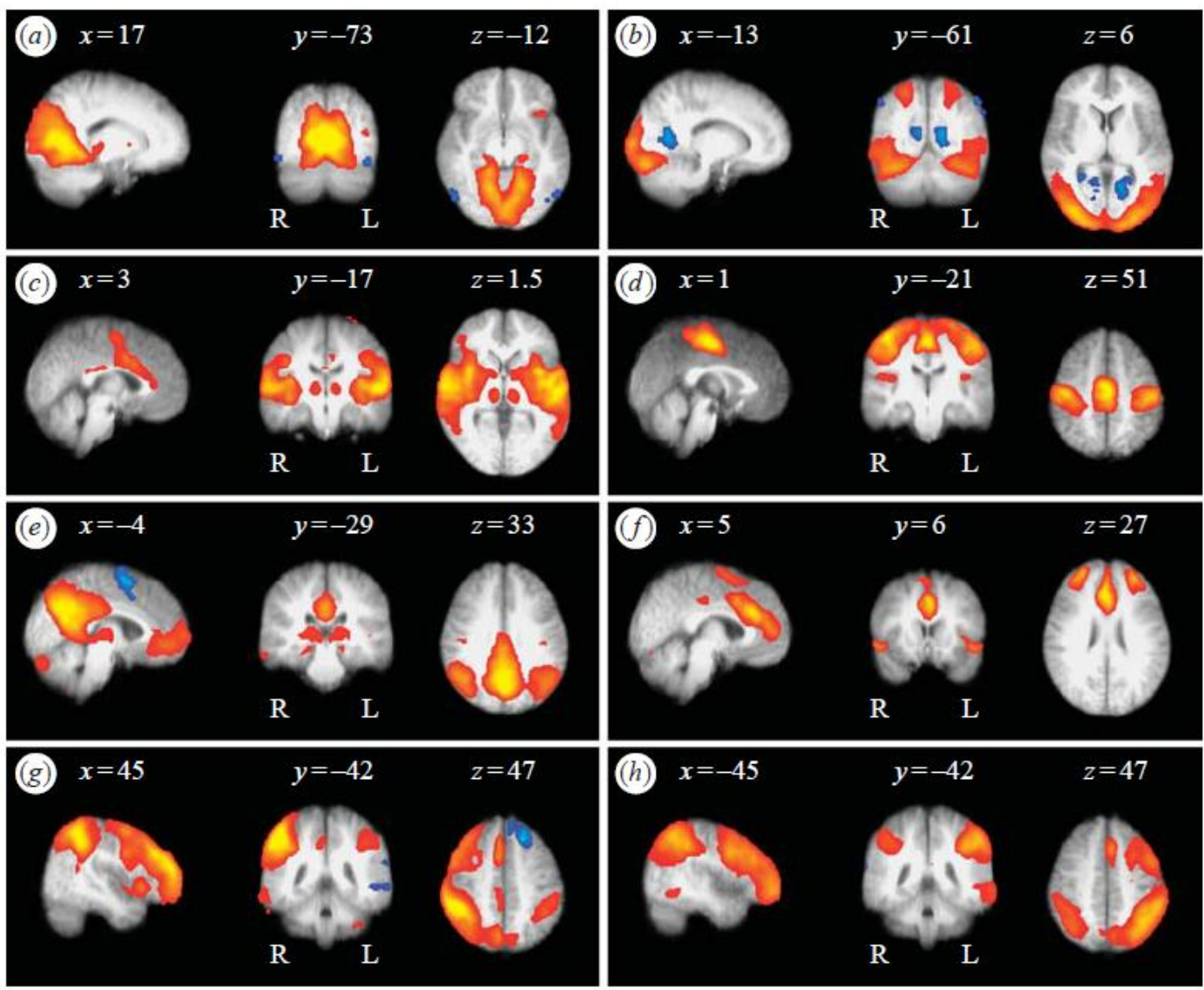

Figura 4. Diferentes padrões no repouso estimados por análise de componentes independentes: (a) regiões corticais visuais mediais, (b) regiões corticais visuais laterais, (c) sistema auditório, (d) sistema sensóriomotor, (e) sistema visuo-espacial, (f) controle executivo, (g) sistema visual dorsal direito e (h) sistema visual dorsal esquerdo. Vistas sagital, coronal e axial de diferentes mapas espaciais associados com padrões de repouso de baixa frequência estimados de um grupo de 10 sujeitos. As coordenadas referem-se às distâncias em milímetros da comissura anterior. Extraída de Beckmann et al., 2005.

Os neurônios são bastante espontâneos e continuamente transportam informação para outros neurônios. Sendo assim, pode-se conjecturar que a conectividade pode ajudar a manter o sistema ativo, melhorando o desempenho cerebral. Também se devem considerar as redes funcionais para elucidar como a arquitetura neural ajuda na dinâmica neurofisiológica (Bullmore e Sporns, 2009).

Estudos mostram a formação de redes consistentes formadas por regiões conectadas funcionalmente no estado de repouso (Damoiseaux et al., 2006). Tais redes incluem regiões funcionalmente relevantes envolvidas na função motora, processamento visual, funcionamento executivo, processamento auditivo e memória. A figura 4 (Beckmann et al., 2005) mostra diferentes padrões de repouso estimados pelo ICA: vistas sagital, coronal e axial de diferentes mapas espaciais associados com padrões de frequência de baixa 
frequência estimados de um grupo de 10 sujeitos. Os mapas definidos pelo limiar podem ser classificados em
a) Regiões corticais visuais mediais;
b) Regiões corticais visuais laterais;
c) Sistema auditório;
d) Sistema sensório-motor;
e) Sistema visuo-espacial (também referido como rede de modo padrão, ou DMN, como será visto a seguir);
f) Controle executivo;
g) Sistema visual dorsal direito;
h) Sistema visual dorsal esquerdo.

Um aspecto interessante das componentes $\mathrm{G}$ e $\mathrm{H}$ é que elas são as únicas a mostrar padrão de ativação similar em hemisférios opostos, o que poderia refletir em especialização hemisférica na função de memória.

\section{3. 2. 1. Rede de modo padrão}

Dentre as redes mais reconhecidas está a rede de modo padrão (Default Mode Network $\mathrm{DMN}$ ), que conecta o córtex cingulado posterior (PCC)/precúneo, regiões frontal medial e parietal inferior e é conhecida por exibir um nível de atividade neuronal elevada durante o repouso (van den Heuvel e Pol, 2010). É composta por córtex frontomedial anterior, córtex frontomedial ventral, giro cingulado posterior, precúneo e algumas regiões do lobo parietal inferior e do giro temporal médio. Acredita-se que a DMN esteja ligada com memória episódica, consolidação de memória, processos relacionados a si mesmo e às relações sociais, pensamentos independentes de estímulo e não relacionados à tarefa, ou seja, tarefas que envolvam atividade mental introspectiva (Raichle et al., 2001; Uddin et al., 2008). Há variabilidade na conectividade funcional na DMN influenciada por fatores como idade, carga cognitiva, genética, nível de consciência e sono (Morgan e Abou-Khalil, 2011).

Mason e colaboradores (2007) empenharam-se em investigar se a DMN, que é mais ativa em períodos em que o sujeito não está focado no ambiente externo, teria implicações no 
processo de divagação, já que esta rede é minimamente interrompida durante processamento sensorial passivo e mais atenuada em tarefas de alta demanda executiva, que é justamente o momento em que a pessoa está mais e menos suscetível à divagação, respectivamente. Nesse experimento, os indivíduos eram treinados para realizar uma tarefa repetidamente. Quanto mais vezes a pessoa repetia a tarefa, maior a incidência de divagação. Portanto, a avaliação de diferentes graus de divagação seria possível através da quantidade de tempo que o indivíduo praticou a tarefa. Foi verificado que períodos de alta incidência de divagação estão associados com aumento no recrutamento da DMN (Mason et al., 2007).

A conectividade funcional dentro da DMN, assim como dentro da rede de memória de trabalho, é modulada pela carga da memória de trabalho (Newton et al., 2011), suportando a visão de que a conectividade funcional varia dentro de redes cognitivas de acordo com uma gradual dificuldade na tarefa, não apenas com a sua presença.

A atividade da DMN pode persistir ou reemergir durante tarefas dirigidas a um objetivo de tal forma que ela compete com o processamento específico para a execução da tarefa e leva o indivíduo a ter lapsos atencionais periódicos e déficits cíclicos no desempenho (Brewer et al., 2011).

Uma vez sugeridas as bases neurais da divagação, é natural que se pergunte qual é a significância funcional do fato de uma mente divagar. Uma possível resposta é de que os pensamentos independentes de estímulo possibilitam o sujeito a manter um estado ótimo de alerta, facilitando assim a realização de tarefas cotidianas. Outra possibilidade é a de que esses pensamentos dão um senso de coerência temporal para o sujeito, baseando-se em experiência passadas, presentes e futuras. Em contrapartida, pode-se também pensar que esses pensamentos autogerados podem não ter um objetivo extrínseco, mas porque a mente pode ter se desenvolvido evolutivamente para dividir a atenção e administrar tarefas mentais concorrentes (Mason et al., 2007). 


\section{3. 2. 2. Rede neural mediando atenção sustentada}

Lawrence et al. (2003) investigou os fundamentos neurais da atenção sustentada (também referido como vigilância) utilizando o teste de processamento rápido de informação visual (rapid visual information processing - RVIP) em 25 voluntários. Esse teste, que requere primariamente atenção sustentada, é composto por blocos de 90 segundos em que algarismos únicos aparecem numa tela numa taxa de 100 dígitos por minuto e os participantes desse estudo foram instruídos a apertarem um botão toda vez que três algarismos ímpares ou três algarismos pares aparecessem na tela consecutivamente. Para uma tarefa controle, os participantes deveriam apertar o botão toda vez que o algarismo zero aparecesse na tela.

Uma rede composta por 29 clusters das ativações e desativações associada com o desempenho na tarefa (seja em número de acertos ou no tempo de reação ao acerto), em relação a uma tarefa controle, foi encontrada e reportada nesse trabalho. Dessas 29 regiões, vinte foram escolhidas para serem usadas em nosso estudo levando como critério a intensidade das correlações e a significância estatística dos resultados. Essas regiões são mostradas na figura 5 juntamente com algumas regiões cerebelares, não utilizadas na análise de nosso trabalho. Regiões que mostraram correlações significantes entre ativação e número de acertos e tempo de reação (correlação positiva) incluíram regiões frontais direitas, giro frontal médio esquerdo, pré-SMA (área motora suplementar), córtex parietal bilateral e ínsula anterior esquerda. Regiões que mostraram correlações negativas incluíram o giro frontal medial esquerdo, PCC e anterior bilateral, giro temporal médio esquerdo e a ínsula direita (Lawrence et al., 2003).

Foi suposto que o uso das coordenadas em que as regiões reportadas estão centradas poderia ser útil ao nosso estudo. Além do nosso trabalho e o trabalho de Lawrence et al. (2003) visarem o estudo do mesmo assunto, embora com metodologias diferentes, a definição de ROls a partir dos achados de Lawrence et al. seria um ponto de partida muito proveitoso para o estudo da conectividade funcional. 


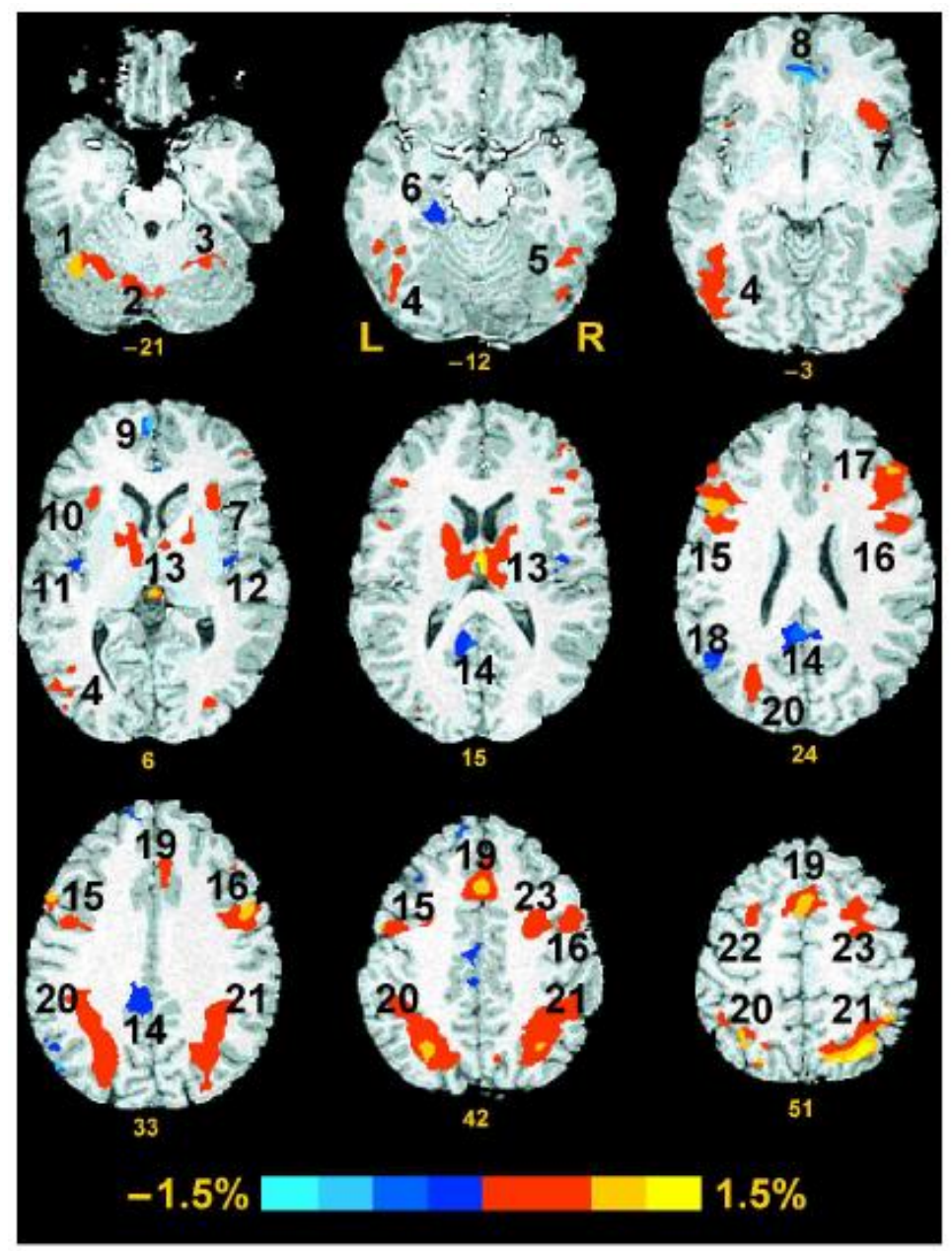

Figura 5. Regiões mostrando diferenças em ativação durante o desempenho da tarefa RVIP e da tarefa controle. Fatias axiais são mostradas a cada $9 \mathrm{~mm}$ de $-21 \mathrm{~mm}$ (inferior) a $51 \mathrm{~mm}$ (superior). Cores quentes indicam ativação durante a tarefa RVIP e cores frias indicam desativação. Regiões: (1) cerebelo esquerdo, (2) cerebelo médio, (3) cerebelo direito, (4) giro occipital esquerdo, (5) giro fusiforme direito, (6) giro parahipocampal esquerdo, (7) ínsula anterior direita, (8) córtex cingulado anterior, (9) córtex frontal medial esquerdo, (10) ínsula anterior esquerda, (11) ínsula média esquerda, (12) ínsula média direita, (13) tálamo/núcleo caudado, (14) córtex cingulado médio/posterior, (15) giro frontal médio/inferior esquerdo, (16) giro frontal médio/inferior direito, (17) giro frontal médio/superior direito, (18) giro temporal médio esquerdo, (19) pré-SMA (área motora suplementar), (20) giro parietal esquerdo, (21) giro parietal direito, (22) giro frontal médio esquerdo, (23) giro frontal médio direito. Extraída de Lawrence et al., 2003.

\section{4. Análise dos grafos}

Como já dito, o cérebro é formado por uma rede complexa de regiões funcionais e estruturais. Uma importante e recente expansão do estudo da conectividade funcional foi oferecer uma melhor compreensão das propriedades organizacionais que permitem redes cerebrais eficientemente segregar e integrar o processamento de informação. Essas explorações têm confiado fortemente na teoria gráfica (Van Dijk et al., 2010).

A análise de redes complexas de dados funcionais e estruturais é um método em ascensão e tem mostrado ser bastante útil por alguns motivos:

- Quantificação confiável de redes complexas com poucas medidas facilmente computáveis;

- Investigação de relações de conectividade funcional e estrutural, definindo as conexões no mesmo mapa de regiões cerebrais; 
- Comparação entre parâmetros de rede de diferentes populações de sujeitos sugere anormalidades de conectividade em desordens psicológicas e neurológicas (Rubinov, 2009).

O campo matemático da teoria gráfica permite abstrair propriedades de sistemas complexos, como sistemas cerebrais, para ser quantitativamente caracterizados e mapeados, possibilitando tomar medidas simples que podem ser usadas para estudar as tendências globais que definem a arquitetura normal do cérebro e sua variabilidade entre sujeitos (Van Dijk et al., 2010). Tanto as redes funcionais como as redes estruturais cerebrais podem ser definidas por um grafo $G=(V, E)$ (figura 7.a), em que $V$ representa a coleção de nodos refletindo as regiões ou os neurônios (figura 6.a) e E representa as conexões (ou arestas) funcionais entre essas regiões, sinapses ou projeções axonais. O nível de conectividade funcional entre duas regiões pode ser computado como o nível de correlação entre as séries temporais entre duas regiões (figura 6.b). Finalmente, a existência de uma conexão entre dois nodos pode ser definida se o nível de conectividade funcional excede um determinado limiar. Isso resulta na modelagem cerebral como uma rede funcionalmente conectada (figura 6.c) (van den Heuvel e Pol, 2010).

Basicamente, a fim de se calcular os parâmetros de uma rede cerebral funcional, é conveniente criar uma matriz em que cada linha e coluna sejam regiões do cérebro e os elementos dessa matriz correlações entre as séries temporais do sinal BOLD para cada região. É preciso lembrar que essas conexões refletem correlações temporais em atividade e podem ocorrer mesmo entre regiões que não estão diretamente conectadas anatomicamente. Logicamente, essa matriz de conectividade pode ser convertida em uma visualização gráfica da rede, chamada grafo. A princípio, a teoria dos grafos poderia ser aplicada a uma matriz de associação de medidas de conectividade funcionais ou efetivas para gerar grafos não-direcionados ou direcionados, respectivamente, embora grande parte dos estudos terem sido baseados em medidas de conectividade funcional (Bullmore e Sporns, 2009). 

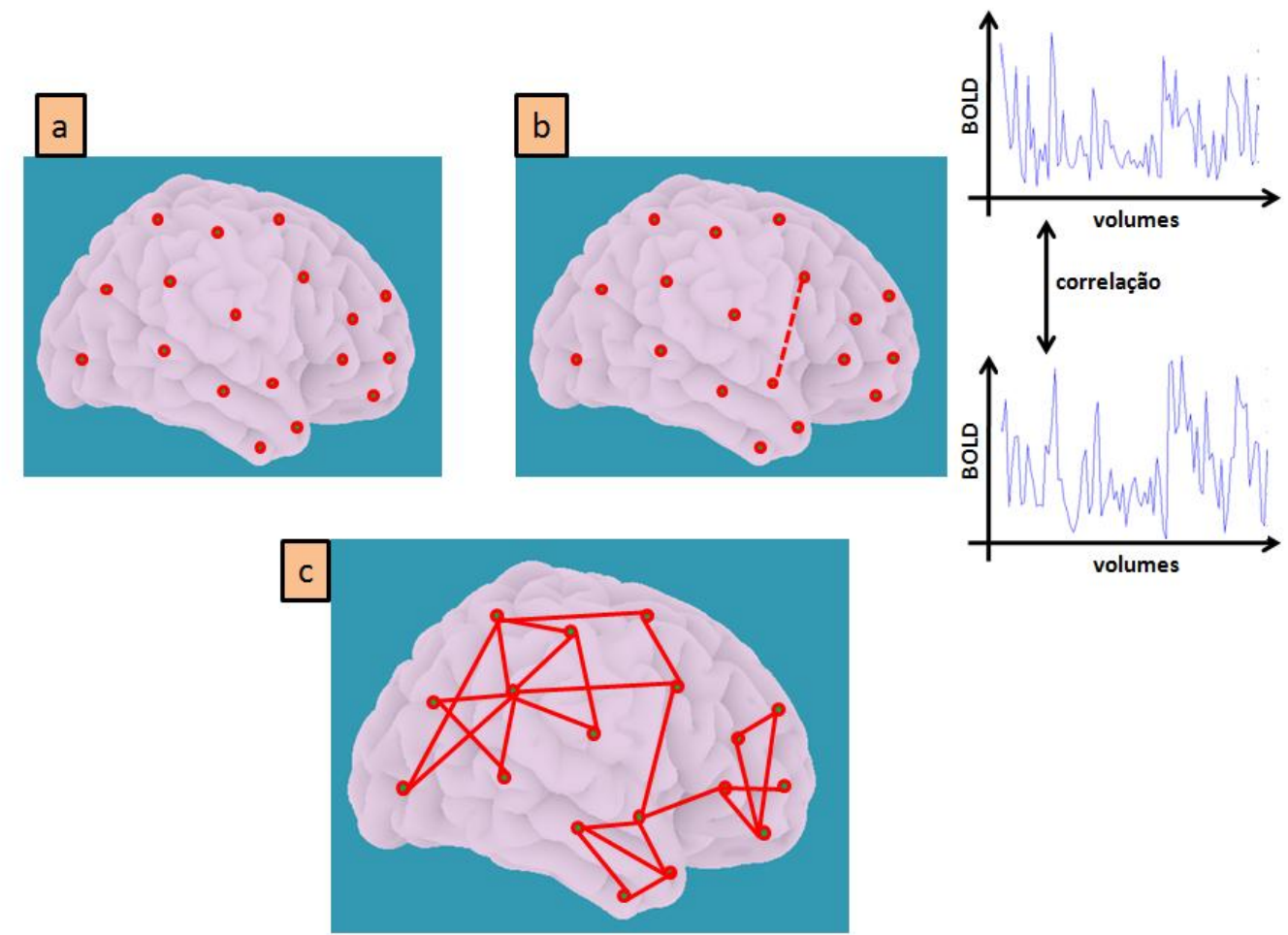

Figura 6. Modelagem de uma rede funcional cerebral. Adaptado de van den Heuvel e Pol, 2010.

A definição dos nodos em redes cerebrais individuais pode ser feita baseando-se na combinação de métodos de mapeamento ou em esquemas de parcelamento anatômico. É necessário ressaltar que essa determinação deve ser realizada com cautela, já que a interpretação neurobiológica da topologia da rede depende fortemente disso. Deve-se ter cuidado também em comparar redes construídas usando esquemas de parcelamento distintos, pois podem diferir em suas propriedades (Rubinov e Sporns, 2009).

As conexões podem ser binárias, que pressupõem a presença ou ausência de ligações, ou ponderadas, que, além disso, contêm informações sobre a intensidade das ligações. Como ligações fracas ou não significantes podem representar conexões espúrias, elas podem ser descartadas aplicando um limiar de ponderação, acima do qual considera-se as duas regiões estão funcionalmente conectadas. Esse limiar muitas vezes é arbitrário, mas idealmente as redes deveriam ser caracterizadas através de uma ampla escala de limiares (Rubinov e Sporns, 2009). Por fim, para a análise das redes, correlações entre regiões iguais e anticorrelações devem ser removidas. Os comprimentos das ligações são inversamente relacionados a intensidades de ligações funcionais, já que maiores intensidades representam associações mais fortes. Vale ressaltar, os comprimentos das conexões nesse contexto são adimensionais e não representam distância espacial. 
Através de medidas de conectividade efetiva podem-se gerar grafos direcionados. Entretanto, estudos de redes funcionais geralmente se baseiam em grafos não direcionados, que vêm de medidas mais simples de conectividade entre regiões cerebrais (Bullmore e Sporns, 2009).

Algumas medidas podem ser feitas a partir dos dados obtidos pela leitura dos grafos, como veremos abaixo. As fórmulas de cada uma das medidas são dadas por Rubinov et al. (2009) e correspondem às definições para grafos binários e não direcionados. A notação usada, nesse trabalho, será a que se segue:

- $n$ é o número de nodos, sendo $N$ o número de todos os nodos da rede;

○ $l$ é o número de conexões, sendo $L$ é o conjunto de todas as conexões da rede;

○ $(i, j)$ indica uma conexão entre os nodos $i$ e $j$;

- $a_{i j}$ representa o estado da conexão entre os nodos $i$ e $j$, sendo igual à unidade quando existe a conexão e nula quando não existe;

- Grau de um nodo $i\left(k_{i}\right)$ (figura 7.b) - trata-se do número total de ligações de um determinado nodo. Valores individuais de grau refletem a sua importância individual para a rede. É dado por

$$
k_{i}=\sum_{j \in N} a_{i j}
$$

- Distribuição de grau - Os graus de todos os nodos da rede compreendem a distribuição de grau, que é cumulativa e é um importante marcador do desenvolvimento e resiliência da rede. É dada por

$$
P(k)=\sum_{k \geq k} p\left(k^{\prime}\right),
$$

em que $p\left(k^{\prime}\right)$ é a probabilidade de um nodo ter grau $k^{\prime}$.

As medidas a seguir refletem segregação funcional no cérebro, ou seja, a habilidade do processamento especializado ocorrer dentro de grupos de regiões cerebrais interconectadas densamente (clusters), quantificando a presença deles. 
- Coeficiente de clusterização do nodo $i\left(C_{i}\right)$ (figura 7.c) - é o número de conexões diretamente vizinhas ao nodo $i$ dividido pelo número máximo de conexões possíveis entre todos os vizinhos desse nodo. Fornece informação sobre a prevalência de conectividade local do grafo. Este coeficiente é expresso para toda a rede como uma média:

$$
C=\frac{1}{n} \sum_{i \in N} C_{i}=\frac{1}{n} \sum_{i \in N} \frac{2 t_{i}}{k_{i}\left(k_{i}-1\right)}
$$

em que $t_{i}$ é o número de triângulos em torno de um nodo $i$,

$$
t_{i}=\frac{1}{2} \sum_{j, h \in N} a_{i j} a_{i h} a_{j h} .
$$

- Transitividade da rede (T) - Rubinov et al. (2009) afirma que "o coeficiente de clusterização médio para uma rede reflete, em média, a prevalência de conectividade clusterizada entre nodos individuais. Essa grandeza é individualmente normalizada para cada nodo e, portanto, pode ser desproporcionalmente influenciada por nodos de baixo grau. Uma variante clássica do coeficiente de clusterização médio, a transitividade, é normalizada coletivamente e não sofre com esse problema". É dada por:

$$
T=\frac{\sum_{i \in N} 2 t_{i}}{\sum_{i \in N} t_{i}\left(t_{i}-1\right)}
$$

- Modularidade - descreve a possível formação de comunidades na rede (figura 7.d). É o grau com que a rede pode ser subdividida em grupos bem delineados e não sobrepostos. A composição da estrutura modular da rede é revelada subdividindo a mesma em grupos de nodos, com um número maximamente possível de conexões dentro de um grupo e um número minimamente possível de conexões entre grupos (Rubinov e Sporns, 2009). 


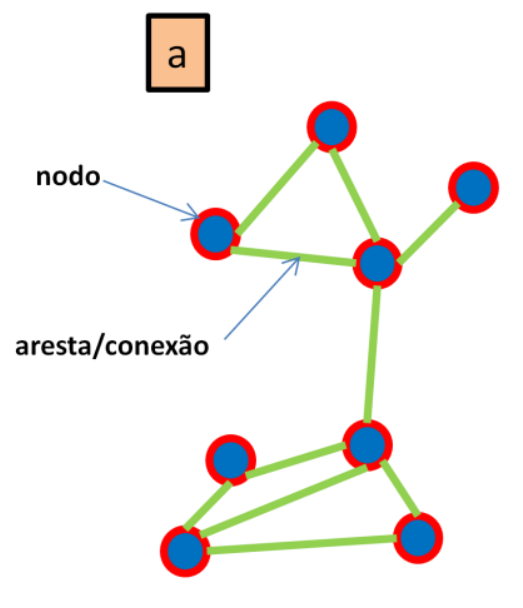

$\mathrm{b}$

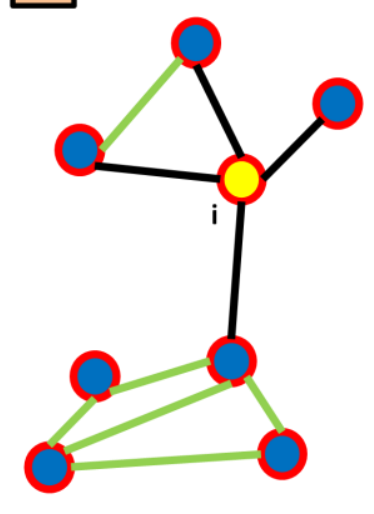

$\mathrm{e}$

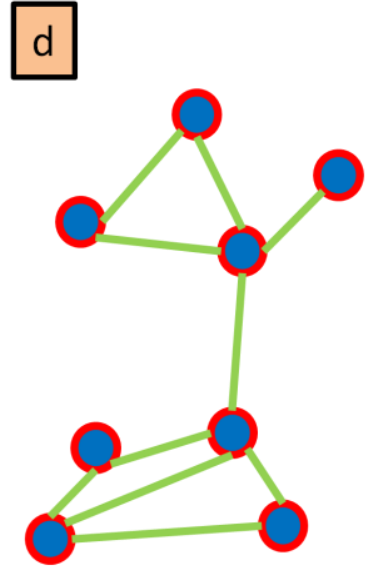

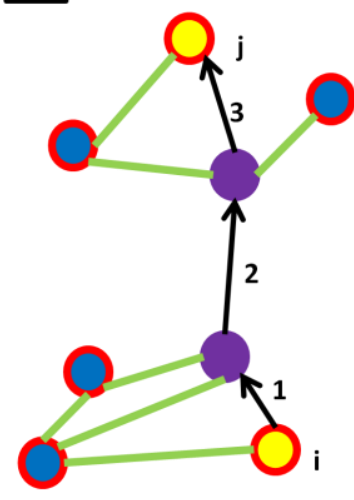

$\mathrm{C}$

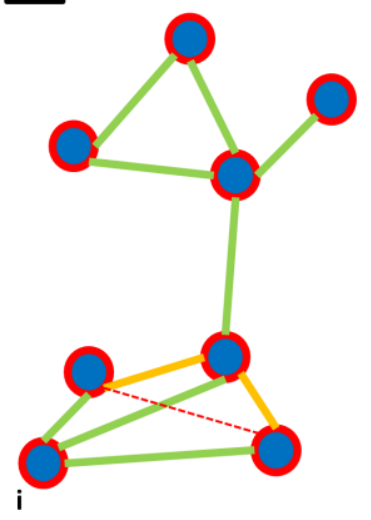

$\mathrm{f}$

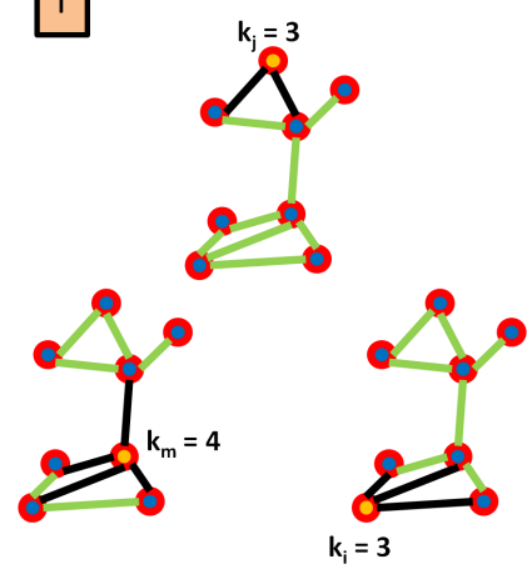

Figura 7. Rede complexa (a) com algumas características gráficas como: (b) grau de um nodo, (c) coeficiente de clusterização do nodo, (d) modularidade, (e) comprimento de caminho característico e (f) centralidade. Adaptado de van den Heuvel e Pol, 2010.

As medidas a seguir se referem à integração funcional do cérebro, ou seja, a habilidade de combinar rapidamente informações de várias regiões, estimando com que facilidade as regiões cerebrais se comunicam. São baseadas no conceito de caminho, ou seja, sequências de nodos e ligações que representam rotas potenciais para o fluxo de informação.

- Comprimento de caminho característico (L) (figura 7.e) - o comprimento de caminho mais curto médio entre todos os pares de nodos na rede é conhecido como o comprimento de caminho característico e é a medida mais comumente usada de integração funcional (Rubinov e Sporns, 2009). Traz informações sobre o nível de eficiência de comunicação global de uma rede. É dado por:

$$
L=\frac{1}{n} \sum_{i \in N} L_{i}=\frac{1}{n} \sum_{i \in N} \frac{\sum_{j \in N, j \neq i} d_{i j}}{n-1}
$$


em que $L_{i}$ é a distância média entre o nodo $i$ e todos os outros nodos.

- O inverso do comprimento de caminho característico é a eficiência global (E) (figura 7.e) e pode ser calculada mesmo em redes desconectadas, pois caminhos entre nodos desconectados são definidos como distância infinita e eficiência correspondente zero. É dada por:

$$
E=\frac{1}{n} \sum_{i \in N} E_{i}=\frac{1}{n} \sum_{i \in N} \frac{\sum_{j \in N, j \neq i} d_{i j}^{-1}}{n-1}
$$

em que $E_{i}$ é a eficiência do nodo $i$. Cabe aqui um comentário: as redes de conectividade funcional, estrutural e efetiva diferem em seus valores de eficiência global. Redes estruturais e efetivas são organizadas de forma similar e têm alta eficiência global. Redes funcionais, por terem conexões mais fracas entre os módulos, possuem menor eficiência global (Rubinov e Sporns, 2009).

Pode-se também calcular a eficiência global na vizinhança do nodo, então chamada eficiência local e relacionada com o coeficiente de clusterização.

- Centralidade (figura 7.f) - indica quantos caminhos mais curtos passam através de nodos específicos. Se um nodo tem alta centralidade, pode-se dizer que o mesmo é importante na intercomunicação dos nodos da rede. Desse modo, um índice de centralidade busca descobrir quais vértices são mais importantes dentro da rede (Vieira, 2011).

- Hubs - são nodos com alto grau ou alta centralidade. Na caracterização de redes, é comum falar em hubs. Eles possibilitam que a distância total da rede seja mínima, já que ligam várias conexões distantes, integrando redes locais e minimizando os custos de metabolismo e de arquitetura estrutural (Van Dijk et al., 2010).

- Robustez - refere-se à integridade estrutural mesmo com a exclusão de nodos ou arestas ou perturbações nos estados de rede local ou global.

No entanto, vale lembrar que essas medidas aplicadas em neurociências são uma tentativa recente de estudo e talvez ainda não se saiba o que exatamente elas têm a dizer. Um exemplo disso é dado pelo recente artigo de Power e colaboradores (2013), no qual os autores demonstraram que, baseando-se no conceito de grau, regiões anteriormente tratadas como hubs em grafos de conectividade funcional no estado de repouso podem ter 
sido identificadas dessa forma por fazerem parte de grandes sub-redes de nodos, mais do que terem papeis especiais em processamento de informação. Foram propostos por Power e colaboradores, em vez de usar apenas o conceito de grau do nodo, dois métodos alternativos para identificar hubs mais adequados às redes de correlação de conectividade funcional: (1) identificar nodos que participem em várias sub-redes do cérebro e (2) identificar locais em que várias sub-redes estejam contidas em um pequeno volume (Power et al., 2013).

Nesse estudo, foram utilizados os conceitos dos seguintes parâmetros de rede citados: coeficiente de clusterização global e local, transitividade, comprimento de caminho característico e eficiência global e local. O cálculo desses parâmetros pode trazer informações importantes e resumir dados sobre o comportamento funcional das redes cerebrais em níveis globais ou locais.

Com base nesses parâmetros, podemos caracterizar as redes complexas pela sua topologia. Vejamos a seguinte classificação e suas características:

- Rede regular - tem um caráter dito mais local por haver nela uma maior probabilidade de conexão de nodos vizinhos e menor para nodos distantes. Essa rede possui o grau de aleatoriedade mínimo. Possui um alto coeficiente de clusterização e alto comprimento de caminho. Imaginemos que seja preciso ir de um nodo a outro em extremidades opostas do grafo. Nesse caso, o número de passos (nodos pelos quais se percorre) é grande (alta eficiência local). Se os nodos de partida estão próximos, por outro lado, o número de passos é provável de ser pequeno (figura 8, à esquerda).

- Randômica - o caráter agora é mais global: a probabilidade de um par de nodos estarem conectados é igual, sem nenhuma preferência que dependa da distância entre eles. A distribuição de grau, nesse caso, é gaussiana (Bullmore e Sporns, 2009). O coeficiente de clusterização é baixo, assim como o comprimento de caminho. Nessa rede, o número de passos necessários para sair de um determinado nodo e chegar a outro distante dele é provável de ser menor que o da rede regular (alta eficiência global), enquanto que, se os nodos estiverem próximos, o número de passos tende a ser maior que o da rede regular (figura 8, à direita). 
- Rede de mundo pequeno - no que diz respeito ao grau de aleatoriedade, é um meiotermo entre a rede regular e a rede aleatória. Tem alto coeficiente de clusterização local, assim como em uma rede regular, e curto comprimento de caminho característico, como em uma rede randômica (Watts e Strogatz, 1998). Há formação de comunidades de nodos próximos, fazendo com que o número de passos entre dois nodos de uma comunidade seja pequeno. No entanto, diferentemente da rede regular, há também um número razoável de ligações entre essas comunidades, tornando o número de passos entre nodos distantes também pequeno. Nesse caso, é dito que há um alto nível de eficiência local e global, tornando a rede robusta: a perda de um nodo aleatoriamente escolhido, não afeta muito a rede (figura 8 , ao centro) (Bullmore e Sporns, 2009; Watts e Strogatz, 1998).

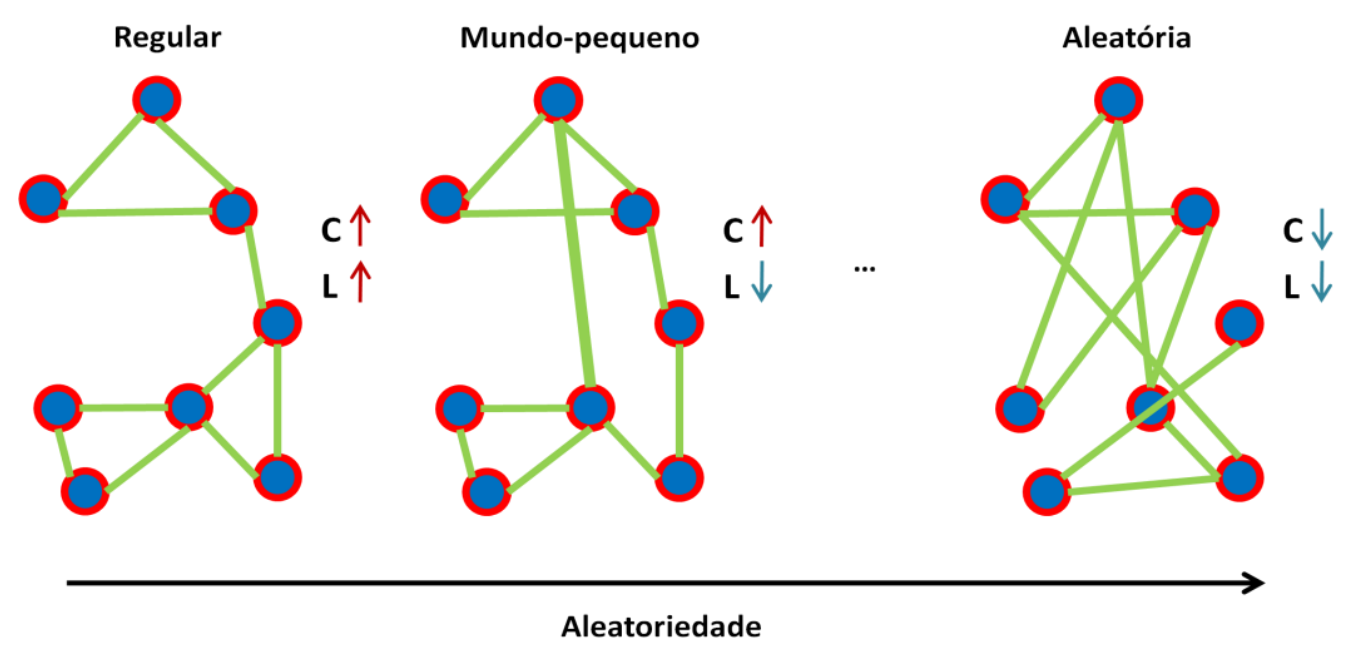

Figura 8. Classificação de topologias de redes complexas. Adaptado de van den Heuvel e Pol, 2010.

Tais redes foram chamadas de redes de mundo pequeno, devido à analogia com o fenômeno de mundo pequeno, popularmente conhecido como seis graus de separação. Sugere-se que essa classificação seja comum para redes esparsas de muitos vértices, mesmo que tenham uma pequena quantidade de ligações entre nodos distantes. Exemplos desse tipo de classificação podem ser encontrados em sistemas biológicos, redes sociais, computacionais, de distribuição de energia elétrica, neurais, internet, assim como em sistemas dinâmicos, que mostram aumento na propagação da informação, como modelos de espalhamento de doenças (Watts e Strogatz, 1998).

A fim de que uma rede complexa seja definida como seguindo o modelo de mundo pequeno, é formalmente definido que (i) a razão gama $(\gamma)$ entre seu coeficiente de clusterização e de 
uma rede randômica de distribuição de grau equivalente seja maior que 1 e (ii) a razão lambda $(\lambda)$ entre seu comprimento de caminho característico e de uma rede randômica de distribuição de grau equivalente seja aproximadamente igual a 1. O parâmetro sigma ( $\sigma)$, definido como a razão entre gama e lambda é tipicamente maior que 1 para redes que seguem a organização de mundo pequeno (Watts e Strogatz, 1998).

Em nosso trabalho, como sugerido por Sporns e Zwi (2004), para o cálculo de matrizes de associação aleatórias equivalentes às matrizes de associação das redes cerebrais de cada um dos participantes, foram computados o número de nodos, que deveria ser igual para as duas redes, e a distribuição de grau, que deveria ser similar, para comparação estatística das duas redes.

Uma outra forma de classificar redes complexas é pelo comportamento livre de escala, que tem a distribuição de grau seguindo uma lei de potência, ou seja, a maior parte dos nodos tem um número baixo de conexões, porém alguns poucos nodos são altamente conectados (chamados de hubs) e lhe conferem um alto nível de conectividade global.

As redes de mundo pequeno e livres de escala são conhecidas por mostrar uma arquitetura de rede robusta na qual a informação pode ser transferida e integrada com alto nível de eficiência, formando um modelo atrativo para o cérebro humano funcionalmente conectado (van den Heuvel et al., 2008). O cérebro pode ser representado como uma rede complexa de mundo pequeno em suas organizações estrutural e funcional, que tem distribuição de grau obedecendo à lei de potência exponencialmente truncada, aumento do coeficiente de clusterização em regiões de alta densidade de conexões e comprimento de caminho curto (Bullmore e Sporns, 2009; van den Heuvel et al., 2008). Tomados juntos, uma arquitetura de mundo pequeno e livre de escala combinados asseguram uma forma ótima de organização de rede, formando um balanço entre a máxima eficiência de comunicação local e global e a fiação mínima (van den Heuvel et al., 2008). Foi sugerido que o desenho espacial de neurônios e regiões cerebrais é economicamente arranjado para minimizar o volume axonal (Chklovskii et al., 2002; Klyachko e Stevens, 2003).

A ideia mais fundamental para o uso da conectividade funcional em patologias é usar a intensidade das correlações acopladas funcionalmente como marcadores da integridade do sistema cerebral. A seguir, são citados alguns exemplos da utilização de parâmetros da rede 
funcional cerebral no estudo de algumas doenças neurológicas, envelhecimento e planejamento cirúrgico:

- Doença de Alzheimer: clusterização reduzida e comprimento de caminho aumentado, indicando degradação da rede de mundo pequeno, embora os resultados não sejam consensuais (Bullmore e Sporns, 2009). Greicius mostrou que a conectividade funcional na DMN em pacientes com Alzheimer é interrompida quando comparados com os controles normais (Greicius et al., 2004).

- Esquizofrenia: perda de simetria, parâmetros próximos aos de rede randômica, perda de organização hierárquica - nodos de alto grau são altamente agrupados com mais frequência (Bullmore e Sporns, 2009).

- Avanço da idade: pessoas mais velhas apresentam eficiência reduzida, já que suas redes devem ter um maior número de conexões para obter a eficiência de transferência de informações vista em redes mais jovens (Bullmore e Sporns, 2009).

- Ruptura funcional também foi relatada em numerosas desordens neuropsiquiátricas como autismo, ADHD e depressão (Van Dijk et al., 2010).

- Outra classe de aplicações é no planejamento cirúrgico. Tratamentos para tumores cerebrais podem envolver a remoção de tecido cerebral e o mapeamento das localizações de sistemas cerebrais é informação crítica que permite ao cirurgião maximizar o tamanho da ressecção ao mesmo tempo em que se minimiza o dano ao córtex eloquente (Van Dijk et al., 2010).

O presente estudo não tratará de aplicações da conectividade funcional e análise gráfica a patologias, mas ao desempenho intelectual, que é uma diferença individual e pode ser estudada através da procura por associações entre valores de conectividade funcional ou parâmetros funcionais e pontuações de índices de inteligência para vários indivíduos, e ao estado de atenção sustentada, que pode ser analisado comparando como a conectividade se altera em relação a outro estado, nesse caso, o estado de repouso. 


\section{5. Desempenho intelectual e conectividade funcional no cérebro}

Atividade e conectividade da DMN podem estar envolvidas no processamento cognitivo e emocional e no monitoramento do mundo ao nosso redor (Gusnard e Raichle, 2001). Além disso, níveis mais altos de atividade na DMN foram relacionados com aumento na ocorrência de pensamentos independentes de estímulo (Mason et al., 2007). Também foi encontrado que o fluxo médio de sangue cerebral médio no estado de repouso nas substâncias cinzenta e branca e uma pontuação de inteligência geral estão correlacionados positivamente (Takeuchi et al., 2011).

Vários estudos recentes sugeriram uma ligação direta entre conectividade funcional ou parâmetros de rede no repouso e habilidade cognitiva humana (Song et al., 2008; Song et al., 2009; van den Heuvel et al., 2009; Cole et al., 2012). O primeiro estudo a investigar a relação entre as flutuações no sinal BOLD e as diferenças individuais de inteligência foi feito por Song e colaboradores (2008) posto que já era aceito que uma rede cerebral caracterizada por interações entre múltiplas regiões seria a base da inteligência (Song et al., 2008). Nesse estudo, os sujeitos foram mantidos em repouso, sem realizar nenhuma tarefa de memória de trabalho ou de raciocínio. Como era sabido que o córtex pré-frontal lateral era uma das regiões mais importantes para o suporte do comportamento inteligente, o mesmo foi definido como região semente para o estudo. Os sujeitos participantes do estudo foram submetidos a um teste de inteligência e suas pontuações foram correlacionadas com a intensidade da conectividade funcional entre regiões. Melhores pontuações de QI foram associadas com conectividade mais forte baseada no método da semente dentro da rede frontoparietal. O estudo sugeriu que a coordenação entre as regiões dentro da rede de controle executivo seria uma importante base neural para a inteligência individual (Song et al., 2008).

As conexões funcionais obedecem a uma organização altamente eficiente de mundo pequeno, com alto nível de clusterização local e curta distância efetiva entre as áreas cerebrais, o que traz alta eficiência global no tráfego de informações à rede. Sendo assim, van den Heuvel e colaboradores encontraram que há uma forte associação entre o nível de eficiência de comunicação global da rede cerebral e o desempenho intelectual, sugerindo que esta eficiência no estado de repouso poderia ser preditiva do QI e que indivíduos com 
inteligência superior teriam uma rede neural melhor organizada (van den Heuvel et al., 2009). Outro estudo relatou que o PCC é o hub mais importante da DMN, sugerindo que esta área poderia ser o centro de processamento de informação dentro dessa rede (Song et al., 2009), embora, como já dito na seção 1.4., dependendo da metodologia utilizada, alguns nodos podem ter sido classificados como hubs por integrarem grandes sub-redes de nodos, não exatamente por exercerem papeis especiais no processamento de informação cerebral (Power et al., 2013).

Cole et al. (2012) encontrou associações entre maior conectividade positiva e o Gf - uma medida de aspectos fluidos (aqueles independentes do conhecimento e da cultura) da inteligência geral - para o córtex pré-frontal lateral esquerdo, pertencente à rede frontoparietal. Neste trabalho, foi demonstrado que indivíduos com maior conectividade tem maior capacidade de controle cognitivo e sugerindo que essa relação reflete processos de controle cognitivos referentes à inteligência via um mecanismo único envolvendo a conectividade global extensivamente. Esse estudo aponta para a importância da natureza da conectividade global dessa região. Também foram encontradas associações do Gf com maior conectividade positiva para outras redes positivas à tarefa e com maior conectividade negativa com as DMN, auditória e somatomotora e a amígdala.

Entretanto, até o presente momento e segundo o que foi pesquisado, não foram encontrados estudos reportados que analisassem como intensidades de conectividade funcional e/ou parâmetros de rede se relacionam com os índices mais fundamentais de inteligência considerando a conectividade funcional entre regiões corticais e sub-corticais para o cérebro todo classificadas pelo atlas AAL (Automated Anatomical Labeling) (TzourioMazoyer et al., 2002) e um detalhado teste de inteligência, como o WAIS-III, que fornece vários sub-índices.

A partir dos achados reportados como possíveis resultados, espera-se: Melhores pontuações de QI total associadas com conectividade mais forte baseada no método da semente na região frontal lateral e alguma associação entre o nível de eficiência de comunicação global da rede cerebral e o desempenho intelectual (van den Heuvel et al., 2009). Além disso, associações entre conectividade funcional e (i) índice de compreensão verbal no córtex frontal inferior esquerdo, (ii) índice de memória de trabalho no córtex parietal e frontal 
esquerdo, (iii) índice de organização perceptual no córtex parietal direito e (iv) nenhuma localização significante para o índice de velocidade de processamento (Gläscher et al., 2009).

\section{6. Diferenças neurais entre estado de repouso e atenção focada}

Nos estudos de fMRI que envolvem a execução de tarefas cognitivas que demandam atenção, duas respostas são comumente observadas (Fox et al., 2005). Um conjunto de regiões corticais parietais e frontais mostra um incremento de sinal BOLD ou "ativação" (Cabeza et al., 2000) durante o desempenho de tarefas dirigidas a um objetivo, também chamadas de regiões positivas à tarefa ou sistema extrínseco. Outro conjunto de regiões negativas à tarefa ou sistema intrínseco, incluindo o PCC, o córtex pré-frontal medial e o córtex parietal medial e lateral, exibe uma redução de sinal BOLD ou "desativação" (Gusnard e Raichle, 2001) durante o desempenho da tarefa, porém exibe maior atividade no repouso. Essa diferença nas respostas observadas fica mais acentuada na medida em que a demanda de atenção da tarefa é incrementada (Fox et al., 2005). Entretanto, a dicotomia ativação/desativação observada na resposta a tarefas demandando atenção é inerente ao cérebro humano, demonstrável na ausência de qualquer tarefa ou comportamento.

Algumas regiões, no entanto, não mostram preferência para nenhuma rede intrínseca ou extrínseca, como são os casos do córtex sensorial primário e motor (Fox et al., 2005).

Os dois sistemas mencionados têm aparentemente uma relação competitiva entre si: uma região

que faz parte do sistema extrínseco do cérebro é ativada em função de uma determinada tarefa enquanto que o sistema intrínseco mostra

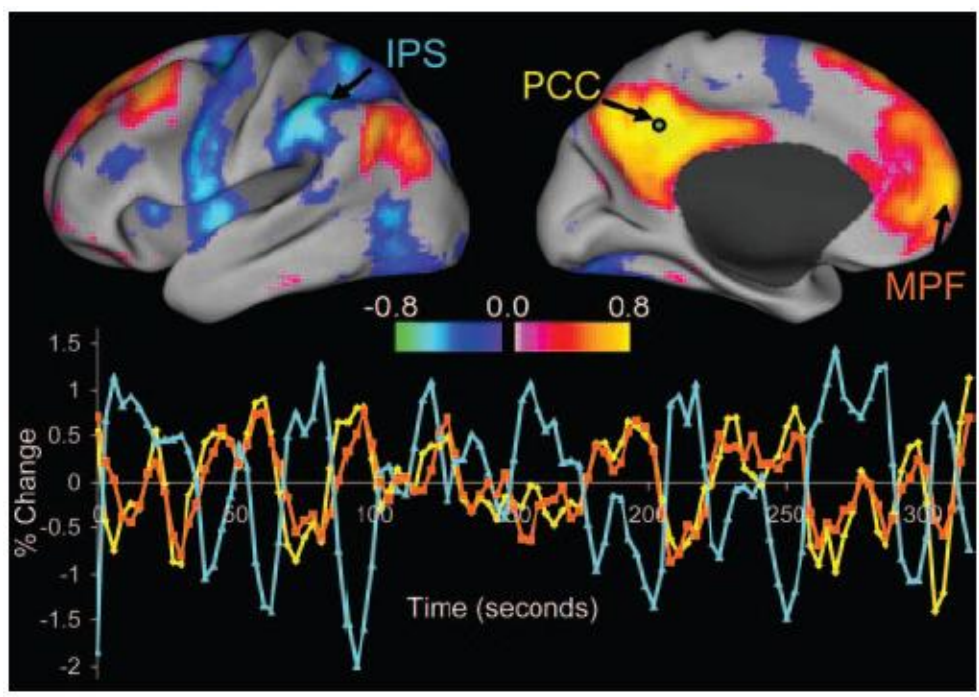

Figura 9. Correlações intrínsecas dentro de uma região semente no PCC e todos os outros voxels no cérebro para um único sujeito durante $o$ repouso. Acima são mostradas distribuição dos coeficientes de correlação; as regiões em cores quentes mostram correlações positivas e as regiões em cores frias mostram correlações negativas. Abaixo, são mostradas as séries temporais para a região semente no PCC (em amarelo) positivamente correlacionadas com a região semente no córtex pré-frontal medial (em laranja) e negativamente correlacionados com a região semente no sulco intraparietal. Extraído de Fox et al., 2005. 
desativação, o que define uma anticorrelação na conectividade funcional. Foi sugerido que essa anticorrelação estaria envolvida em funções aparentemente opostas como, por exemplo, atenção orientada internamente em contrapartida da atenção orientada externamente (Uddin et al., 2008). A figura 9 (Fox et al., 2005) mostra as correlações intrínsecas entre uma região semente no PCC, que faz parte do sistema intrínseco, e todos os outros voxels para um sujeito no repouso. As cores quentes mostram coeficientes de correlação positivos e as cores frias mostram coeficientes de correlação negativos.

A observação desse comportamento competitivo pode ser importante para entender o fluxo de informações através das vias de processamento e sua compreensão traria consequências de longo alcance sobre o que sabemos sobre as interações entre sistemas cerebrais (Van Dijk et al., 2010).

Se nenhuma tarefa é requisitada ou se o indivíduo já está acostumado com a mesma (Mason et al., 2007), há uma maior ativação no sistema intrínseco, havendo por ora uma sobreposição ao sistema extrínseco (Josipovic et al., 2012). Como o sistema intrínseco está relacionado, entre outras coisas, com divagação (definida como pensar em algo que não está acontecendo no presente momento), pode-se notar essa competição na tendência da mente divagar e se tornar distraída do momento presente em favor de um pensamento independente de estímulo (Farb et al., 2007). Lapsos momentâneos na atenção têm sido associados com falhas em suprimir a atividade na DMN (Castellanos et al., 2008). Decréscimos na conectividade funcional relacionados com déficit de atenção na DMN sugerem uma base neural para a associação entre déficits de memória de trabalho e flutuações atencionais (Castellanos et al., 2008). A supressão da divagação através do foco em um empreendimento cognitivo tem sido usada terapeuticamente em desordens psicológicas como depressão e ansiedade (Fox et al., 2005).

Foi sugerido que uma forma de manipular a supressão de uma rede em favor da manifestação da outra seria a aquisição e análise de imagens de dois grupos de indivíduos que faziam ou não uso do treino de meditação atentiva (Farb et al., 2007; Josipovic et al., 2012). Nesta meditação, os indivíduos desenvolvem a habilidade de dirigir e manter a atenção no presente momento. Os dois grupos teriam como diferencial a habilidade de sustentar a atenção durante o tempo e haveria um maior "contraste" em redes relacionadas 
à atenção entre estado de repouso e atenção focada para meditadores (Brefczynski-Lewis et al., 2007). Esta forma de manipulação seria mais efetiva quando comparada a uma abordagem de pedir para que os indivíduos se empenhem em realizar tarefas de autoreferência, porém seria necessário dispor de voluntários com extensiva experiência na área de meditação de concentração para se encontrar diferenças significativas entre os grupos e houve suficiente dificuldade em se encontrar indivíduos com esse perfil na região de Ribeirão Preto. Unindo isso e a atração pela novidade em estudar indivíduos sem habilidade prévia em meditação de atenção sustentada, mas que seriam incentivados financeiramente em se aplicarem da melhor forma possível à tarefa, foram recrutadas pessoas saudáveis e não-meditadores para participarem da pesquisa.

No estado de atenção focada, mantém-se a concentração consistentemente num objeto pequeno no momento presente (Brewer et al., 2011) ou na respiração (ou pensamentos, sons ambientes, sensações introspectivas (Kilpatrick et al., 2011)) trazendo a mente de volta ao objeto sempre que se divaga (Hasenkamp et al., 2012) ou se coloca à solução ativa de problemas. $\mathrm{O}$ experimento, em nosso estudo, foi feito com indivíduos que foram instruídos a usar a mesma técnica para sustentar a atenção num único ponto. Para melhorar o desempenho atentivo deles, foram incentivados com um bônus em dinheiro. De fato, no experimento de Brefczynski-Lewis e colaboradores verificou-se uma função de resposta hemodinâmica mais sustentada para a atenção de indivíduos incentivados em relação a indivíduos não-incentivados (Brefczynski-Lewis et al., 2007).

Para a comparação entre o estado de repouso e de atenção focada, esperam-se como possíveis resultados: uma maior anticorrelação entre os sistemas intrínseco e extrínseco (Josipovic et al., 2012) para o estado de atenção sustentada em relação ao estado de repouso para indivíduos sem experiência em meditação de concentração, porém incentivados. Considerando que o estado de atenção sustentada estaria relacionado com regiões positivas à tarefa e o estado de repouso, que pressupõe divagação, estaria relacionado com regiões negativas à tarefa, a hipótese é de que essas regiões concorrentes estariam mais anticorrelacionadas no estado de atenção em relação ao estado de repouso. Fox et al. (2005) estudou redes anticorrelacionadas para um estado de repouso e é sugerido aqui que essa análise seja feita também para um estado de atenção sustentado para investigar as diferenças neurais envolvidas. 
Capítulo 2

\section{Objetivos}

A partir de imagens de RM, estudaremos como a conectividade funcional entre regiões cerebrais pré-definidas está relacionada com o desempenho intelectual e a capacidade de sustentar a atenção. Desta forma, os objetivos ou perguntas específicas que conformam este projeto são:

- Há associações entre parâmetros globais de rede cerebral e desempenho intelectual?

- Há associações entre parâmetros locais de rede cerebral e desempenho intelectual? Se sim, em que regiões cerebrais?

- Há associações entre conectividade funcional no cérebro e desempenho intelectual? Se sim, em quais conexões?

- Quais as diferenças no cérebro entre um estado de atenção sustentada e um estado de repouso para redes positivas e negativas à tarefa em termos de conectividade funcional? 


\section{Capítulo 3}

\section{Materiais e métodos}

\section{1. Sujeitos}

Um total de 31 sujeitos saudáveis foram recrutados espontaneamente da comunidade acadêmica e do corpo de funcionários do Hospital das Clínicas de Ribeirão Preto, destros, sem histórico de doenças neurológicas. Não foram aproveitadas as imagens de um dos sujeitos por excesso de movimento na máquina e 30 sujeitos foram considerados para o estudo de atenção sustentada (idade: $27,0 \pm 5,7,15$ mulheres). Para o estudo do desempenho intelectual, um participante não realizou o teste de avaliação de inteligência a tempo e 29 participantes foram considerados para as análises (idade: 26,8 \pm 5,8 anos, 14 mulheres). A idade dos participantes variou entre 18,8 e 37,7 anos, classificados como adultos jovens, e houve o cuidado de pareá-los por sexo. Os indivíduos participaram desse estudo depois de passar pela entrevista de triagem padrão no setor de RM do Hospital das Clínicas de Ribeirão Preto e assinar o Termo de Consentimento Livre e Esclarecido aprovado pelo Comitê de Ética em Pesquisa da FFCLRP da Universidade de São Paulo. Quando participaram do experimento, eram ingênuos em relação ao propósito da pesquisa.

A tabela 1 descreve as características dos dados demográficos (para o estudo de desempenho intelectual) e de inteligência adquiridos. Os detalhes sobre o teste aplicado para obter as pontuações de inteligência são apresentados na seção 3.3. 


\begin{tabular}{|c|c|}
\hline Categoria & Dados \\
\hline Gênero (homem/mulher) & $15 / 14$ \\
\hline Idade (anos) & $26,8 \pm 5,8$ \\
\hline Quociente de inteligência verbal & $111,7 \pm 10,8$ \\
\hline Quociente de inteligência executivo & $116,0 \pm 11,4$ \\
\hline Quociente de inteligência total & $114,2 \pm 10,0$ \\
\hline Índice de compreensão verbal & $111,9 \pm 11,0$ \\
\hline Índice de organização perceptual & $115,3 \pm 11,9$ \\
\hline Índice de memória de trabalho & $111,4 \pm 12,3$ \\
\hline Índice de velocidade de processamento & $116,1 \pm 12,0$ \\
\hline
\end{tabular}

Tabela 1. Dados demográficos e pontuações de inteligência estimadas. Idade e pontuações de inteligência são mostradas como média \pm desvio-padrão.

\section{2. Aspectos éticos}

O estudo foi aprovado pelo Comitê de Ética em Pesquisa da FFCLRP-USP. Todos os voluntários participantes desse estudo leram e assinaram o Termo de Consentimento Livre e Esclarecido antes de começar qualquer etapa do experimento. Através dele, foi informado aos voluntários que se poderia deixar de participar do estudo a qualquer momento sem perder os direitos e benefícios de ser atendido na clínica em questão. Foram também explicados os eventuais riscos associados a exames de RM.

Todo voluntário passou por uma entrevista de triagem feita por um enfermeiro para assegurar que o voluntário estava em condições de realizar o exame de RM portando artigos de metal no corpo. Também foi pedido a cada voluntário que respondesse um questionário com perguntas de aspectos psicossociais, médicos e escolares, a fim de conhecer os voluntários para o estudo e filtrá-los, caso fosse preciso.

\section{3. Estimativa do nível de inteligência individual}

O nível de desempenho intelectual foi medido com o teste WAIS-III (Wechsler Adult Intelligence Scale) (Wechsler, 1939) revisado para o Brasil, aplicado por um neuropsicólogo com experiência na área. Este teste foi aplicado para cada sujeito de forma individual em uma sessão diferente da aquisição de imagens e com uma duração média de 1 h e 30 min.

O teste WAIS é uma família de avaliações dos domínios cognitivos que contribuem para a inteligência e é um dos instrumentos de medição da inteligência mais usados hoje em dia 
nas clínicas. Possui alta confiabilidade teste-reteste em populações sadias e clínicas e uma enorme base de dados para prover comparação e padronização (Gläscher et al., 2009). As medidas derivadas desse teste são quociente de inteligência verbal (QIV) e quociente de inteligência de executivo (QIE), que resumem as habilidades relacionadas à linguagem e ao processamento visuo-espacial, respectivamente, e o quociente de inteligência de larga escala ou total (QIT). O advento da terceira versão do teste produziu quatro índices que definem domínios cognitivos principais: índice de compreensão verbal (ICV - estimado através de testes de Vocabulário, Similaridades e Informação e diz respeito à habilidade em linguagem. É um índice de inteligência mais cristalizado, pois está ligado à capacidade de usar habilidades, conhecimento e experiência), índice de organização perceptual (IOP estimado através de testes de Organização de Blocos, Raciocínio de Matrizes e Construção Mental de Figuras e diz respeito à solução de problemas visualmente. Esse é um índice mais fluido que o ICV, ou seja, relaciona-se com a capacidade de pensar logicamente e resolver problemas em situações novas), índice de memória de trabalho (IMT - estimado através de Testes Aritméticos, Organização Mental de Dígitos e Sequências de Letras e Números e diz respeito à quantidade de informação que uma pessoa pode manipular) e índice de velocidade de processamento (IVP - estimado através de testes de Procura de Símbolos e diz respeito à velocidade com que a pessoa consegue manipular as informações).

No WAIS-III, o ICV e o IMT juntos compõem o QIV e o IVP e o IOP juntos compõem o QIE, enquanto que o QIT é composto pelos quatro índices fundamentais. No WAIS-IV, não há mais as classificações QIV e QIE.

\section{4. Aquisição das imagens}

As séries temporais de $\mathrm{fMRI}$ no estado de repouso e no estado de atenção incentivada de cada participante foram adquiridas em um tomógrafo Phillips de 3 Tesla (figura 10) com um sistema de gradientes Quasar Dual (máxima intensidade de $80 \mathrm{mT} / \mathrm{m}$ e taxa de

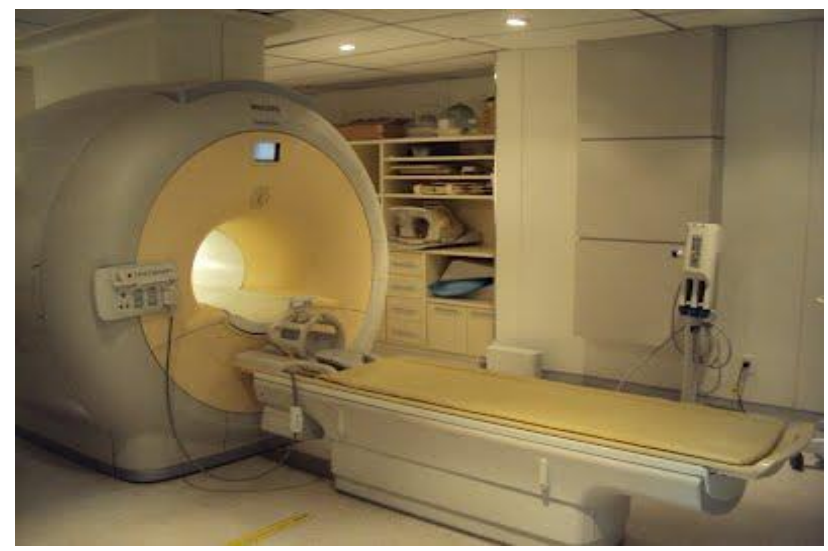

Figura 10. Tomógrafo de MRI de 3 Tesla localizado no Hospital das Clínicas de Ribeirão Preto (SP). 
variação de até $200 \mathrm{mT} / \mathrm{m} / \mathrm{ms}$ ), usando uma bobina de cabeça de oito canais com disponibilidade da técnica SENSE. O aparelho encontra-se no Hospital das Clínicas da Faculdade de Medicina de Ribeirão Preto, em atividade regular e condições normais de funcionamento. O equipamento vem sendo usado por nosso grupo desde sua instalação, em agosto de 2008.

Para as imagens funcionais adquiridas durante o repouso e durante a tarefa de atenção, foram utilizados a sequência EPI single shot e os seguintes parâmetros: número de fatias = 32 (em ordem ascendente), tempo de repetição $=2000 \mathrm{~ms}$, espessura do corte $=4,0 \mathrm{~mm}$, gap $=0,5 \mathrm{~mm}$, tempo de eco $=30 \mathrm{~ms}$, ângulo de flip $=80^{\circ}$, número de volumes $=200$, field of view $=240 \times 240 \mathrm{~mm}^{2}$, tamanho do pixel $=3 \times 3 \mathrm{~mm}^{2}$, largura de banda por pixel $=25,2 \mathrm{~Hz}$. 0 tempo total de aquisição para cada um dos estados foi de 6 minutos e 48 segundos.

Imagens anatômicas de alta resolução também foram adquiridas a fim de se sobreporem às imagens funcionais e facilitarem a localização das regiões cerebrais. Utilizou-se para tal uma sequência gradiente de eco 3D ponderada em T1 com os seguintes parâmetros: tempo de repetição $=7,0 \mathrm{~ms}$, tempo de eco $=3,2 \mathrm{~ms}$, tamanho do pixel $=1 \times 1 \mathrm{~mm}^{2}$, espessura do corte $=1,0 \mathrm{~mm}$, ângulo de flip $=8^{\circ}$, field of view $=240 \times 240 \times 160 \mathrm{~mm}^{3} .0$ tempo total para essa etapa foi de 5 minutos e 19 segundos.

\section{5. Protocolo do experimento}

Como sugerido por Van Dijk e colaboradores (2010), a intensidade da conectividade funcional pode ser estimada rapidamente e depende minimamente da resolução temporal e espacial. Especificamente, estimativas da intensidade da conectividade das redes comumente estudadas se beneficiaram minimamente estendendo a aquisição dos dados além dos 6 minutos. Os mesmos autores estudaram se haveria diferenças em termos de conectividade funcional para os voluntários com olhos fechados, olhos abertos com fixação (pequena cruz do meio da tela) e olhos abertos sem fixação. Concluíram que correlações mais fortes foram produzidas quando os sujeitos estavam de olhos abertos, com ou sem fixação na tela, em relação aos olhos fechados. Foi também observado que sujeitos no 
estado de repouso produziram correlações mais fortes que quando eles se empenhavam em uma tarefa de classificação semântica contínua (Van Dijk et al., 2010).

Nosso estudo consistiu em um protocolo de fMRI de 14 minutos de duração. Em um bloco de aproximadamente 7 minutos (estado de repouso), os sujeitos permaneceram de olhos abertos e sem dormir no escuro, e no outro bloco com a mesma duração (atenção sustentada), e mantiveram o olhar fixo em uma pequena cruz refletida por um espelho (Jang et al., 2011, Josipovic et al., 2012, Brefczynski-Lewis et al., 2007). Foi feito um treino prévio para verificar se os sujeitos eram capazes de reproduzir cada um dos estados, sendo avaliados por auto-relato. Ambas as condições foram contrabalanceadas entre os sujeitos e a eles foram dadas as seguintes instruções durante período de aquisição:

Para o estado de repouso: "Por favor, mantenha seus olhos abertos e não pense em nada em particular. Relaxe sem dormir. Seu estado emocional não precisa ser nem prazeroso nem desagradável". Para a atenção sustentada: "Por favor, preste atenção na cruz que será exibida na tela. Apenas se concentre nela. Se você achar que sua concentração está se divagando, gentil e firmemente traga-a de volta para a cruz na tela". Cada instrução era lida para o participante, que a ouvia através de um fone de ouvido, imediatamente antes de cada bloco.

Para que tivéssemos maior segurança de que os participantes se esforçavam em sustentar a atenção durante a realização do estudo, era oferecida uma bonificação no valor de 50 reais (Brefczynski-Lewis et al., 2007). Não foi possível verificar em tempo real se os participantes realmente estavam se aplicando à tarefa, mas, sendo ingênuos a isso, eles procuravam se esforçar a fim de ganhar o prêmio, o qual era concedido a todos os participantes no fim da seção experimental.

A entrada visual da cruz de fixação para a tarefa de atenção foi garantida pela colocação de um espelho sobre a bobina de cabeça, o que permitiu a visualização do interior da sala e do corpo do próprio sujeito. A condição de olhos abertos no estado de repouso foi escolhida devido a resultados já reportados na literatura (Raichle et al., 2001; Josipovic et al., 2012; Castellanos et al., 2008; Pagnoni, 2012; Brefczynski-Lewis et al., 2007) e pela justificativa de correlação de correlação mais intensa, explicada no primeiro parágrafo desta sub-seção. 


\section{6. Pré-processamento e análise das imagens}

Antes da análise gráfica, os dados de fMRI foram pré-processados pelo toolbox SPM, versão 8.0, e pelo toolbox de conectividade funcional CONN (figura 11), ambos implementados no software MatLab. O toolbox CONN traz consigo o método CompCor, uma estratégia de redução de fontes de ruído baseada em suas componentes, além de realizar remoção adicional de movimento e covariáveis temporais, filtro temporal, janelamento de sinal de contraste BOLD residual, estimativa de primeiro nível de medidas de fcMRI múltiplas e análise de segundo nível para o estado de repouso e/ou dados relacionados a uma dada tarefa (Whitfield-Gabrieli, 2012).

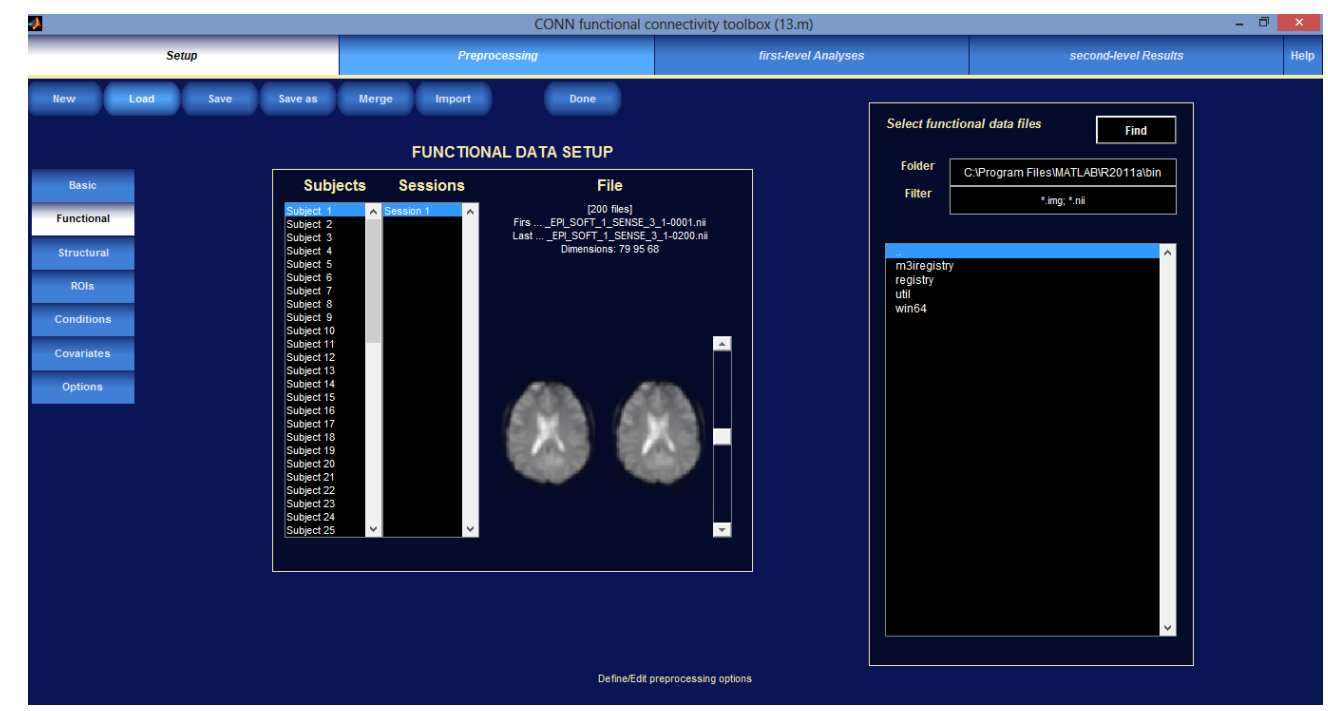

Figura 11. Interface do toolbox CONN, implementado para MatLab, versão 13.m.

Os passos de pré-processamento são resumidos na figura 12 e detalhados a seguir. Fazendo uso do SPM, para cada conjunto de imagens funcionais de cada indivíduo e para cada estado (repouso e atenção sustentada) foi realizada a correção de movimento de corpo rígido através de uma transformação espacial de seis parâmetros. Um procedimento de duas etapas foi utilizado para o realinhamento, em que a primeira das imagens funcionais especificadas foi utilizada como referência para a qual todas as imagens subsequentes foram realinhadas. Depois desse primeiro realinhamento, as imagens funcionais foram coregistradas para a média das imagens. Houve o cuidado de remover os dados de qualquer participante que ultrapassasse $2 \mathrm{~mm}$ de translação e 1 grau de rotação. A escolha destes valores está relacionada com as dimensões da imagem (3 $\mathrm{mm}$ de resolução), evitando a contaminação do sinal de um pixel pelo sinal vizinho em uma série temporal. 


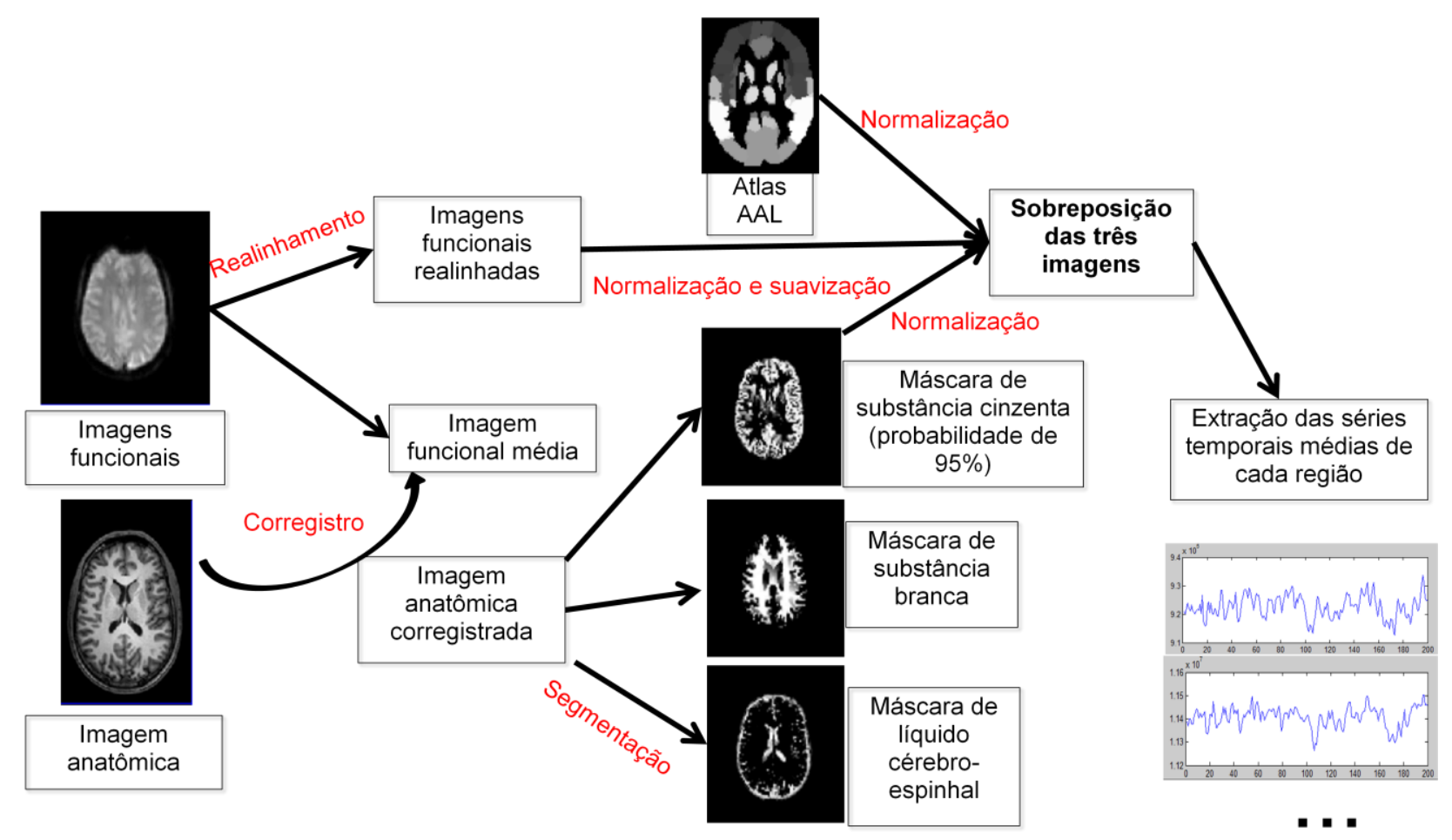

Figura 12. Extração de séries temporais de sinal BOLD de cada região do atlas AAL.

Em seguida, as imagens anatômicas de cada voluntário e para cada estado foram coregistradas para a imagem média das funcionais, criada na etapa anterior. Os volumes anatômicos foram segmentados em substância cinzenta, substância branca e fluido cérebroespinhal, cada um sendo levado para um espaço padrão. As máscaras resultantes foram erodidas para minimizar efeitos de volume parcial. A etapa anterior produziu parâmetros de normalização espaciais, que foram usados para aplicar as transformações utilizadas nas imagens funcionais. Nesta normalização, as imagens funcionais são levadas a um espaço padrão.

Como foi feita posteriormente uma análise de grupo, as imagens funcionais foram suavizadas espacialmente usando um núcleo gaussiano de $5 \mathrm{~mm}$ de largura à meia-altura. Esse passo do pré-processamento reduz os ruídos e os efeitos das diferenças anatômicas e funcionais que aparecem durante o cálculo da média entre os participantes. Após seguir esses passos, as regiões do atlas AAL mostraram um alinhamento satisfatório com as imagens funcionais. O erro para um cérebro individual é de geralmente alguns poucos milímetros, mas a suavização espacial aplicada resolve essa diferença.

Como comentado brevemente, no presente trabalho foi utilizado o toolbox CONN. O CONN é baseado no método CompCor, em que um número de séries de tempo são estimadas 
usando PCA do sinal BOLD entre cada uma das ROls de ruído específicas para cada sujeito, que podem ser as máscaras de substância branca e de fluido cérebro-espinhal ou outras áreas especificadas. Posteriormente, as séries temporais residuais resultantes são filtradas por um filtro passa-banda. Essa estratégia generaliza a prática comum de extrair as séries temporais médias do sinal BOLD de regiões semente localizadas em regiões de substância branca e/ou de fluido cérebro espinhal. Com isso, o método provê uma maior proteção contra possíveis efeitos confundidores na conectividade funcional sem introduzir tendências de artefatos nas medidas estimadas (Whitfield-Gabrieli e Nieto-Castanon, 2012), como a normalização de cérebro inteiro alterando a distribuição das correlações e introduzindo correlações negativas. Saber se correlações negativas refletem interações neurofisiológicas é crucialmente importante porque anticorrelações entre sistemas cerebrais têm sido interpretadas como evidência de uma relação antagônica entre os sistemas (Van Dijk et al., 2010).

Através desse toolbox, as séries temporais da substância branca e do fluido cérebro-espinhal e os seis parâmetros de movimento, assim como suas primeiras derivadas, foram extraídos de cada sujeito e seus efeitos sobre os sinais de cada região foram removidos. Foi aplicado um filtro temporal passa-banda entre $0,008 \mathrm{~Hz}$ e 0,09 Hz (Andrews-Hanna et al., 2003; Fox et al., 2005) para reduzir os efeitos de flutuações de baixa frequência, como as oscilações cardíacas e respiratórias, e ruído de alta frequência de fontes espúrias indesejadas (Van Dijk et al., 2010).

O toolbox CONN também permite a definição de regiões semente utilizando práticas padronizadas. Uma delas é a utilização de volumes de imagens baseados em um atlas, em que as múltiplas ROls podem ser definidas. Foi feita a análise entre regiões do atlas AAL e não ao nível do voxel para analisar a conectividade de regiões que encerram semelhanças anatômicas e funcionais. A escolha desse método em contraposição à análise de todos os voxels teria como vantagem uma maior facilidade na localização cerebral dos achados e uma varredura mais rápida que a de nível do voxel.

Para o estudo do desempenho intelectual, as redes cerebrais individuais foram representadas por grafos em que os nodos eram as regiões do atlas AAL e as arestas eram as medidas de conectividade funcional medidas pelo coeficiente de correlação de Pearson 
(equação 2) entre as séries temporais médias extraídas das regiões do atlas AAL sobrepostas às imagens funcionais processadas. Regiões do cerebelo e do vermis cerebelar foram excluídas da análise e as 90 regiões restantes do atlas foram consideradas, sendo cada ROI caracterizada por voxels compartilhando o mesmo número de identificação. $O$ atlas AAL é baseado no parcelamento anatômico dos volumes adquiridos por contraste T1 normalizados realizado pelo Montreal Neurological Institute (MNI) (Tzourio-Mazoyer et al., 2002).

Para o estudo da atenção focada, a correlação entre regiões também foi analisada mas desta vez através de ROls esféricas de $6 \mathrm{~mm}$ de raio centradas em coordenadas previamente publicadas para regiões da DMN e da rede de atenção sustentada. Essa forma de análise foi realizada porque o interesse seria investigar as variações nas componentes dessas redes entre os dois estados. O estudo de cérebro inteiro poderia introduzir diversos falsos positivos ou resultados irrelevantes para a compreensão do mecanismo responsável para a sustentação da atenção.

As coordenadas em que as ROIs foram centradas nesse estudo são mostradas na tabela 2 . Elas estão localizadas na DMN (Fox et al., 2005) e na rede de atenção sustentada (Lawrence et al., 2003), essa última dividida em regiões onde se esperariam ativações durante a tarefa de atenção (regiões positivas, definidas pela letra $P$ seguida de um número) e regiões onde se esperariam desativações durante a tarefa de atenção (regiões negativas, definidas pela letra $\mathrm{N}$ seguida de um número). Os números na abreviatura seguem a numeração usada por Lawrence et al., 2003 e foram excluídas as três ROls localizadas no cerebelo (numeradas nesse trabalho por 1, 2 e 3). As coordenadas, originalmente escritas no espaço Talairach, foram convertidas para o espaço MNI através do software MatLab, assim como a definição dos volumes de interesse. 


\begin{tabular}{|c|c|c|c|}
\hline $\begin{array}{c}\text { Redes } \\
\text { associadas às } \\
\text { regiões }\end{array}$ & ROls & $\begin{array}{l}\text { Abreviaturas usadas } \\
\text { nesse trabalho }\end{array}$ & $\begin{array}{l}\text { Coordenadas no } \\
\text { espaço } \mathrm{MNI}(\mathrm{mm})\end{array}$ \\
\hline \multirow{3}{*}{ DMN } & Córtex pré-frontal medial & MPFC & $(-0,3 ; 51,0 ;-14,1)$ \\
\hline & Cingulado posterior/precúneo & PCC & $(-3,6 ;-46,5 ; 44,9)$ \\
\hline & Córtex parietal lateral & LPC & $(-46,8 ;-66,2 ; 43,1)$ \\
\hline \multirow{13}{*}{$\begin{array}{l}\text { Rede de atenção } \\
\text { sustentada - } \\
\text { regiões positivas } \\
\text { à tarefa }\end{array}$} & Giro occipital esquerdo & $\mathrm{P} 4$ & $(-46,3 ;-67,3 ;-2,7)$ \\
\hline & Giro fusiforme direito & P5 & $(47,6 ;-63,3 ;-11,5)$ \\
\hline & Ínsula anterior direita & P7 & $(35,6 ; 20,8 ;-6,1)$ \\
\hline & Ínsula anterior esquerda & P10 & $(-32,5 ; 20,8 ;-2,7)$ \\
\hline & Tálamo/núcleo caudado & P13 & $(-0,9 ;-6,9 ; 9,6)$ \\
\hline & $\begin{array}{c}\text { Giro frontal médio/inferior } \\
\text { esquerdo }\end{array}$ & P15 & $(-45,1 ; 14,9 ; 27,2)$ \\
\hline & Giro frontal médio/inferior direito & P16 & $(49,0 ; 9,1 ; 28,4)$ \\
\hline & Giro frontal médio/superior direito & P17 & $(46,6 ; 32,8 ; 18,3)$ \\
\hline & $\begin{array}{c}\text { Pré-SMA (área motora } \\
\text { suplementar) }\end{array}$ & P19 & $(2,7 ; 22,1 ; 43,6)$ \\
\hline & Giro parietal esquerdo & $\mathrm{P} 20$ & $(-28,9 ; 67,0 ; 31,9)$ \\
\hline & Giro parietal direito & $\mathrm{P} 21$ & $(32,7 ; 64,4 ; 35,6)$ \\
\hline & Giro frontal médio esquerdo & P22 & $(-26,4 ; 9,5 ; 48,7)$ \\
\hline & Giro frontal médio direito & $\mathrm{P} 23$ & $(29,8 ; 8,6 ; 46,7)$ \\
\hline \multirow{7}{*}{$\begin{array}{l}\text { Rede de atenção } \\
\text { sustentada - } \\
\text { regiões negativas } \\
\text { à tarefa }\end{array}$} & Giro parahipocampal esquerdo & N6 & $(-24,9 ;-33,7 ;-12,0)$ \\
\hline & Córtex cingulado anterior & N8 & $(1,9 ; 41,8 ;-9,9)$ \\
\hline & Córtex frontal medial esquerdo & N9 & $(-2,3 ; 61,7 ;-2,8)$ \\
\hline & Ínsula média esquerda & N11 & $(-39,9 ;-11,7 ; 6,2)$ \\
\hline & Ínsula média direita & N12 & $(42,4 ;-11,6 ; 13,8)$ \\
\hline & Córtex cingulado médio/posterior & N14 & $(-4,9 ;-39,3 ; 30,8)$ \\
\hline & Giro temporal médio esquerdo & N18 & $(-49,1 ;-59,8 ; 31,3)$ \\
\hline
\end{tabular}

Tabela 2. Coordenadas no espaço MNI (mm) onde as ROIs (acompanhadas pelas abreviaturas usadas nesse trabalho) estão centradas e as redes que contém essas coordenadas. Essas coordenadas foram utilizadas para o estudo de atenção.

Duas análises foram feitas para o estudo da atenção. Na primeira delas, as correlações entre e dentro das redes foram avaliadas. Foram tomadas as três regiões da DMN e quatro regiões de cada uma das redes de atenção sustentada, mostradas na tabela 2. As regiões da rede de atenção foram extraídas do trabalho de Lawrence et al. (2003), do qual foram selecionadas as associações mais fortes entre ativação (ou desativação) e/ou número de acertos no teste RVIP e tempo de reação para os acertos (ver seção 1.3.2.2). Para a análise da conectividade dentro das redes, as médias e os desvios-padrão para as correlações entre as regiões contidas em uma dada rede foram calculadas e comparadas para os dois estados. Para a análise da conectividade entre as redes, as médias e os desvios-padrão para as correlações entre uma semente constituída pelas regiões de uma dada rede e as regiões de outra rede foram calculadas e comparadas para os dois estados. Como esse primeiro tipo de análise poderia esconder detalhes das diferenças entre os dois estados, outro tipo de análise foi também realizado. Nela, as intensidades de conectividade de todos os participantes para 
cada uma das regiões da tabela 2 nos dois estados foram submetidas a testes-t de duplaamostragem, testando se as correlações eram diferentes para um nível de significância menor ou igual a 0,05 para os trinta sujeitos no estado de repouso e no estado de atenção sustentada. Isso mostraria que conexões se alteraram significativamente entre os dois estados de forma individual.

\section{7. Análise gráfica}

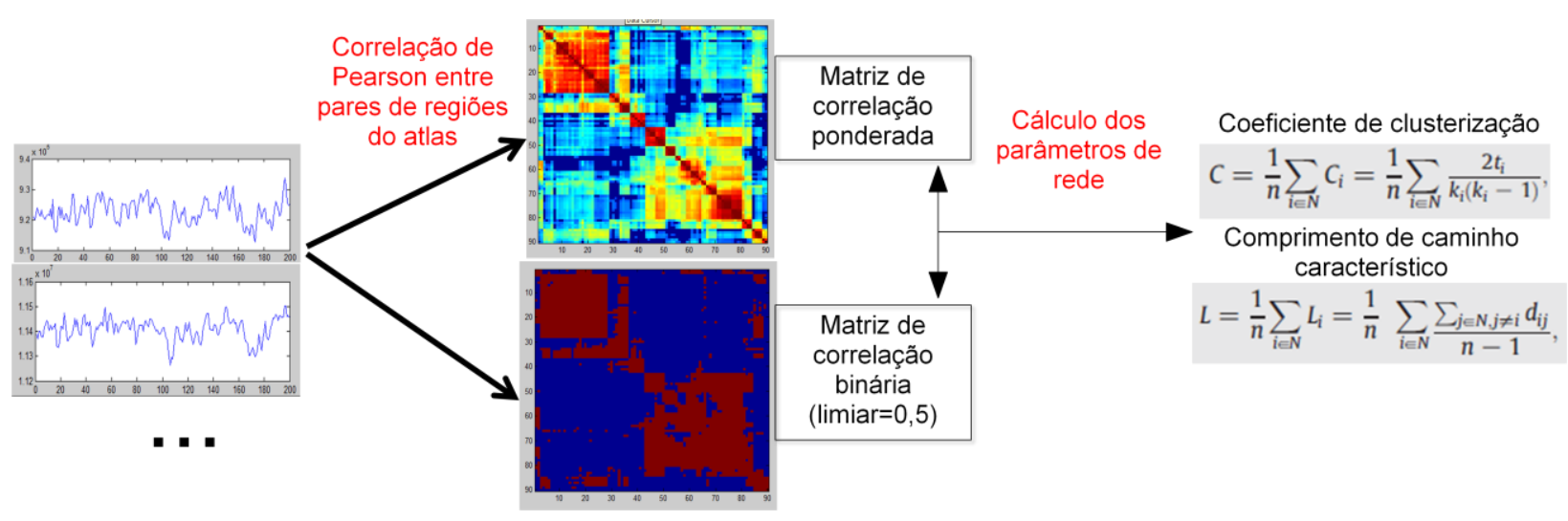

Figura 13. Construção de redes cerebrais e cálculo de parâmetros de rede.

As médias das séries temporais extraídas de cada região definida pelo atlas para cada sujeito foram correlacionadas entre si usando a equação (2) para estimar a intensidade de conexão funcional entre as regiões. Esses dados podem ser organizados na forma de uma matriz de associação (ou correlação). Dessa forma, obtém-se uma matriz de correlação ponderada, ou seja, os elementos da matriz podem assumir uma ampla margem de valores contínuos entre -1 e 1. Posteriormente, a partir da matriz de correlação ponderada pode-se estabelecer um valor limiar acima do qual aos elementos da matriz são atribuídos valores unitários e abaixo do qual valores nulos, definindo dessa forma uma correspondente matriz de correlação binária (figura 13). Para possibilitar alguns cálculos posteriores, algumas vezes foi preciso converter elementos negativos da matriz ponderada para o valor zero.

Para verificação da característica de mundo pequeno da rede, deve-se considerar uma vasta gama de valores de limiar, gerando-se várias matrizes de correlação binárias de uma mesma matriz de correlação ponderada. É preciso também construir matrizes aleatórias equivalentes, ou seja, matrizes com um mesmo número de nodos e distribuição de grau 
similar ao das matrizes cerebrais correspondentes (ver seção 1.4). Calcula-se o coeficiente de clusterização (equação 7) e o comprimento de caminho característico (equação 10) das redes binárias cerebrais e aleatórias correspondentes para cada um dos limiares definidos. Para o cálculo dos parâmetros das redes aleatórias, várias iterações são necessárias e uma média é considerada, já que há uma variação entre uma rede aleatória e outra, dada uma correspondente rede cerebral. Para esse estudo, foram usados limiares entre 0,05 e 0,50 para as redes binárias. Acima desses valores, as matrizes se tornaram muito esparsas e os resultados apresentaram grande variabilidade, sendo excluídos da representação neste documento. As matrizes aleatórias equivalentes foram reiteradas 20 vezes para cálculo dos parâmetros de rede.

Todos os parâmetros de rede (comprimento de caminho característico, coeficiente de clusterização local e global, transitividade, eficiência local e global, distribuição de grau, lambda e gama) foram calculados pelo pacote Brain Connectivity Toolbox (Rubinov e Sporns, 2010), implementado para o software SPM, usando as equações de 5 a 11 . Todos os testes estatísticos, a procura por associações e a classificação de dados também foram computados no software SPM.

As intensidades de conectividade funcional e parâmetros de rede foram associados através de regressão linear. O coeficiente de correlação de Pearson foi usado novamente para mensurar a força da associação das medidas e parâmetros com os índices. Foram calculados também os níveis descritivos para análise de significância estatística assim como sua correção pelo FDR para o nível das regiões consideradas (e não da análise completa como descrito mais adiante). Também foi estimado o intervalo de confiança de cada uma das associações, para figurar a variabilidade dos achados. As regiões cerebrais são mostradas como os rótulos dados pelo atlas AAL. As associações entre parâmetros locais de rede (coeficiente de clusterização e eficiência local) e índices de inteligência foram calculadas para valores de significância menores que 0,10. Para as associações entre intensidades de conectividade funcional e índices de inteligência, somente as 15 maiores intensidades de correlação são mostradas. 


\section{Capítulo 4}

\section{Resultados}

Pela tabela 3, pode-se notar que o QIV é fortemente correlacionado com o ICV e com o IMT, assim como o QIE é fortemente correlacionado com o IOP, resultado esperado pela forma como o QIV e o QIE são calculados. Houve correlação moderada entre o QIE e o IVP. Vê-se também que o QIT é fortemente correlacionado com IOP e IMT e moderadamente correlacionado com ICV e IVP, o que também era esperado, já que o QIT é derivado de todas essas medidas.

\begin{tabular}{|c|c|c|c|c|c|c|}
\hline & QIV & QIE & QIT & ICV & IOP & IMT \\
\hline QIE & $\mathbf{0 , 5 4}$ & & & & & \\
\hline QIT & $\mathbf{0 , 9 0}$ & $\mathbf{0 , 8 5}$ & & & & \\
\hline ICV & $\mathbf{0 , 8 4}$ & 0,29 & $\mathbf{0 , 6 7}$ & & & \\
\hline IOP & $\mathbf{0 , 5 2}$ & $\mathbf{0 , 9 5}$ & $\mathbf{0 , 8 1}$ & 0,23 & & \\
\hline IMT & $\mathbf{0 , 7 3}$ & $\mathbf{0 , 5 6}$ & $\mathbf{0 , 7 4}$ & $\mathbf{0 , 4 9}$ & $\mathbf{0 , 5 2}$ & \\
\hline IVP & 0,45 & $\mathbf{0 , 5 5}$ & $\mathbf{0 , 5 5}$ & 0,38 & 0,35 & $\mathbf{0 , 5 3}$ \\
\hline
\end{tabular}

Tabela 3. Correlações entre pontuações de inteligência. Valores em negrito são significantes para $\alpha<0,01$.
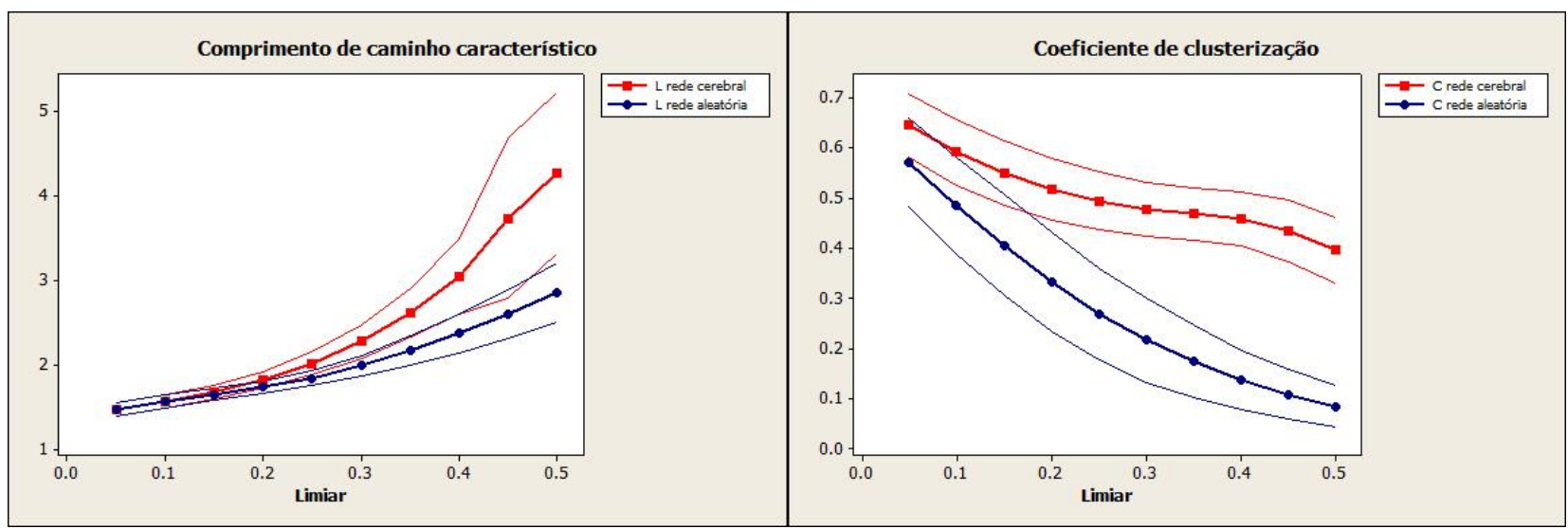

Figura 14. No gráfico da esquerda, são mostrados os resultados para o comprimento de caminho característico médio para redes cerebrais (vermelho) e para redes aleatórias (azul) para limiares entre 0,05 e 0,5. No gráfico da direita, são mostrados os resultados para o coeficiente de clusterização médio para redes cerebrais (vermelho) e para redes aleatórias (azul) para o mesmo intervalo de limiares. As linhas de maior espessura ligam os pontos resultantes dos cálculos, enquanto que as linhas de menor espessura representam a adição e subtração do desvio-padrão. 
A figura 14 (gráfico da esquerda) mostra como o comprimento de caminho característico variou em função dos valores de limiar definidos para as redes binárias. A linha vermelha destacada corresponde aos valores médios de comprimento de caminho característico para as redes cerebrais de trinta voluntários saudáveis. As linhas vermelhas mais fracas, acima e abaixo da linha principal, correspondem a esses valores de comprimento de caminho característico mais e menos um desvio padrão da média, respectivamente. A linha azul corresponde ao comprimento de caminho característico médio para vinte redes aleatórias geradas a partir de uma rede cerebral equivalente para cada limiar adotado. As linhas azuis fracas tem o mesmo significado para as redes aleatórias que as linhas vermelhas fracas para as redes cerebrais. A figura 14 (gráfico da direita) mostra, para as mesmas características, como o coeficiente de clusterização global varia para vários limiares adotados.

Dividindo-se o comprimento de caminho característico e o coeficiente de clusterização global da rede cerebral pelo da rede aleatória, obtém-se os parâmetros lambda e gama, respectivamente. Para os mesmos trinta voluntários saudáveis das figuras anteriores, foram construídos os gráficos de lambda e gama em função dos diferentes limiares adotados, figura 15, respectivamente. As linhas fracas acima e abaixo da linha principal correspondem à adição e à subtração do desvio-padrão, respectivamente.

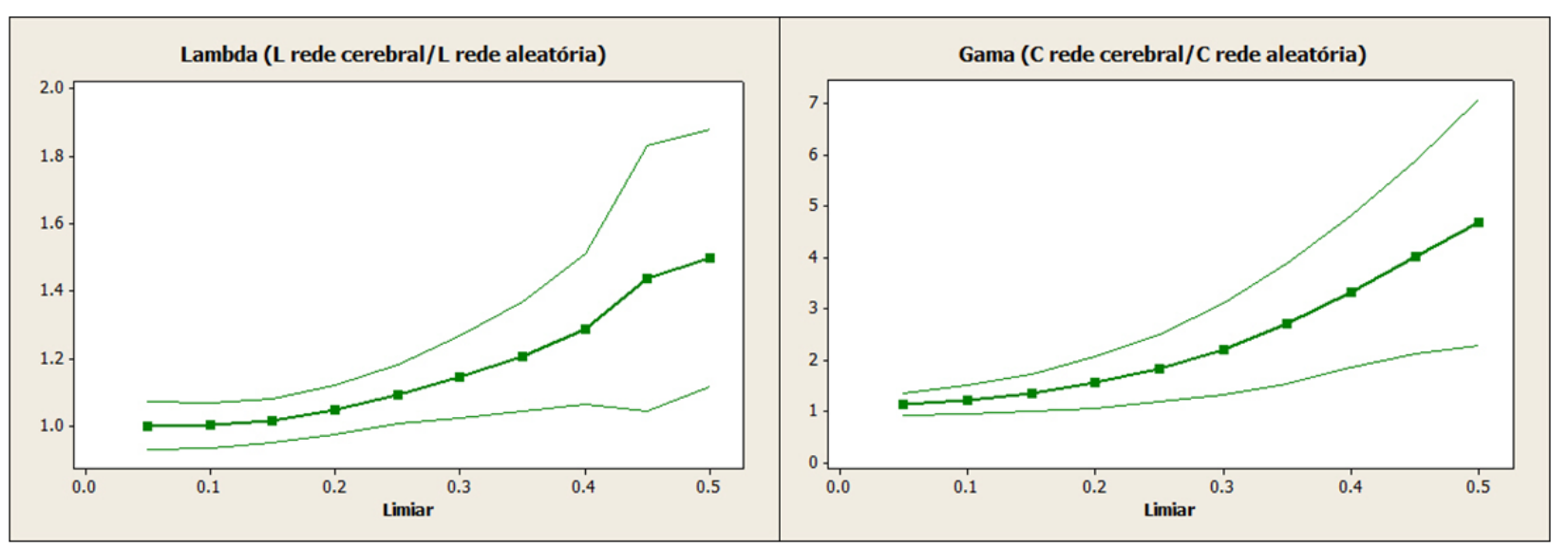

Figura 15. Para todos os limiares usados, são mostrados os gráficos de lambda e gama. As linhas de maior espessura ligam os pontos resultantes dos cálculos, enquanto que as linhas de menor espessura representam a adição e subtração do desvio-padrão.

Tais redes cerebrais funcionais mostraram uma clara organização de mundo pequeno para limiares iguais ou maiores que 0,2 , caracterizada por $L \approx L_{\text {random }}$ e $\lambda \approx 1$ para todos os limiares medidos e $C \gg C_{\text {random }}$ e $\gamma \gg 1$ para todos os limiares medidos, ou seja, de 0,05 a 0,50 (teste-t de dupla amostragem, nível de significância de 0,05). 


\section{1. Associações entre parâmetros de rede/conectividade funcional e desempenho intelectual}

Não foram encontradas associações significativas (para um valor de $p$ de 0,05 ) entre todos os índices de inteligência medidos e os parâmetros globais calculados: comprimento de caminho característico, eficiência global, coeficiente de clusterização global e transitividade. Todos esses parâmetros foram estimados para matrizes de conectividade ponderadas e os resultados estão mostrados na tabela 4.

\begin{tabular}{|c|c|c|c|c|}
\hline \multicolumn{5}{|c|}{ QIV } \\
\hline & $\begin{array}{l}\text { Comprimento de } \\
\text { caminho } \\
\text { característico }\end{array}$ & Eficiência global & $\begin{array}{l}\text { Coeficiente de } \\
\text { clusterização } \\
\text { global }\end{array}$ & Transitividade \\
\hline Correlação & 0,02 & $-0,04$ & $-0,06$ & $-0,07$ \\
\hline p-valor não-corrigido & 0,9 & 0,8 & 0,8 & 0,7 \\
\hline Intervalo de confiança & {$[-0,35 ; 0,38]$} & {$[-0,40 ; 0,33]$} & {$[-0,42 ; 0,31]$} & {$[-0,42 ; 0,31]$} \\
\hline \multicolumn{5}{|c|}{ QIE } \\
\hline Correlação & 0,16 & 0,06 & 0,09 & 0,08 \\
\hline p-valor não-corrigido & 0,4 & 0,8 & 0,7 & 0,7 \\
\hline Intervalo de confiança & {$[-0,22 ; 0,49]$} & {$[-0,31 ; 0,42]$} & {$[-0,29 ; 0,44]$} & {$[-0,29 ; 0,44]$} \\
\hline \multicolumn{5}{|c|}{ QIT } \\
\hline Correlação & 0,09 & 0,003 & 0,004 & $-0,003$ \\
\hline p-valor não-corrigido & 0,6 & 0,99 & 0,99 & 0,99 \\
\hline Intervalo de confiança & {$[-0,28 ; 0,44]$} & {$[-0,36 ; 0,37]$} & {$[-0,36 ; 0,37]$} & {$[-0,37 ; 0,36]$} \\
\hline \multicolumn{5}{|c|}{ ICV } \\
\hline Correlação & $-0,006$ & $-0,10$ & $-0,16$ & $-0,17$ \\
\hline p-valor não-corrigido & 0,98 & 0,6 & 0,4 & 0,4 \\
\hline Intervalo de confiança & {$[-0,37 ; 0,36]$} & {$[-0,45 ; 0,28]$} & {$[-0,50 ; 0,22]$} & {$[-0,50 ; 0,21]$} \\
\hline \multicolumn{5}{|c|}{ IOP } \\
\hline Correlação & 0,14 & 0,07 & 0,11 & 0,11 \\
\hline p-valor não-corrigido & 0,5 & 0,7 & 0,6 & 0,6 \\
\hline Intervalo de confiança & {$[-0,24 ; 0,48]$} & {$[-0,30 ; 0,43]$} & {$[-0,27 ; 0,46]$} & {$[-0,27 ; 0,46]$} \\
\hline \multicolumn{5}{|c|}{$\mathrm{IMT}$} \\
\hline Correlação & 0,09 & $-0,015$ & $-0,003$ & $-0,03$ \\
\hline p-valor não-corrigido & 0,6 & 0,9 & 0,99 & 0,9 \\
\hline Intervalo de confiança & {$[-0,29 ; 0,44]$} & {$[-0,38 ; 0,35]$} & {$[-0,37 ; 0,36]$} & {$[-0,40 ; 0,34]$} \\
\hline \multicolumn{5}{|c|}{ IVP } \\
\hline Correlação & 0,09 & $-0,05$ & $-0,06$ & $-0,08$ \\
\hline $\mathrm{p}$-valor não-corrigido & 0,6 & 0,8 & 0,8 & 0,7 \\
\hline Intervalo de confiança & {$[-0,28 ; 0,44]$} & {$[-0,41 ; 0,32]$} & {$[-0,42 ; 0,32]$} & {$[-0,43 ; 0,30]$} \\
\hline
\end{tabular}

Tabela 4. Valores de correlação entre parâmetros globais de rede cerebral e índices de inteligência, p-valores nãocorrigidos e intervalos de confiança.

A figura 16 mostra dois gráficos extraídos de um trabalho similar ao nosso (van den Heuvel et al., 2009). O da esquerda mostra uma correlação negativa significante $(p=0,01, r=-0,54)$ entre comprimento de caminho característico normalizado (lambda) e QIT, para redes 
binárias dentro da escala de mundo pequeno (limiar de 0,45 ) e os nodos representados pelos voxels da imagem funcional processada de cada participante. O gráfico da direita mostra que não houve correlação significativa entre coeficiente de clusterização (gama) e QIT, para o mesmo tipo de rede considerada. A figura 17 mostra os mesmos gráficos utilizando os dados coletados para o nosso estudo. Do gráfico à esquerda foram retirados dois pontos discrepantes, reduzindo a amostra para um número de 27 . Observa-se que não houve nenhuma correlação entre as grandezas consideradas, utilizando redes binárias com o mesmo limiar, mas com os nodos representados pelas regiões do atlas AAL.

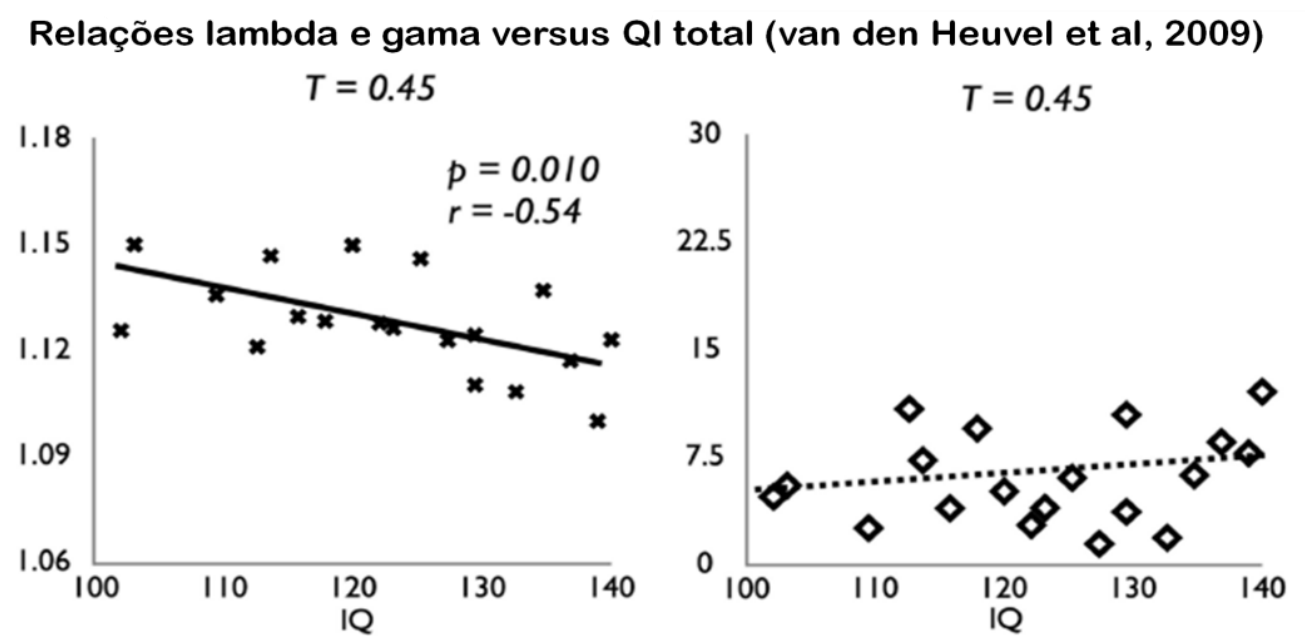

Figura 16. Comprimento de caminho característico normalizado (lambda) (gráfico à esquerda) negativamente correlacionado com QIT no estudo de van den Heuvel et al. (2009). No mesmo estudo, não foi encontrada correlação entre o coeficiente de clusterização normalizado (gama) e o QIT. Foram utilizadas redes binárias dentro da escala de mundo-pequeno (limiar de 0,45), em que os nodos eram cada um dos voxels. Extraída de van den Heuvel et al., 2009.

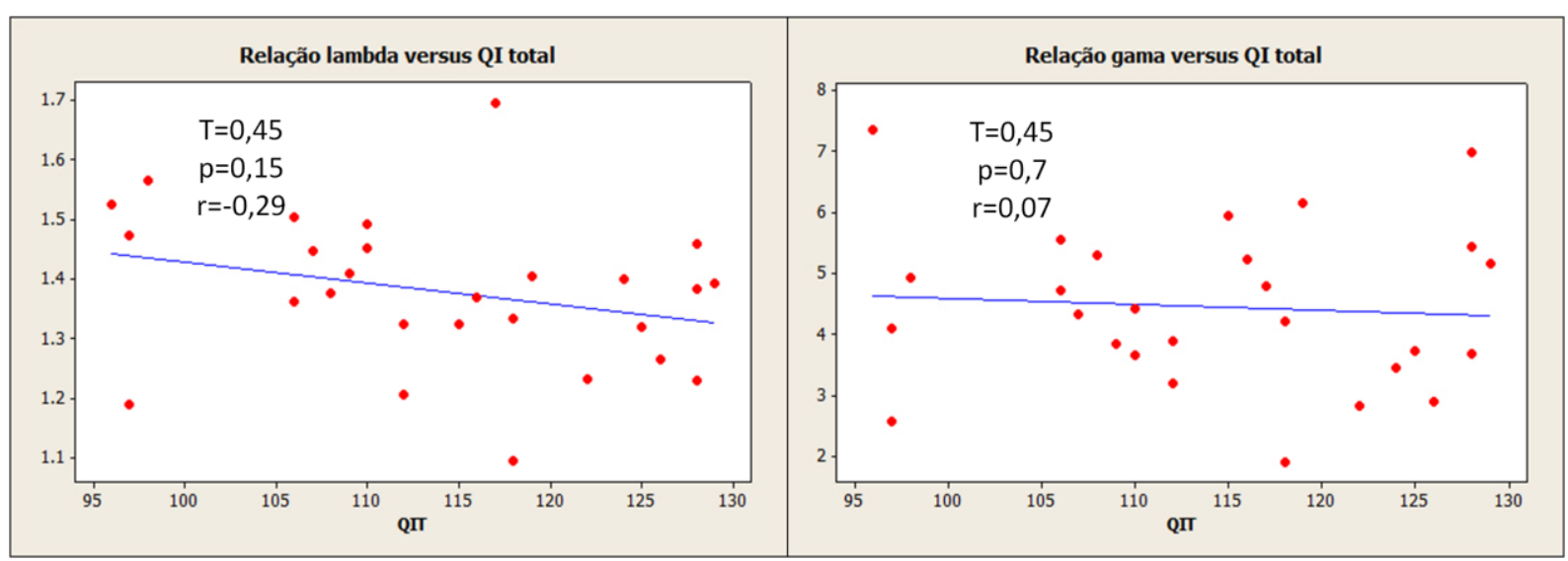

Figura 17. Comprimento de caminho característico normalizado (lambda) (gráfico à esquerda) e coeficiente de clusterização normalizado (gama) (gráfico à direita) sem correlação significante com o QIT, utilizando os dados do nosso estudo. Foram utilizadas redes binárias dentro da escala de mundo-pequeno (limiar de 0,45 ), em que os nodos eram cada uma das regiões do atlas $\mathrm{AAL}$. 
Também foram analisadas propriedades locais de redes cerebrais complexas, através de estimativas de coeficiente de clusterização local e eficiência local, procurando pelas mais fortes associações com os índices de inteligência. Os resultados para cada índice de inteligência medido são mostrados separadamente para facilitar a visualização.

Não foram encontradas associações significantes ( $p$ não-corrigido<0,10) entre parâmetros locais e pontuações de QIV. Os resultados para os outros índices são mostrados nas tabelas 5 a 10 e nas figuras 18 a 23. 


\begin{tabular}{|c|c|c|c|c|c|c|c|}
\hline \multirow{7}{*}{ 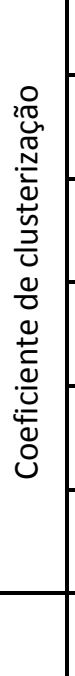 } & Classificação & 1 & 2 & 3 & 4 & 5 & 6 \\
\hline & $\begin{array}{c}\text { Região do atlas } \\
\text { AAL }\end{array}$ & $\begin{array}{l}\text { Frontal Med } \\
\text { Orb L }\end{array}$ & $\begin{array}{l}\text { Frontal Med } \\
\text { Orb R }\end{array}$ & Caudate R & $\begin{array}{l}\text { Temporal } \\
\text { Pole Mid R }\end{array}$ & Thalamus L & $\begin{array}{c}\text { Thalamus } \\
\text { R }\end{array}$ \\
\hline & Correlação & 0,50 & 0,41 & 0,35 & $-0,34$ & 0,32 & 0,32 \\
\hline & $\begin{array}{l}\text { p-valor não- } \\
\text { corrigido }\end{array}$ & 0,006 & 0,03 & 0,06 & 0,07 & 0,09 & 0,095 \\
\hline & $\begin{array}{l}\mathrm{p} \text {-valor } \\
\text { corrigido }\end{array}$ & 0,5 & 0,99 & 0,99 & 0,99 & 0,99 & 0,99 \\
\hline & $\begin{array}{l}\text { Intervalo de } \\
\text { confiança }\end{array}$ & {$[0,16 ; 0,73]$} & {$[0,05 ; 0,67]$} & {$[-0,014 ; 0,64]$} & {$[-0,62 ; 0,03]$} & {$[-0,06 ; 0,61]$} & {$[-0,06 ; 0,61]$} \\
\hline & Classificação & 1 & 2 & 3 & 4 & 5 & 6 \\
\hline \multirow{5}{*}{ 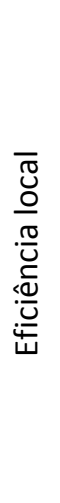 } & $\begin{array}{c}\text { Região do atlas } \\
\text { AAL }\end{array}$ & $\begin{array}{c}\text { Frontal Med } \\
\text { Orb L }\end{array}$ & $\begin{array}{l}\text { Frontal Med } \\
\text { Orb R }\end{array}$ & Caudate R & $\begin{array}{l}\text { Temporal } \\
\text { Pole Mid R }\end{array}$ & Thalamus L & $\begin{array}{c}\text { Thalamus } \\
\text { R }\end{array}$ \\
\hline & Correlação & 0,50 & 0,39 & 0,33 & $-0,37$ & 0,36 & 0,34 \\
\hline & $\begin{array}{l}\text { p-valor não- } \\
\text { corrigido }\end{array}$ & 0,006 & 0,04 & 0,09 & 0,04 & 0,06 & 0,07 \\
\hline & $\begin{array}{l}\text { p-valor } \\
\text { corrigido }\end{array}$ & 0,5 & 0,99 & 0,99 & 0,99 & 0,99 & 0,99 \\
\hline & $\begin{array}{l}\text { Intervalo de } \\
\text { confiança }\end{array}$ & {$[0,16 ; 0,73]$} & {$[0,025 ; 0,66]$} & {$[-0,04 ; 0,62]$} & {$[-0,65 ; 0,009]$} & {$[-0,01 ; 0,64]$} & {$[-0,03 ; 0,63]$} \\
\hline
\end{tabular}

Tabela 5. Valores de correlação, $\mathrm{p}$-valores não-corrigidos, $\mathrm{p}$-valores corrigidos pelo FDR e intervalos de confiança para associações significativas para p-valores não corrigidos menores que 0,05 entre coeficiente de clusterização e/ou eficiência local para a rede cerebral e QIE.
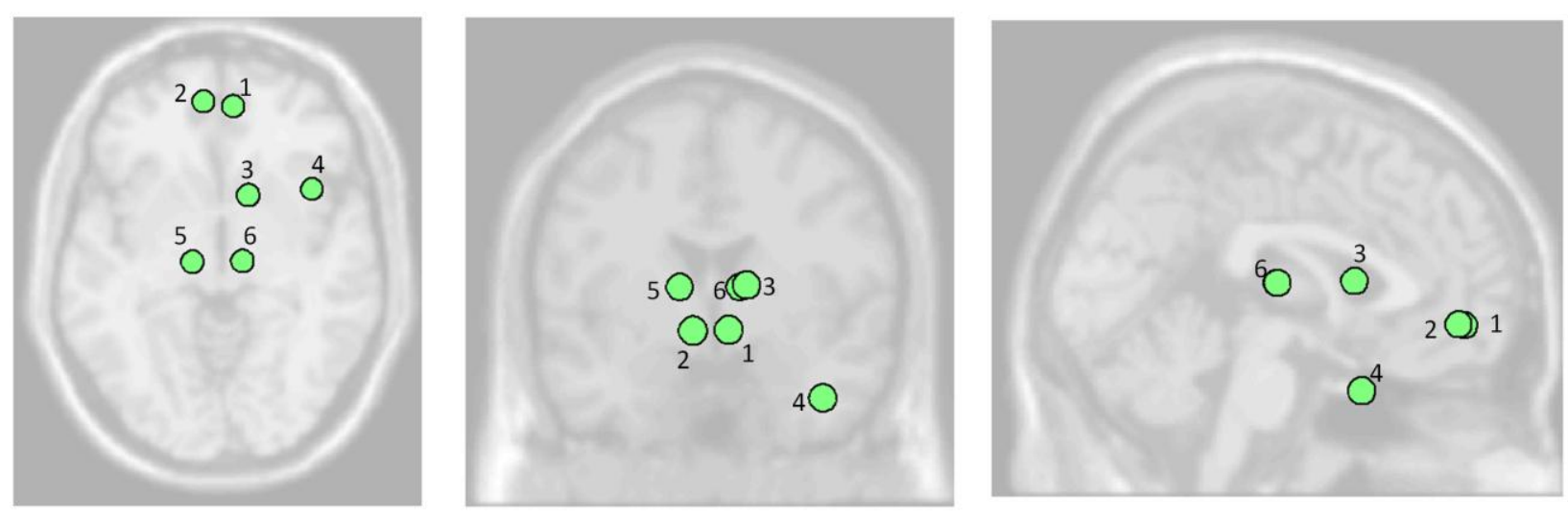

Figura 18. Visões axial, coronal e axial das regiões com associação significante entre coeficiente de clusterização e/ou eficiência local para a rede cerebral e QIE. Os números correspondem à classificação mostrada na tabela 5. 


\begin{tabular}{|c|c|c|}
\hline \multirow{5}{*}{ 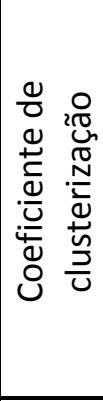 } & Região do atlas AAL & Frontal Med Orb R \\
\hline & Correlação & 0,36 \\
\hline & $\begin{array}{l}\text { p-valor não- } \\
\text { corrigido }\end{array}$ & 0,05 \\
\hline & p-valor corrigido & 0,99 \\
\hline & $\begin{array}{l}\text { Intervalo de } \\
\text { confiança }\end{array}$ & {$[-0,005 ; 0,64]$} \\
\hline \multirow{5}{*}{ 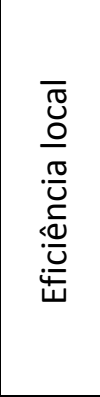 } & Região do atlas AAL & Frontal Med Orb R \\
\hline & Correlação & 0,36 \\
\hline & $\begin{array}{c}\text { p-valor não- } \\
\text { corrigido }\end{array}$ & 0,06 \\
\hline & p-valor corrigido & 0,95 \\
\hline & $\begin{array}{c}\text { Intervalo de } \\
\text { confiança }\end{array}$ & {$[-0,010 ; 0,64]$} \\
\hline
\end{tabular}

Tabela 6. Valores de correlação, $p$-valores não-corrigidos, $p$-valores corrigidos pelo FDR e intervalos de confiança para associações significativas para p-valores não corrigidos menores que 0,05 entre coeficiente de clusterização e/ou eficiência local para a rede cerebral e QIT.
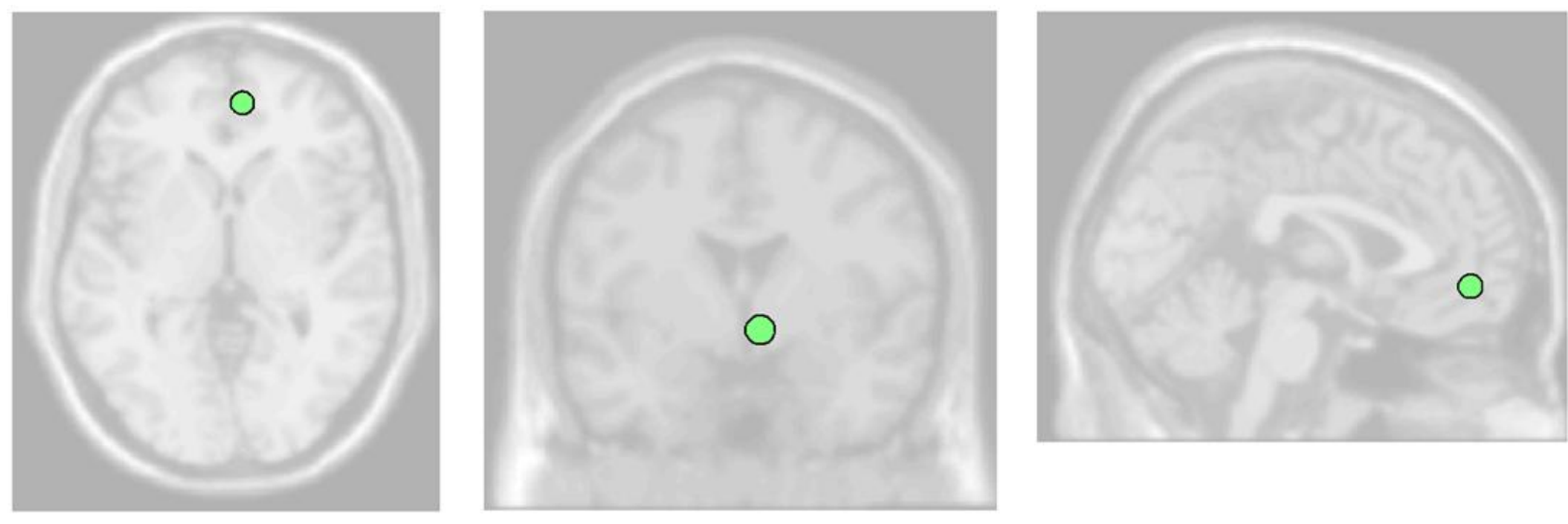

Figura 19. Visões axial, coronal e axial das regiões com associação significante entre coeficiente de clusterização e/ou eficiência local para a rede cerebral e QIT. 


\begin{tabular}{|c|c|c|c|}
\hline \multirow{6}{*}{ 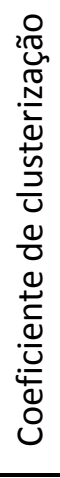 } & Classificação & 1 & \\
\hline & Região do atlas AAL & Fusiform L & \\
\hline & Correlação & $-0,33$ & \\
\hline & $\begin{array}{c}\text { p-valor não- } \\
\text { corrigido }\end{array}$ & 0,08 & \\
\hline & p-valor corrigido & 0,98 & \\
\hline & $\begin{array}{c}\text { Intervalo de } \\
\text { confiança }\end{array}$ & {$[-0,62 ; 0,04]$} & \\
\hline \multirow{6}{*}{ 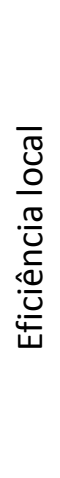 } & Classificação & 2 & 3 \\
\hline & Região do atlas AAL & Pallidum L & Lingual $\mathrm{R}$ \\
\hline & Correlação & 0,34 & $-0,32$ \\
\hline & $\begin{array}{c}\text { p-valor não- } \\
\text { corrigido }\end{array}$ & 0,07 & 0,09 \\
\hline & p-valor corrigido & $>0,99$ & $>0,99$ \\
\hline & $\begin{array}{c}\text { Intervalo de } \\
\text { confiança }\end{array}$ & {$[-0,03 ; 0,63]$} & {$[-0,61 ; 0,05]$} \\
\hline
\end{tabular}

Tabela 7. Valores de correlação, $p$-valores não-corrigidos, $p$-valores corrigidos pelo FDR e intervalos de confiança para associações significativas para $p$-valores não corrigidos menores que 0,05 entre coeficiente de clusterização e/ou eficiência local para a rede cerebral e ICV.
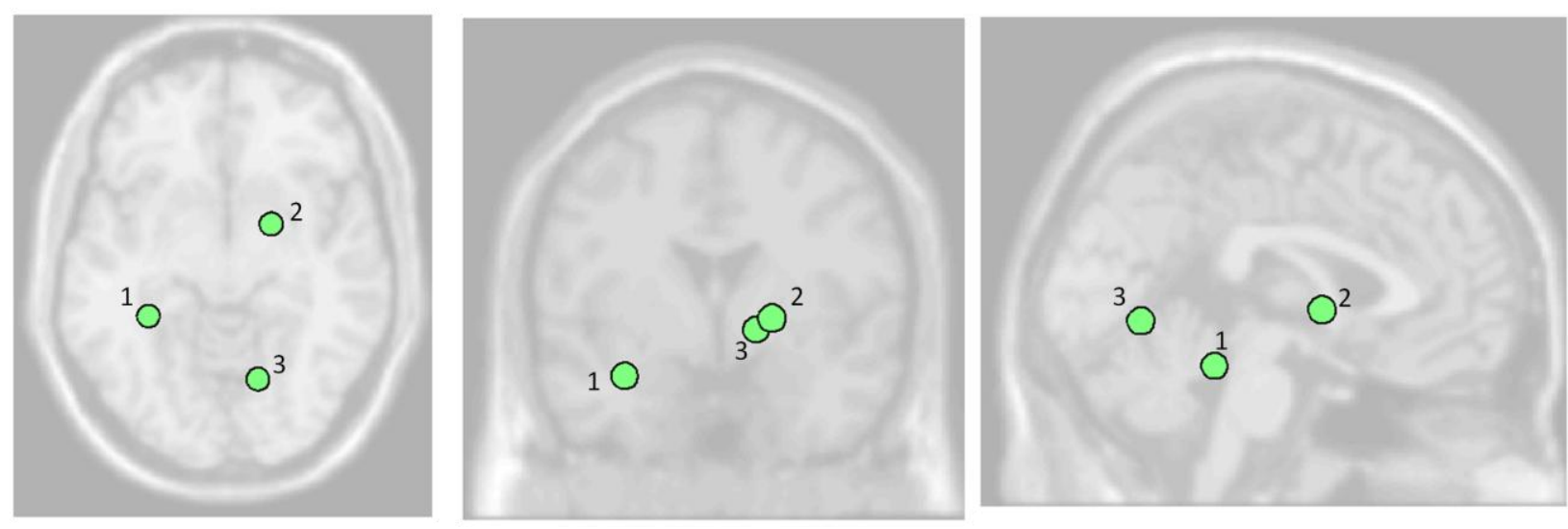

Figura 20. Visões axial, coronal e sagital das regiões com associação significante entre coeficiente de clusterização e/ou eficiência local para a rede cerebral e ICV. Os números correspondem à classificação mostrada na tabela 7. 


\begin{tabular}{|c|c|c|c|c|c|c|c|}
\hline \multirow{6}{*}{ 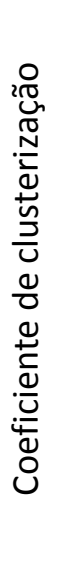 } & Classificação & 1 & 2 & 3 & 4 & 5 & 6 \\
\hline & $\begin{array}{l}\text { Região do atlas } \\
\text { AAL }\end{array}$ & $\begin{array}{c}\text { Frontal } \\
\text { Med Orb R }\end{array}$ & $\begin{array}{c}\text { Frontal } \\
\text { Med Orb L }\end{array}$ & Caudate R & Thalamus L & $\begin{array}{c}\text { Thalamus } \\
\text { R }\end{array}$ & $\begin{array}{l}\text { Supp Motor } \\
\text { Area L }\end{array}$ \\
\hline & Correlação & 0,46 & 0,4 & 0,39 & 0,32 & 0,32 & 0,31 \\
\hline & $\begin{array}{l}\text { p-valor não- } \\
\text { corrigido }\end{array}$ & 0,011 & 0,03 & 0,04 & 0,09 & 0,09 & 0,1 \\
\hline & $\begin{array}{l}\mathrm{p} \text {-valor } \\
\text { corrigido }\end{array}$ & 0,99 & 0,99 & 0,99 & 0,99 & 0,99 & 0,99 \\
\hline & $\begin{array}{l}\text { Intervalo de } \\
\text { confiança }\end{array}$ & {$[0,12 ; 0,71]$} & $\begin{array}{l}{[0,04 ;} \\
0,67]\end{array}$ & {$[0,026 ; 0,66]$} & {$[-0,05 ; 0,61]$} & {$[-0,05 ; 0,61]$} & {$[-0,06 ; 0,61]$} \\
\hline \multirow{6}{*}{ 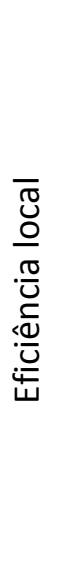 } & Classificação & 1 & 2 & 7 & 4 & 5 & 3 \\
\hline & $\begin{array}{c}\text { Região do atlas } \\
\text { AAL }\end{array}$ & $\begin{array}{c}\text { Frontal } \\
\text { Med Orb R }\end{array}$ & $\begin{array}{c}\text { Frontal } \\
\text { Med Orb L }\end{array}$ & $\begin{array}{l}\text { Temporal } \\
\text { Pole Mid R }\end{array}$ & Thalamus L & $\begin{array}{c}\text { Thalamus } \\
\text { R }\end{array}$ & Caudate R \\
\hline & Correlação & 0,45 & 0,38 & $-0,34$ & 0,34 & 0,33 & 0,32 \\
\hline & $\begin{array}{l}\text { p-valor não- } \\
\text { corrigido }\end{array}$ & 0,014 & 0,04 & 0,07 & 0,07 & 0,08 & 0,09 \\
\hline & $\begin{array}{l}\mathrm{p} \text {-valor } \\
\text { corrigido }\end{array}$ & 0,99 & 0,99 & 0,99 & 0,99 & 0,99 & 0,99 \\
\hline & $\begin{array}{l}\text { Intervalo de } \\
\text { confiança }\end{array}$ & {$[0,10 ; 0,70]$} & $\begin{array}{c}{[0,02 ;} \\
0,66]\end{array}$ & {$[-0,63 ; 0,02]$} & {$[-0,03 ; 0,63]$} & {$[-0,04 ; 0,62]$} & {$[-0,05 ; 0,62]$} \\
\hline
\end{tabular}

Tabela 8. Valores de correlação, $p$-valores não-corrigidos, $p$-valores corrigidos pelo FDR e intervalos de confiança para associações significativas para $p$-valores não corrigidos menores que 0,05 entre coeficiente de clusterização e/ou eficiência local para a rede cerebral e IOP.
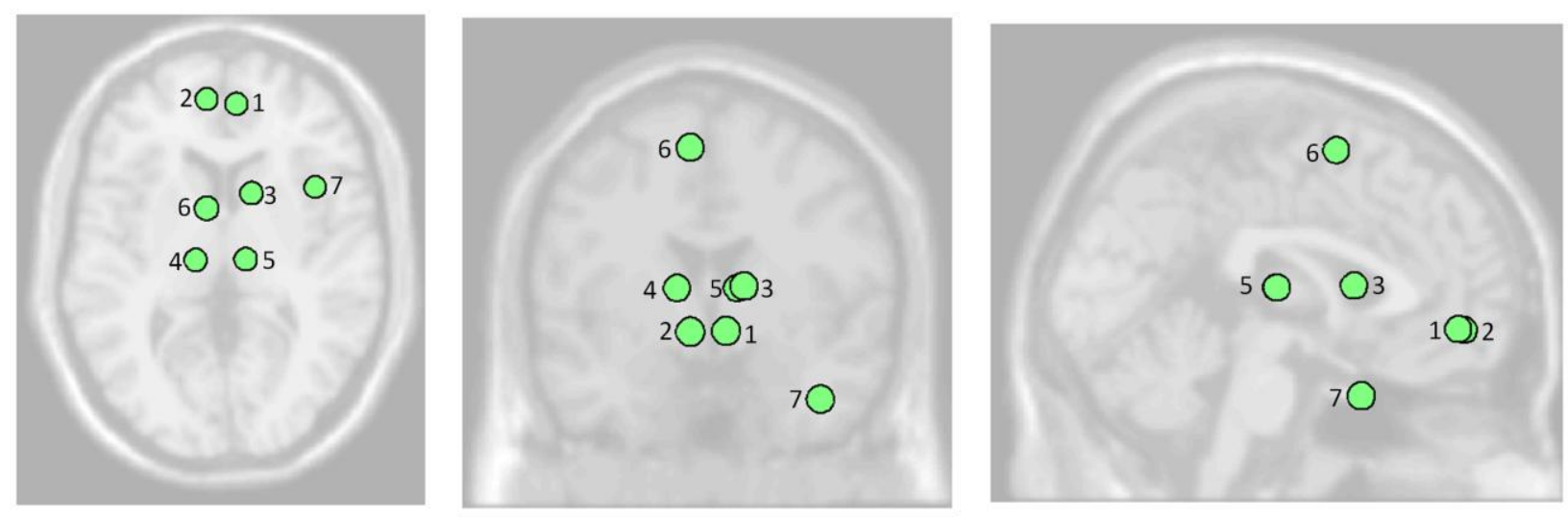

Figura 21. Visões axial, coronal e axial das regiões com associação significante entre coeficiente de clusterização e/ou eficiência local para a rede cerebral e IOP. Os números correspondem à classificação mostrada na tabela 8. 


\begin{tabular}{|c|c|c|c|}
\hline \multirow{5}{*}{ 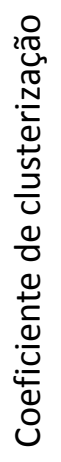 } & Região do atlas AAL & Amygdala $\mathrm{R}$ & Frontal Inf Oper L \\
\hline & Correlação & -0.35 & 0,27 \\
\hline & p-valor não-corrigido & 0.06 & 0,15 \\
\hline & p-valor corrigido & 0.99 & 0,99 \\
\hline & Intervalo de confiança & {$[-0,63 ; 0,02]$} & {$[-0,10 ; 0,58]$} \\
\hline \multirow{5}{*}{$\begin{array}{l}\bar{J} \\
\frac{\mathrm{O}}{0} \\
\frac{\pi}{U} \\
\frac{\mathrm{C}}{\mathrm{d}} \\
\frac{\mathrm{U}}{\mathrm{U}} \\
\frac{\mathrm{U}}{\mathrm{U}}\end{array}$} & Região do atlas AAL & Amygdala $\mathrm{R}$ & Frontal Inf Oper L \\
\hline & Correlação & -0.38 & 0,29 \\
\hline & p-valor não-corrigido & 0.04 & 0,13 \\
\hline & p-valor corrigido & 0.99 & 0,99 \\
\hline & Intervalo de confiança & {$[-0,66 ;-0,02]$} & {$[-0,09 ; 0,59]$} \\
\hline
\end{tabular}

Tabela 9. Valores de correlação, p-valores não-corrigidos, p-valores corrigidos pelo FDR e intervalos de confiança para associações significativas para $p$-valores não corrigidos menores que 0,05 entre coeficiente de clusterização e/ou eficiência local para a de rede cerebral e IMT. $O$ valores da última coluna, embora sem significância estatística pelo pvalor não corrigido ou pelo p-valor corrigido, são mostrados para comparação com os resultados de Cole et al., 2012.
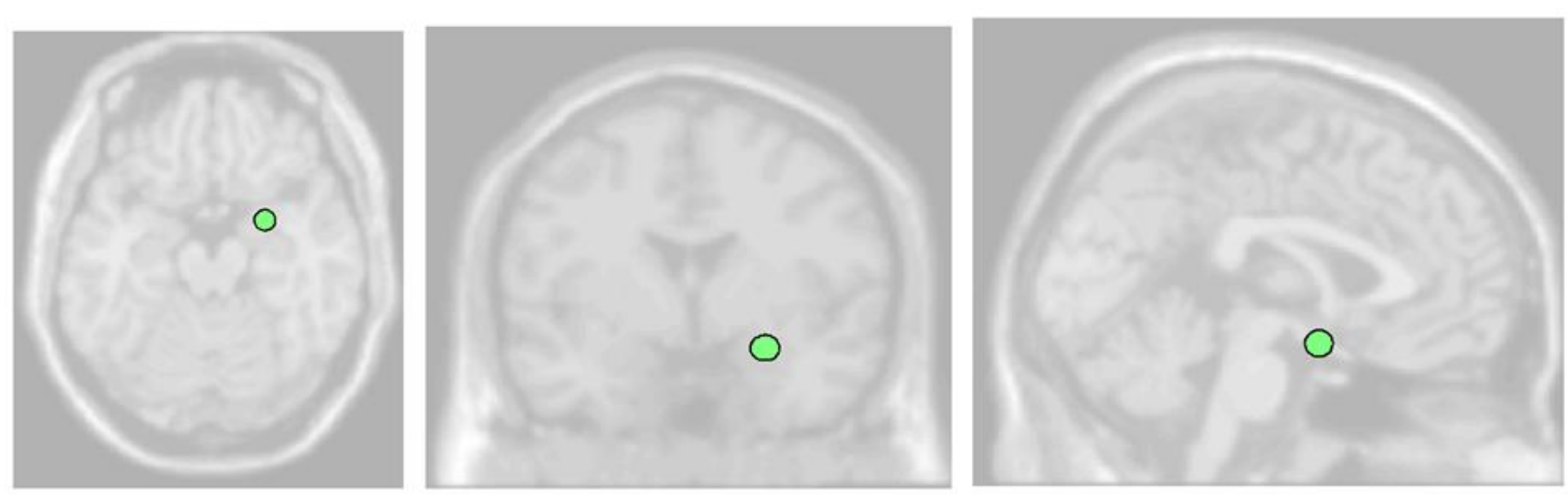

Figura 22. Visões axial, coronal e axial das região com associação significante entre coeficiente de clusterização e/ou eficiência local para a rede cerebral e IMT. 


\begin{tabular}{|c|c|c|c|c|c|c|c|c|}
\hline \multirow{6}{*}{ 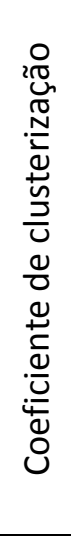 } & Classificação & 1 & 2 & 3 & 4 & & & \\
\hline & $\begin{array}{c}\text { Região do atlas } \\
\text { AAL }\end{array}$ & $\begin{array}{c}\text { Frontal } \\
\text { Med Orb } \\
\text { R } \\
\end{array}$ & $\begin{array}{l}\text { Cingulum } \\
\text { Ant } R\end{array}$ & $\begin{array}{c}\text { Fusiform } \\
\text { L }\end{array}$ & $\begin{array}{c}\text { Caudate } \\
\text { L }\end{array}$ & & & \\
\hline & Correlação & 0,4 & 0,37 & $-0,33$ & 0,32 & & & \\
\hline & $\begin{array}{l}\text { p-valor não- } \\
\text { corrigido }\end{array}$ & 0,03 & 0,05 & 0,08 & 0,09 & & & \\
\hline & $\begin{array}{l}\mathrm{p} \text {-valor } \\
\text { corrigido }\end{array}$ & 0,99 & 0,99 & 0,99 & 0,99 & & & \\
\hline & $\begin{array}{c}\text { Intervalo de } \\
\text { confiança }\end{array}$ & {$[0,04 ; 0,67]$} & $\begin{array}{c}{[0,009} \\
0,65] \\
\end{array}$ & $\begin{array}{c}{[-0,62 ;} \\
0,04] \\
\end{array}$ & $\begin{array}{c}{[-0,05} \\
0,61] \\
\end{array}$ & & & \\
\hline \multirow{6}{*}{ 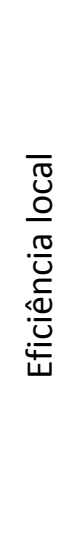 } & Classificação & 1 & 2 & 4 & 5 & 6 & 3 & 7 \\
\hline & $\begin{array}{c}\text { Região do atlas } \\
\text { AAL }\end{array}$ & $\begin{array}{c}\text { Frontal } \\
\text { Med Orb } \\
\text { R }\end{array}$ & $\begin{array}{l}\text { Cingulum } \\
\text { Ant } R\end{array}$ & $\begin{array}{c}\text { Caudate } \\
\text { L }\end{array}$ & $\begin{array}{c}\text { Caudate } \\
\quad \mathrm{R}\end{array}$ & $\begin{array}{l}\text { Cingulum } \\
\text { Ant } \mathrm{L}\end{array}$ & $\begin{array}{c}\text { Fusiform } \\
\text { L }\end{array}$ & $\begin{array}{l}\text { Pallidum } \\
\quad \mathrm{R}\end{array}$ \\
\hline & Correlação & 0,47 & 0,41 & 0,36 & 0,34 & 0,34 & $-0,34$ & 0,32 \\
\hline & $\begin{array}{l}\text { p-valor não- } \\
\text { corrigido }\end{array}$ & 0,011 & 0,03 & 0,06 & 0,07 & 0,07 & 0,07 & 0,09 \\
\hline & $\begin{array}{c}\mathrm{p} \text {-valor } \\
\text { corrigido }\end{array}$ & 0,95 & 0,97 & 0,97 & 0,97 & 0,97 & 0,97 & 0,97 \\
\hline & $\begin{array}{c}\text { Intervalo de } \\
\text { confiança }\end{array}$ & {$[0,12 ; 0,71]$} & {$[0,05 ; 0,68]$} & $\begin{array}{c}{[-0,01 ;} \\
0,64]\end{array}$ & $\begin{array}{c}-0,03 ; \\
0,63]\end{array}$ & {$[-0,03 ; 0,63]$} & $\begin{array}{c}{[-0,63} \\
0,03]\end{array}$ & $\begin{array}{c}{[-0,05} \\
0,62]\end{array}$ \\
\hline
\end{tabular}

Tabela 10. Valores de correlação, $p$-valores não-corrigidos, $p$-valores corrigidos pelo FDR e intervalos de confiança para associações significativas para p-valores não corrigidos menores que 0,05 entre coeficiente de clusterização e/ou eficiência local para a de rede cerebral e IVP.
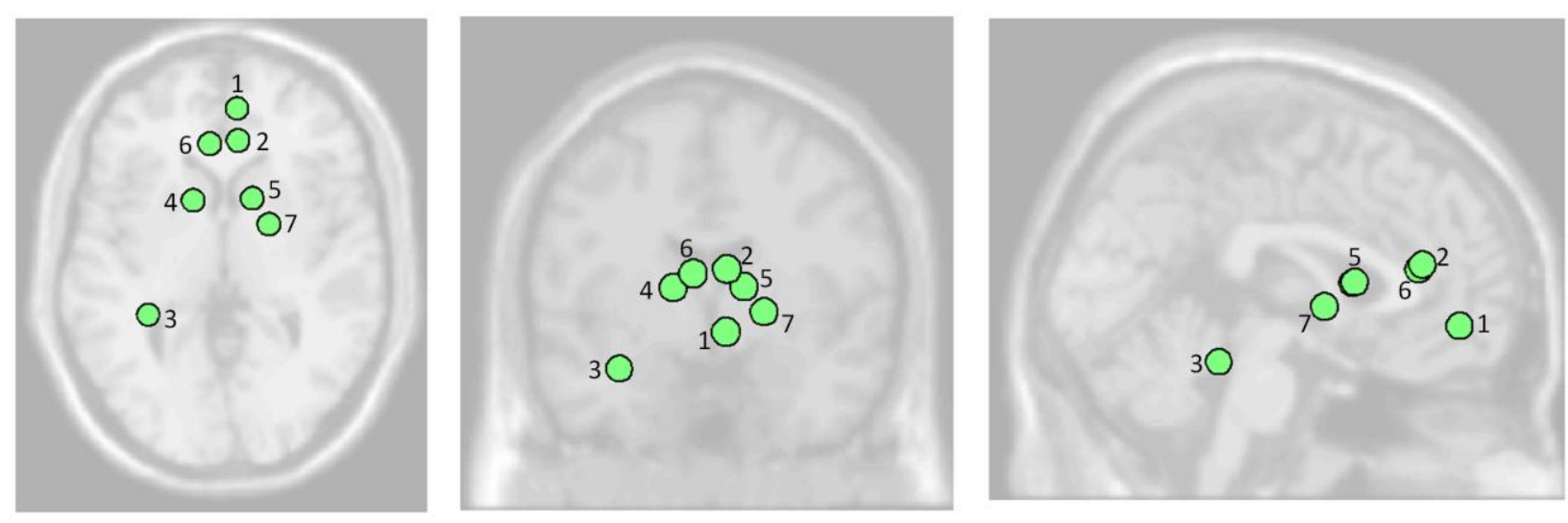

Figura 23. Visões axial, coronal e axial das regiões com associação significante entre coeficiente de clusterização e/ou eficiência local para a rede cerebral e IVP. Os números correspondem à classificação mostrada na tabela 10.

Finalmente, foram analisadas como as conexões funcionais se associam com os índices de inteligência. Os resultados para cada índice são mostrados nas tabelas 11 a 17 e nas figuras 24 a 29 separadamente para facilitar a visualização. 


\begin{tabular}{|c|c|c|c|c|c|c|c|}
\hline Classificação & \multicolumn{2}{|c|}{ Conectividade entre as regiões } & Correlação & $\begin{array}{c}\text { p-valor não- } \\
\text { corrigido }\end{array}$ & $\begin{array}{c}\text { p-valor } \\
\text { corrigido }\end{array}$ & $\begin{array}{c}\text { Limite } \\
\text { inferior }\end{array}$ & $\begin{array}{c}\text { Limite } \\
\text { superior }\end{array}$ \\
\hline 1 & Precentral L & Occipital Sup R & 0,59 & 0,0008 & 0,10 & 0,28 & 0,78 \\
\hline 2 & Rectus L & Putamen R & 0,57 & 0,0014 & 0,16 & 0,25 & 0,77 \\
\hline 3 & Occipital Sup R & Parietal Sup L & 0,56 & 0,0017 & 0,10 & 0,24 & 0,77 \\
\hline 4 & Precentral R & Lingual L & 0,55 & 0,0021 & 0,17 & 0,23 & 0,76 \\
\hline 5 & Calcarine R & Parietal Sup L & 0,55 & 0,0022 & 0,26 & 0,22 & 0,76 \\
\hline 6 & Fusiform R & Parietal Sup L & 0,54 & 0,0023 & 0,18 & 0,22 & 0,76 \\
\hline 7 & Heschl L & Heschl R & 0,54 & 0,0024 & 0,29 & 0,22 & 0,76 \\
\hline 8 & Frontal Sup L & Occipital Inf R & $-0,54$ & 0,0027 & 0,14 & $-0,75$ & $-0,21$ \\
\hline 9 & Frontal Sup L & Temporal Mid L & 0,54 & 0,0028 & 0,14 & 0,21 & 0,75 \\
\hline 10 & Precentral R & Cuneus R & 0,52 & 0,004 & 0,17 & 0,19 & 0,75 \\
\hline 11 & Precentral L & Occipital Mid L & 0,52 & 0,004 & 0,16 & 0,19 & 0,74 \\
\hline 12 & Frontal Sup L & Occipital Inf L & $-0,52$ & 0,004 & 0,14 & $-0,74$ & $-0,19$ \\
\hline 13 & Lingual L & Parietal Sup L & 0,52 & 0,004 & 0,23 & 0,19 & 0,74 \\
\hline 14 & Precentral L & Occipital Mid R & 0,52 & 0,004 & 0,16 & 0,18 & 0,74 \\
\hline 15 & Fusiform R & Thalamus L & 0,51 & 0,005 & 0,19 & 0,17 & 0,74 \\
\hline
\end{tabular}

Tabela 11. Valores de correlação, p-valores não-corrigidos, $p$-valores corrigidos pelo FDR e intervalos de confiança ordenados em ordem decrescente para os valores de correlação para associações entre conectividade entre duas regiões e QIV.
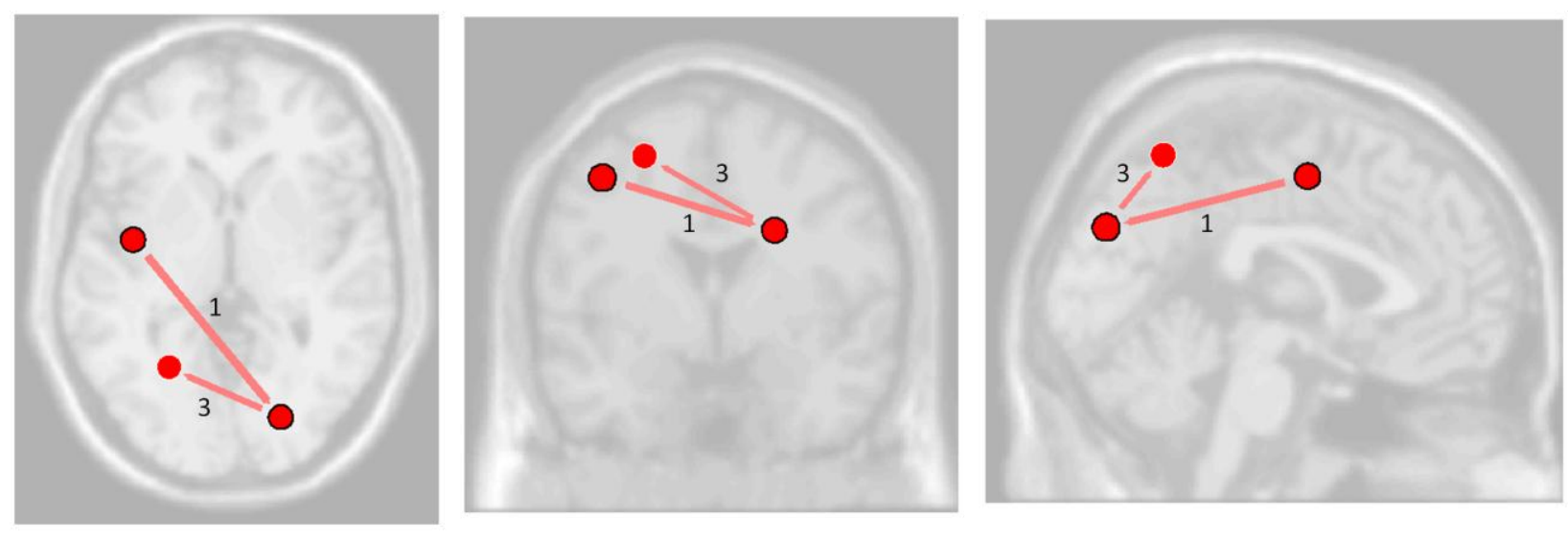

Figura 24. Visões axial, coronal e axial de pares de regiões conectadas funcionalmente com associação significante com QIV para um p-valor corrigido pelo FDR menor que 0,1 . As conexões em vermelho representam correlações positivas. Os números correspondem às classificações mostradas na tabela 11 . 


\begin{tabular}{|c|c|c|c|c|c|c|c|}
\hline Classificação & Conectividade entre as regiões & Correlação & $\begin{array}{c}\text {-valor não- } \\
\text { corrigido }\end{array}$ & $\begin{array}{c}\text { p-valor } \\
\text { corrigido }\end{array}$ & $\begin{array}{c}\text { Limite } \\
\text { inferior }\end{array}$ & $\begin{array}{c}\text { Limite } \\
\text { superior }\end{array}$ \\
\hline 1 & Parietal Sup R & Paracentral lobule L & 0,64 & 0,00019 & 0,017 & 0,36 & 0,81 \\
\hline 2 & Precentral L & Occipital Inf L & 0,64 & 0,00021 & 0,019 & 0,35 & 0,81 \\
\hline 3 & Precentral L & Occipital Inf R & 0,58 & 0,0010 & 0,04 & 0,27 & 0,78 \\
\hline 4 & Frontal Sup Orb L & Rectus L & 0,57 & 0,0012 & 0,09 & 0,26 & 0,78 \\
\hline 5 & Precentral L & SupraMarginal R & 0,55 & 0,0019 & 0,06 & 0,23 & 0,76 \\
\hline 6 & Frontal Sup Orb L & Frontal Sup Orb R & 0,55 & 0,0019 & 0,09 & 0,23 & 0,76 \\
\hline 7 & Precentral R & Frontal Inf Oper R & 0,55 & 0,0020 & 0,18 & 0,23 & 0,76 \\
\hline 8 & Cingulum Mid L & SupraMarginal R & 0,54 & 0,0024 & 0,12 & 0,22 & 0,76 \\
\hline 9 & Cingulum Mid L & SupraMarginal L & 0,54 & 0,0027 & 0,12 & 0,21 & 0,75 \\
\hline 10 & Rectus R & Precuneus R & $-0,53$ & 0,003 & 0,25 & $-0,75$ & $-0,21$ \\
\hline 11 & Occipital Inf R & Postcentral L & 0,53 & 0,003 & 0,12 & 0,21 & 0,75 \\
\hline 12 & Fusiform R & Parietal Sup L & 0,52 & 0,004 & 0,4 & 0,19 & 0,74 \\
\hline 13 & Cingulum Mid R & SupraMarginal L & 0,52 & 0,004 & 0,4 & 0,18 & 0,74 \\
\hline 14 & Cingulum Mid L & Parietal Sup R & 0,51 & 0,005 & 0,15 & 0,17 & 0,74 \\
\hline 15 & Precentral L & Parietal Sup R & 0,51 & 0,005 & 0,15 & 0,17 & 0,74 \\
\hline
\end{tabular}

Tabela 12. Valores de correlação, p-valores não-corrigidos, $p$-valores corrigidos pelo FDR e intervalos de confiança ordenados em ordem decrescente para os valores de correlação para associações entre conectividade entre duas regiões e QIE.
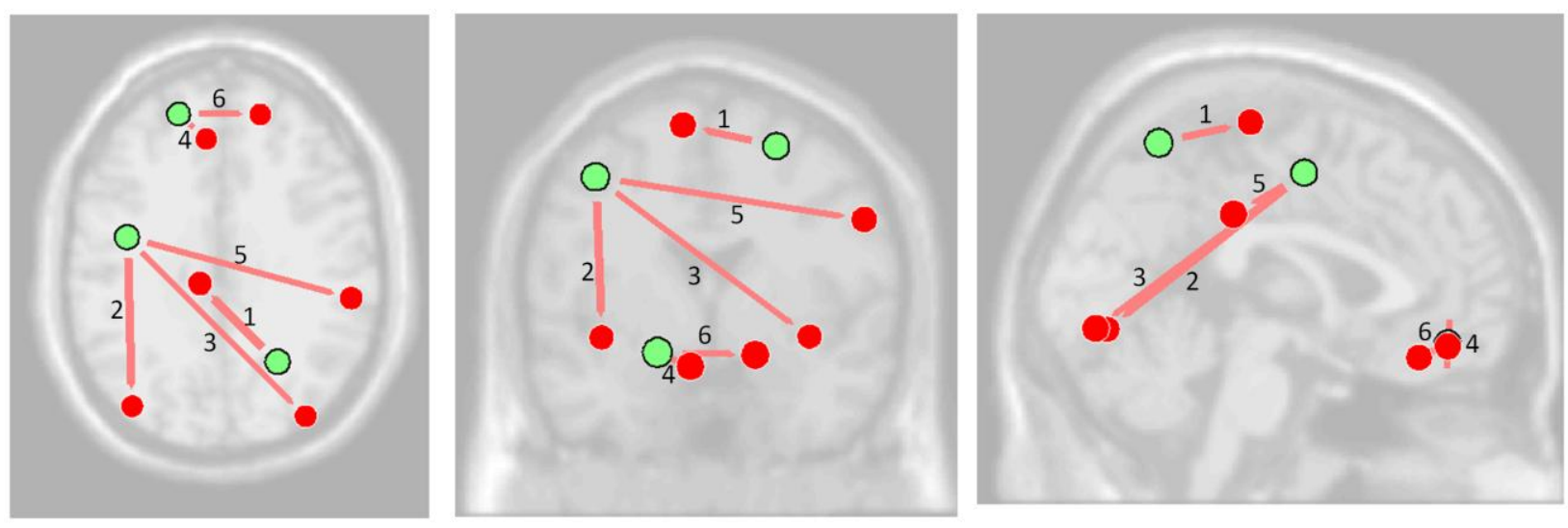

Figura 25. Visões axial, coronal e axial de pares de regiões conectadas funcionalmente com associação significante com QIE para um p-valor corrigido pelo FDR menor que 0,1 . As conexões em vermelho representam correlações positivas. Os números correspondem às classificações mostradas na tabela 12. 


\begin{tabular}{|c|c|c|c|c|c|c|c|}
\hline Classificação & Conectividade entre as regiões & Correlação & $\begin{array}{c}\text {-valor não- } \\
\text { corrigido }\end{array}$ & $\begin{array}{c}\text { p-valor } \\
\text { corrigido }\end{array}$ & $\begin{array}{c}\text { Limite } \\
\text { inferior }\end{array}$ & $\begin{array}{c}\text { Limite } \\
\text { superior }\end{array}$ \\
\hline 1 & Fusiform R & Parietal Sup L & 0,62 & 0,0004 & 0,03 & 0,32 & 0,80 \\
\hline 2 & Precentral L & Occipital Sup R & 0,60 & 0,0006 & 0,05 & 0,30 & 0,79 \\
\hline 3 & Occipital Sup R & Parietal Sup L & 0,59 & 0,0008 & 0,03 & 0,29 & 0,79 \\
\hline 4 & Precentral L & Occipital Inf R & 0,57 & 0,0012 & 0,05 & 0,26 & 0,78 \\
\hline 5 & Thalamus L & Temporal Pole Sup R & 0,54 & 0,0027 & 0,24 & 0,21 & 0,76 \\
\hline 6 & Precentral R & Lingual L & 0,54 & 0,0027 & 0,21 & 0,21 & 0,75 \\
\hline 7 & Precentral L & Occipital Inf L & 0,53 & 0,0028 & 0,07 & 0,21 & 0,75 \\
\hline 8 & Precentral L & Occipital Mid R & 0,53 & 0,0029 & 0,07 & 0,21 & 0,75 \\
\hline 9 & Occipital Inf R & Postcentral L & 0,52 & 0,004 & 0,16 & 0,19 & 0,75 \\
\hline 10 & Cingulum Mid L & SupraMarginal L & 0,52 & 0,004 & 0,3 & 0,19 & 0,75 \\
\hline 11 & Calcarine R & Parietal Sup L & 0,52 & 0,004 & 0,3 & 0,19 & 0,75 \\
\hline 12 & Lingual L & Paracentral lobule L & 0,52 & 0,004 & 0,11 & 0,19 & 0,75 \\
\hline 13 & Precuneus L & Thalamus R & 0,52 & 0,004 & 0,21 & 0,19 & 0,74 \\
\hline 14 & Insula L & Paracentral lobule R & 0,51 & 0,005 & 0,4 & 0,18 & 0,74 \\
\hline 15 & Lingual L & Parietal Sup R & 0,51 & 0,005 & 0,11 & 0,18 & 0,74 \\
\hline
\end{tabular}

Tabela 13. Valores de correlação, p-valores não-corrigidos, $p$-valores corrigidos pelo FDR e intervalos de confiança ordenados em ordem decrescente para os valores de correlação para associações entre conectividade entre duas regiões e QIT.
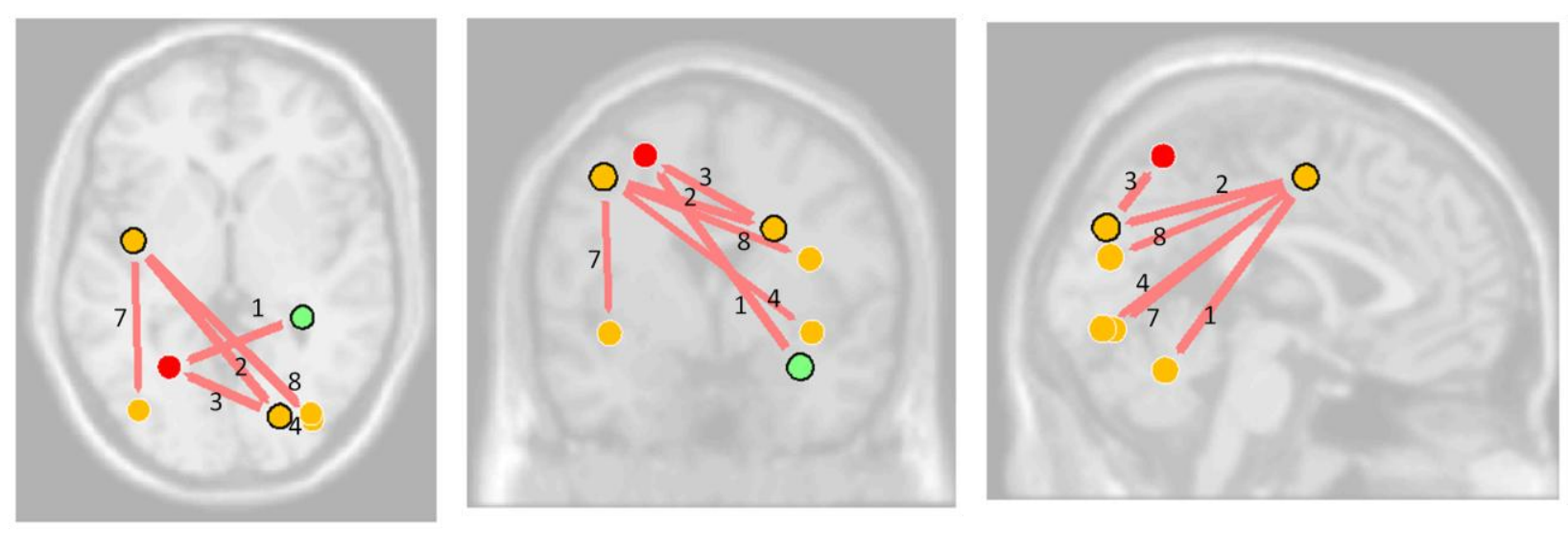

Figura 26. Visões axial, coronal e axial de pares de regiões conectadas funcionalmente com associação significante com QIT para um p-valor corrigido pelo FDR menor que 0,1 . As conexões em vermelho representam correlações positivas. Os números correspondem às classificações mostradas na tabela 13. 


\begin{tabular}{|c|c|c|c|c|c|c|c|}
\hline Classificação & \multicolumn{2}{|c|}{ Conectividade entre as regiões } & Correlação & $\begin{array}{c}\text {-valor não- } \\
\text { corrigido }\end{array}$ & $\begin{array}{c}\text { p-valor } \\
\text { corrigido }\end{array}$ & $\begin{array}{c}\text { Limite } \\
\text { inferior }\end{array}$ & $\begin{array}{c}\text { Limite } \\
\text { superior }\end{array}$ \\
\hline 1 & Heschl L & Heschl R & 0,64 & 0,00018 & 0,016 & 0,36 & 0,82 \\
\hline 2 & Temporal Mid R & Temporal Inf L & $-0,60$ & 0,0007 & 0,06 & $-0,79$ & $-0,29$ \\
\hline 3 & Cingulum Post L & Caudate R & 0,59 & 0,0008 & 0,07 & 0,28 & 0,78 \\
\hline 4 & Rectus L & Putamen R & 0,59 & 0,0008 & 0,07 & 0,28 & 0,78 \\
\hline 5 & Frontal Sup L & Caudate R & 0,56 & 0,0014 & 0,05 & 0,25 & 0,77 \\
\hline 6 & Precentral R & Occipital Mid L & 0,56 & 0,0016 & 0,09 & 0,24 & 0,77 \\
\hline 7 & Frontal Sup Medial L & Caudate R & 0,56 & 0,0017 & 0,05 & 0,24 & 0,77 \\
\hline 8 & Frontal Sup L & Caudate L & 0,55 & 0,0020 & 0,10 & 0,23 & 0,76 \\
\hline 9 & Frontal Sup Medial L & Caudate L & 0,55 & 0,0022 & 0,10 & 0,22 & 0,76 \\
\hline 10 & Rectus R & Putamen R & 0,54 & 0,0024 & 0,22 & 0,22 & 0,76 \\
\hline 11 & Postcentral L* & Heschl R & 0,54 & 0,003 & 0,20 & 0,21 & 0,76 \\
\hline 12 & Precentral R & Lingual L & 0,53 & 0,003 & 0,09 & 0,21 & 0,75 \\
\hline 13 & Precentral R & Calcarine R & 0,53 & 0,003 & 0,09 & 0,21 & 0,75 \\
\hline 14 & Olfactory R & Heschl L & 0,53 & 0,003 & 0,28 & 0,20 & 0,75 \\
\hline 15 & Fusiform L & Postcentral R & 0,53 & 0,003 & 0,29 & 0,20 & 0,75 \\
\hline
\end{tabular}

Tabela 14. Valores de correlação, $p$-valores não-corrigidos, $p$-valores corrigidos pelo FDR e intervalos de confiança ordenados em ordem decrescente para os valores de correlação para associações entre conectividade entre duas regiões e ICV. Regiões marcadas com (*) estão em concordância com Gläscher et al., 2009.
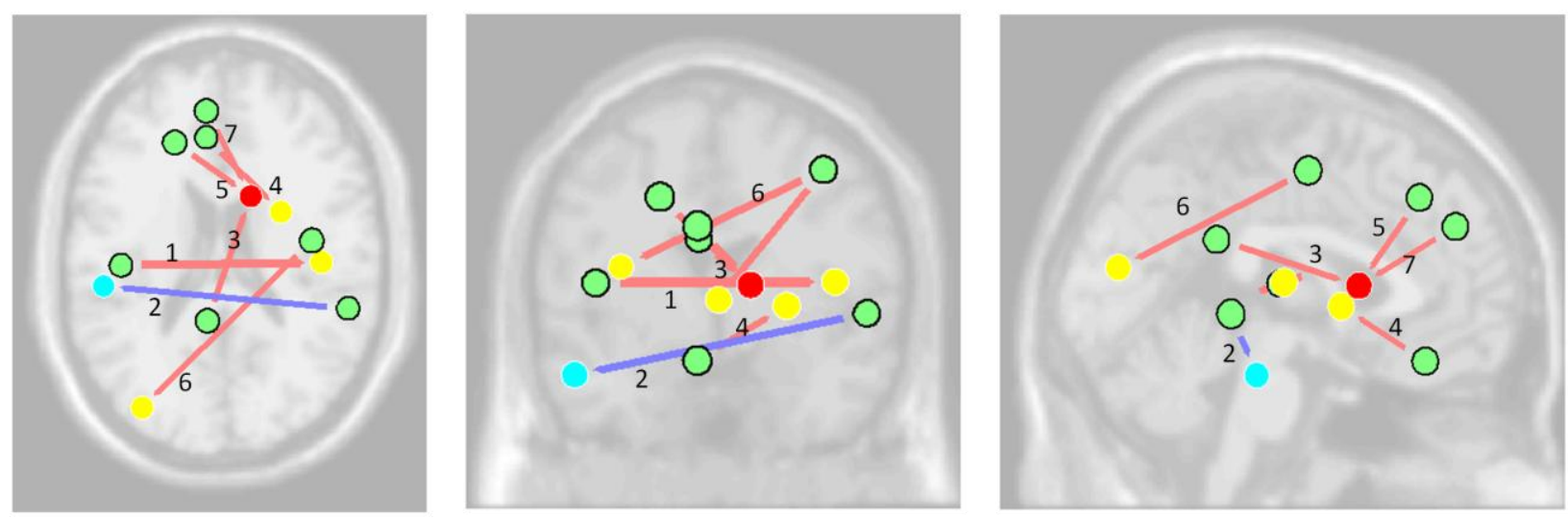

Figura 27. Visões axial, coronal e sagital de pares de regiões conectadas funcionalmente com associação significante com ICV para um p-valor corrigido pelo FDR menor que 0,1 . As conexões em vermelho representam correlações positivas e a conexão em azul representa uma correlação negativa. Os números correspondem às classificações mostradas na tabela 


\begin{tabular}{|c|c|c|c|c|c|c|c|}
\hline Classificação & Conectividade entre as regiões & Correlação & $\begin{array}{c}\text { p-valor não- } \\
\text { corrigido }\end{array}$ & $\begin{array}{c}\text { p-valor } \\
\text { corrigido }\end{array}$ & $\begin{array}{c}\text { Limite } \\
\text { inferior }\end{array}$ & $\begin{array}{c}\text { Limite } \\
\text { superior }\end{array}$ \\
\hline 1 & Precentral L & Occipital Inf L & 0,67 & 0,00008 & 0,007 & 0,40 & 0,83 \\
\hline 2 & Parietal Sup R & Paracentral Lobule L & 0,66 & 0,00011 & 0,013 & 0,38 & 0,82 \\
\hline 3 & Occipital Inf R & Postcentral L & 0,63 & 0,00022 & 0,017 & 0,35 & 0,81 \\
\hline 4 & Precentral L & Occipital Inf R & 0,62 & 0,0004 & 0,017 & 0,32 & 0,80 \\
\hline 5 & Frontal Sup Orb L & Frontal Sup Orb R & 0,61 & 0,0005 & 0,04 & 0,31 & 0,80 \\
\hline 6 & Precentral L & Parietal Sup R & 0,59 & 0,0007 & 0,021 & 0,29 & 0,79 \\
\hline 7 & Rectus R & Precuneus R & $-0,57$ & 0,0011 & 0,10 & $-0,78$ & $-0,26$ \\
\hline 8 & Frontal Sup Orb L & Rectus L & 0,57 & 0,0013 & 0,06 & 0,25 & 0,77 \\
\hline 9 & Occipital Inf R & Postcentral R* & 0,55 & 0,0019 & 0,06 & 0,23 & 0,76 \\
\hline 10 & Lingual L & Putamen R & 0,55 & 0,0021 & 0,14 & 0,23 & 0,76 \\
\hline 11 & Calcarine L & Pallidum L & 0,53 & 0,003 & 0,25 & 0,21 & 0,75 \\
\hline 12 & Precentral R & Frontal Inf Oper L & 0,53 & 0,003 & 0,28 & 0,20 & 0,75 \\
\hline 13 & Temporal Sup R* & Temporal Mid R* & $-0,52$ & 0,004 & 0,3 & $-0,75$ & $-0,20$ \\
\hline 14 & Rectus R & Precuneus L & $-0,52$ & 0,004 & 0,10 & $-0,74$ & $-0,19$ \\
\hline 15 & Precentral L & Occipital Sup R & 0,52 & 0,004 & 0,09 & 0,19 & 0,74 \\
\hline
\end{tabular}

Tabela 15. Valores de correlação, p-valores não-corrigidos, $p$-valores corrigidos pelo FDR e intervalos de confiança ordenados em ordem decrescente para os valores de correlação para associações entre conectividade entre duas regiões e IOP. Regiões marcadas com (*) estão em concordância com Gläscher et al., 2009.
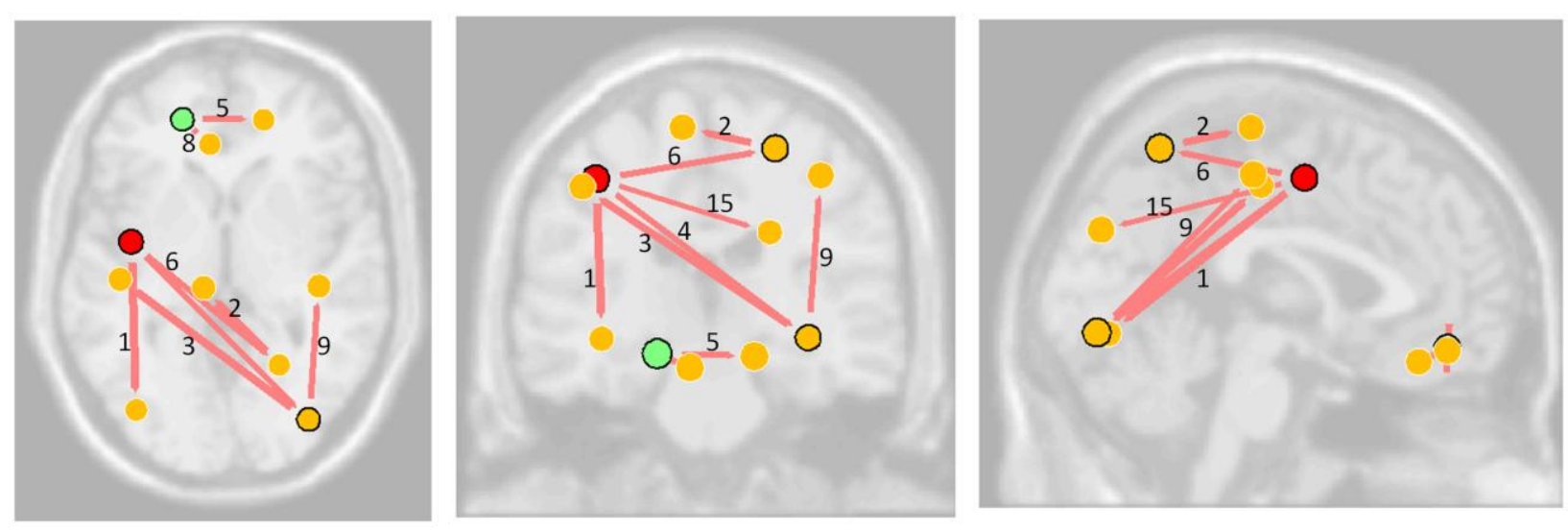

Figura 28. Visões axial, coronal e axial de pares de regiões conectadas funcionalmente com associação significante com IOP para um p-valor corrigido pelo FDR menor que 0,1 . As conexões em vermelho representam correlações positivas. Os números correspondem às classificações mostradas na tabela 15. 


\begin{tabular}{|c|c|c|c|c|c|c|c|}
\hline Classificação & \multicolumn{2}{|c|}{ Conectividade entre as regiões } & Correlação & $\begin{array}{c}\text { p-valor não- } \\
\text { corrigido }\end{array}$ & $\begin{array}{c}\text { p-valor } \\
\text { corrigido }\end{array}$ & $\begin{array}{c}\text { Limite } \\
\text { inferior }\end{array}$ & $\begin{array}{c}\text { Limite } \\
\text { superior }\end{array}$ \\
\hline 1 & Frontal Mid R & Frontal Mid Orb R & $-0,58$ & 0,0009 & 0,06 & $-0,78$ & $-0,28$ \\
\hline 2 & Frontal Mid Orb R & Cingulum Mid R & $-0,56$ & 0,0014 & 0,06 & $-0,77$ & $-0,25$ \\
\hline 3 & Frontal Sup Orb L & Parietal Sup R & $-0,54$ & 0,0023 & 0,14 & $-0,76$ & $-0,22$ \\
\hline 4 & Rolandic Oper R & Temporal Mid R & $-0,54$ & 0,0025 & 0,15 & $-0,76$ & $-0,22$ \\
\hline 5 & Precuneus R & Thalamus R & 0,53 & 0,0029 & 0,25 & 0,21 & 0,75 \\
\hline 6 & Fusiform R & Parietal Sup L & 0,53 & 0,003 & 0,26 & 0,20 & 0,75 \\
\hline 7 & Precentral L* & Occipital Mid R & 0,53 & 0,003 & 0,20 & 0,20 & 0,75 \\
\hline 8 & Frontal Sup Orb R & Parietal Sup R & $-0,53$ & 0,003 & 0,14 & $-0,75$ & $-0,20$ \\
\hline 9 & Frontal Sup L & Temporal Mid R & 0,52 & 0,004 & 0,15 & 0,19 & 0,75 \\
\hline 10 & Frontal Sup L & Temporal Mid L* & 0,52 & 0,004 & 0,3 & 0,19 & 0,74 \\
\hline 11 & Amygdala R & SupraMarginal L & $-0,52$ & 0,004 & 0,3 & $-0,74$ & $-0,18$ \\
\hline 12 & SupraMarginal R & Caudate L & $-0,51$ & 0,004 & 0,4 & $-0,74$ & $-0,18$ \\
\hline 13 & Precentral L* & Occipital Mid L & 0,51 & 0,004 & 0,2 & 0,18 & 0,74 \\
\hline 14 & Cingulum Ant R & Occipital Mid R & $-0,50$ & 0,005 & 0,4 & $-0,73$ & $-0,17$ \\
\hline 15 & ParaHippocampal R & Fusiform R & 0,50 & 0,006 & 0,26 & 0,16 & 0,73 \\
\hline
\end{tabular}

Tabela 16. Valores de correlação, $p$-valores não-corrigidos, $p$-valores corrigidos pelo FDR e intervalos de confiança ordenados em ordem decrescente para os valores de correlação para associações entre conectividade entre duas regiões e IMT. Regiões marcadas com (*) estão em concordância com Gläscher et al., 2009.
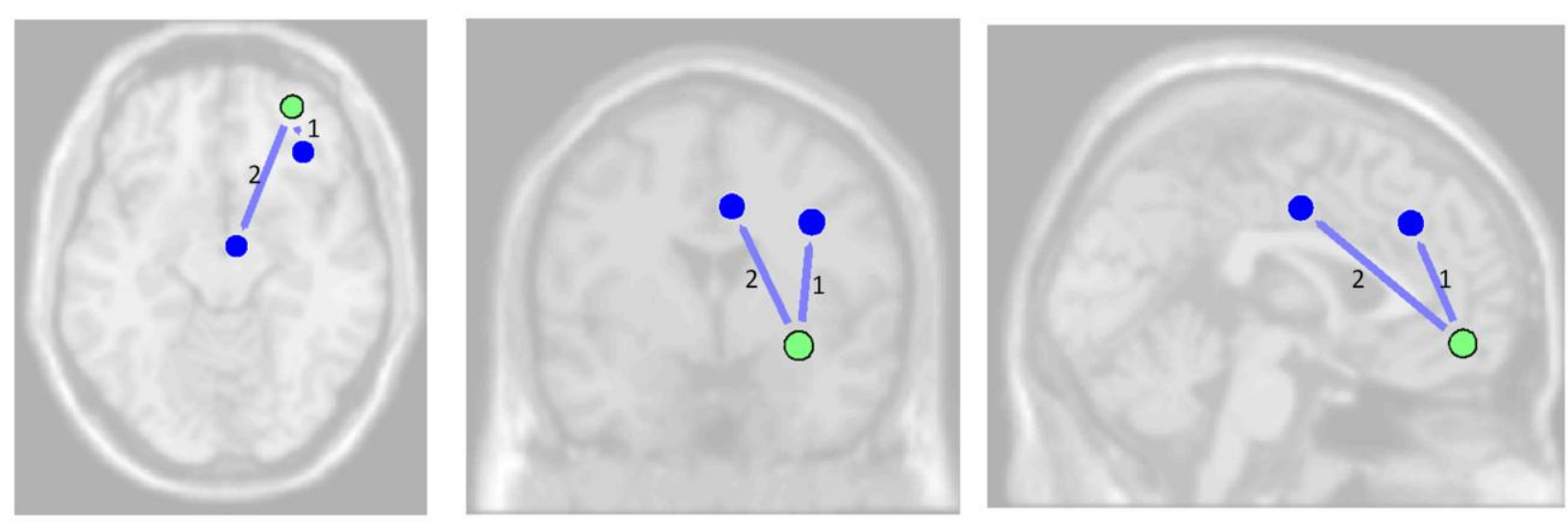

Figura 29. Visões axial, coronal e axial de pares de regiões conectadas funcionalmente com associação significante com IMT para um p-valor corrigido pelo FDR menor que 0,1 . As conexões em azul representam correlações positivas. Os números correspondem às classificações mostradas na tabela 16. 


\begin{tabular}{|c|c|c|c|c|c|c|c|}
\hline \multirow{2}{*}{ Classificação } & \multicolumn{2}{|c|}{ Conectividade entre as regiões } & Correlação & $\begin{array}{c}\text { p-valor não- } \\
\text { corrigido }\end{array}$ & $\begin{array}{c}\text { p-valor } \\
\text { corrigido }\end{array}$ & $\begin{array}{c}\text { Limite } \\
\text { inferior }\end{array}$ & $\begin{array}{c}\text { Limite } \\
\text { superior }\end{array}$ \\
\hline 1 & Cingulum Mid L & SupraMarginal L & 0,58 & 0,0011 & 0,10 & 0,27 & 0,78 \\
\hline 2 & SupraMarginal L & Thalamus L & 0,54 & 0,0027 & 0,12 & 0,21 & 0,75 \\
\hline 3 & Frontal Sup Medial R & Frontal Med Orb L & 0,53 & 0,003 & 0,24 & 0,20 & 0,75 \\
\hline 4 & Heschl L & Temporal Sup L & 0,53 & 0,003 & 0,18 & 0,20 & 0,75 \\
\hline 5 & Precentral R & Rectus L & $-0,53$ & 0,003 & 0,14 & $-0,75$ & $-0,20$ \\
\hline 6 & Putamen R & Temporal Sup L & 0,52 & 0,004 & 0,18 & 0,19 & 0,74 \\
\hline 7 & Insula L & Heschl L & 0,51 & 0,004 & 0,4 & 0,18 & 0,74 \\
\hline 8 & Frontal Mid R* & Hippocampus R & $-0,51$ & 0,004 & 0,4 & $-0,74$ & $-0,18$ \\
\hline 9 & Insula R & Thalamus R & 0,51 & 0,005 & 0,4 & 0,18 & 0,74 \\
\hline 10 & Caudate R & Temporal Mid R & 0,51 & 0,005 & 0,4 & 0,18 & 0,74 \\
\hline 11 & Frontal Inf Oper R & Rectus L & $-0,51$ & 0,005 & 0,14 & $-0,74$ & $-0,17$ \\
\hline 12 & SupraMarginal R & Heschl L & 0,50 & 0,005 & 0,4 & 0,17 & 0,74 \\
\hline 13 & Putamen R & Temporal Mid L & 0,50 & 0,005 & 0,24 & 0,17 & 0,73 \\
\hline 14 & Frontal Sup Medial R & Cingulum Ant L & 0,50 & 0,005 & 0,24 & 0,17 & 0,73 \\
\hline 15 & Frontal Inf Oper R & Supp Motor Area R & 0,50 & 0,005 & 0,24 & 0,17 & 0,73 \\
\hline
\end{tabular}

Tabela 17. Valores de correlação, $p$-valores não-corrigidos, $p$-valores corrigidos pelo FDR e intervalos de confiança ordenados em ordem decrescente para os valores de correlação para associações entre conectividade entre duas regiões e IVP. Regiões marcadas com (*) estão em concordância com Gläscher et al., 2009.

A tabela 17 não mostra nenhum valor de correlação com p-valor corrigido para o FDR menor que 0,1 , o critério para que regiões das tabelas 11 a 16 fossem exibidas em figuras. Sendo assim, não há figura correspondente para as regiões da tabela 17 pois não foram encontradas correlações significantes para p-valores corrigidos menores que 0,1.

Não foram encontradas associações significantes entre IVP e conectividade funcional para um p-valor corrigido $<0,1$.

\section{2. Diferenças de conectividade funcional entre atenção sustentada e estado de repouso}

A figura 30 mostra as médias de correlação para todos os indivíduos dentro de cada uma das redes e entre elas. Foram estudadas três redes, DMN, RNA (rede negativa à atenção) e RPA (rede positiva à atenção). Cada uma dessas redes foram definidas por ROIs especificadas na tabela 2, escolhendo aquelas em que as conectividades funcionais apresentaram maior associação entre número de acertos e tempo de reação nos acertos da tarefa RVIP (Lawrence et al., 2003). A rede DMN foi definida pelas ROls esféricas mostradas na tabela 2 
como MPFC, PCC e LPC, a rede RNA foi definida por N8, N9, N12 e N14 - regiões que exibiram correlações negativas para o grau de atenção sustentada no estudo citado - e a rede RPA foi definida por P16, P19, P20 e P23 - regiões que exibiram correlações positivas para o grau de atenção sustentada no estudo citado. Desta forma, na figura 30 apresentamos as médias das correlações para dentro das redes (DMN-DMN, RNA-RNA e RPA-RPA) e as médias das correlações entre as redes (DMN-RNA, DMN-RPA e RNA-RPA).

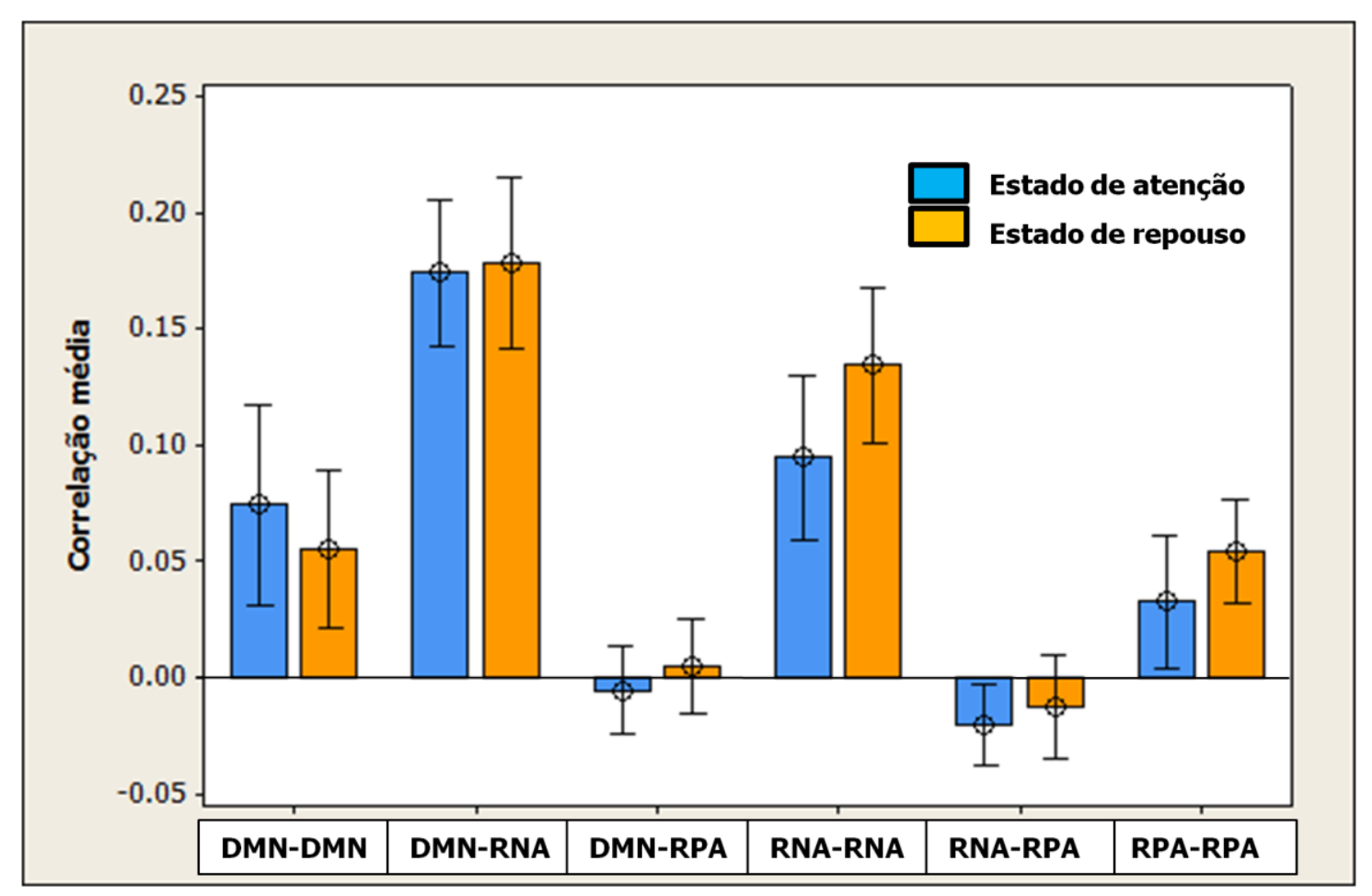

Figura 30. Médias de correlação de todos os participantes dentro de algumas redes funcionais e entre elas. Foram definidas três redes: DMN, RNA (rede negativa à atenção) e RPA (rede positiva à atenção). As barras azuis representam as médias de correlação das ROIs tomadas durante o estado de atenção e as barras laranjas durante o estado de repouso. Os intervalos de confiança também são indicados para um nível de significância de 0,05.

Não foram encontradas diferenças significativas entre nenhuma das médias de correlação dentro das redes ou entre as redes segundo um teste-t de dupla-amostragem para um nível de significância de 0,05. Na figura 30, as barras azuis representam as médias de correlação das ROls tomadas durante o estado de atenção e as barras laranjas durante o estado de repouso. Os intervalos de confiança também são indicados.

Como não foram encontradas quaisquer diferenças significantes no nível da correlação das redes, uma análise mais específica e regional foi realizada. As médias de correlação de todos os participantes entre todas as ROIs definidas na tabela 2 (contidas na DMN, RNA e RPA) foram calculadas separadamente. Apenas os resultados de diferenças significantes de 
correlações entre ROls são mostrados na tabela 31, segundo um teste-t pareado para um nível de significância de 0,05.

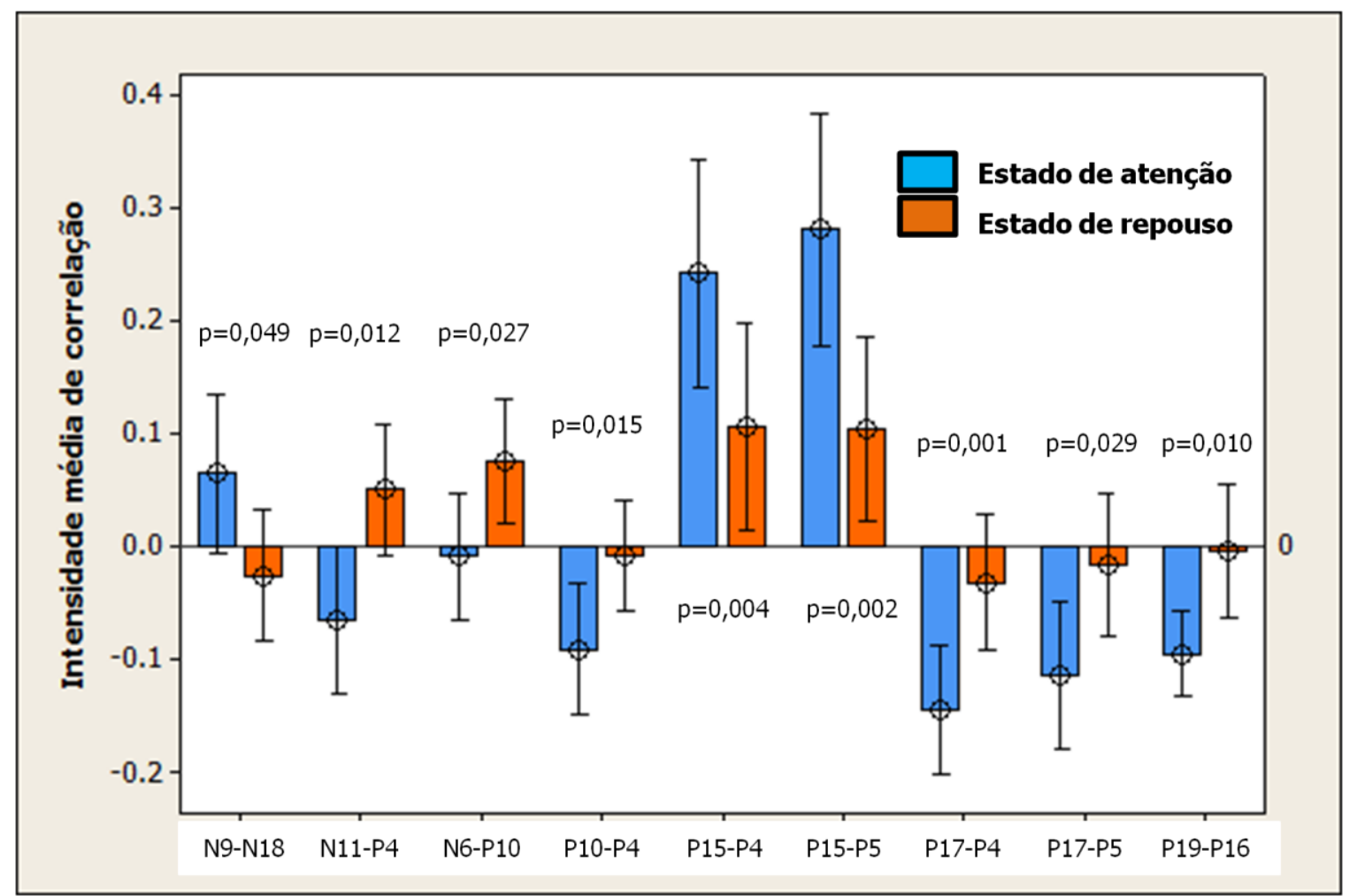

Figura 31. Médias de correlação de todos os participantes para as ROIs definidas na tabela 2 com diferença significante para um nível de significância de $\mathbf{0 , 0 5}$. As abreviaturas das ROls mostradas no eixo horizontal são explicadas segundo a tabela 2. Regiões que fazem parte da rede que responde positivamente à tarefa de atenção sustentada iniciam-se com a letra "P" e regiões que constituem a rede que responde negativamente à tarefa iniciam-se com a letra " $N "$ ". As barras azuis representam as médias de correlação das ROls tomadas durante o estado de atenção e as barras laranjas durante 0 estado de repouso. Os intervalos de confiança também e os p-valores não corrigidos pelo FDR são mostrados. 


\section{Capítulo 5}

\section{Discussão}

Antes de entrar na discussão dos resultados propriamente ditos, é pertinente aqui fazer alguns breves comentários sobre detalhes metodológicos usados neste trabalho. Os resultados serão discutidos em seções separadas dentro deste capítulo seguindo a mesma lógica do capítulo de resultados.

Como explicado na seção 3.5, durante o experimento foi pedido que os participantes mantivessem seus olhos abertos, já que isso produziria correlações mais fortes em relação a olhos fechados (Van Dijk et al., 2010). Segundo os mesmos autores, seis minutos de estado de repouso seriam o suficiente para analisar a conectividade funcional com uma máquina de ressonância magnética de 3 Tesla, os resultados não se alterariam significativamente para tempos maiores. O tempo de estado de repouso e de atenção sustentada para esse estudo foi de 6 minutos e 48 segundos cada um.

Para assegurar que os participantes compreendessem as tarefas pedidas, as instruções foram lidas e explanadas minutos antes do experimento, além de lidas durante o mesmo, informando quando cada uma começaria. Essas instruções são baseadas em artigos de meditação de concentração (Josipovic et al., 2012; Brewer et al., 2011; Pagnoni, 2012; Brefczynski-Lewis et al., 2007; Manna et al., 2010). Embora os participantes não tivessem experiência na meditação de concentração (basicamente baseada em atenção sustentada durante um período de médio ou longo-termo), eles foram incentivados com uma quantia em dinheiro (Brefczynski-Lewis et al., 2007).

O teste WAIS-III foi escolhido para avaliação de domínios intelectuais dos voluntários participantes desse estudo. Alguns fatores contribuíram para essa opção, como a 
reprodutibilidade dos resultados desse teste; extensivo uso no cotidiano de clínicas psiquiátricas e psicológicas; a terceira versão do teste avalia quatro índices fundamentais (ICV, IOP, IMT e IVP) que trazem informações mais específicas sobre o intelecto do participante e dos quais são calculados índices mais gerais; avaliação designada para adultos; experiência do neuropsicólogo em sua aplicação; e mais especificidade e conteúdo avaliado que outros testes para aferição de inteligência, como, por exemplo, o teste RAVEN.

Foi escolhida a análise entre regiões do atlas AAL, em vez da análise voxel-a-voxel, devido a algumas vantagens como a facilidade para classificação e interpretação dos resultados; parcelamento das regiões mais preciso, em comparação ao atlas Talairach; velocidade de processamento dos resultados para nodos reduzidos; e capacidade computacional restrita para análise voxel-a-voxel.

Para a investigação de associações entre pontuações de inteligência com parâmetros globais e locais de rede e conectividade funcional, somente foram usadas matrizes de correlação ponderadas. Dessa forma, considera-se um amplo espectro de intensidades de correlação entre uma região e outra ao invés da definição de um limiar arbitrário em que, acima e abaixo dele, julga-se haver conexão ou não, respectivamente, o que reduz e despreza a quantidade de informações obtidas dos dados. No entanto, para a constatação da organização de mundo pequeno da rede cerebral, é necessário definir vários limiares de correlação entre séries temporais para entender em quais deles esse tipo de organização seria seguido. A transformação das redes cerebrais ponderadas em redes binárias possibilita construções de redes aleatórias equivalentes, necessárias para os cálculos para análise de características de mundo pequeno.

A elaboração da presente dissertação é elemento constituinte para a conclusão do curso de mestrado pela FFCLRP-USP e atividades complementares foram realizadas durante o curso, a fim de introduzir o aluno às práticas acadêmicas, expandir o conhecimento na linha de conectividade funcional no cérebro e divulgar o trabalho desenvolvido ao longo de dois anos. Pode-se citar as seguintes:

- Seminários para o grupo de pesquisa InBrain, localizado na USP Ribeirão Preto, do qual o aluno é integrante. 
- Participação como ouvinte do XXXII Encontro Nacional de Física da Matéria Condensada em maio de 2012 sediado em Águas de Lindoia e do VI Workshop CInAPCe em agosto de 2012 sediado em Campinas/SP.

- Apresentação oral em língua inglesa do trabalho "Analysing the association between brain network topological parameters and individual differences" no XXXIII Encontro Nacional de Física da Matéria Condensada em maio de 2013 sediado em Águas de Lindoia.

- Apresentação de pôster do trabalho "Associação entre parâmetros topológicos de rede cerebral e diferenças individuais" no XVIII Congresso Brasileiro de Física Médica em maio de 2013 sediado em São Pedro/SP.

- Apresentação de pôster do trabalho "Analyzing the association between brain network topological parameters and intellectual performance" no II ComplexNet em outubro de 2013 sediado em Ribeirão Preto/SP.

- Visita ao centro de pesquisa de referência Vanderbilt University Institute of Imaging Science (VUIIS), localizado em Nashville, Tennessee, nos Estados Unidos, assistido pelo Professor Baxter Rogers, PhD., durante novembro e dezembro de 2013. Os objetivos da visita foram a ampliação da experiência do aluno em análise de conectividade funcional do cérebro humano, o aprendizado de técnicas para estudar as redes cerebrais funcionais, a obtenção de experiência com fMRI de campo ultraalto (7 Tesla) e a iniciação de uma colaboração com o Professor Rogers. Durante esta visita, também foi apresentado o seminário "Putting a new edge on the graph: studying functional connectivity at Vanderbilt University".

\section{1. Associações entre parâmetros de rede/conectividade funcional e desempenho intelectual}

As redes cerebrais funcionais, cujos nodos foram definidos pelas diversas regiões contidas no atlas AAL e cujas arestas são as estimativas de conectividade funcional entre elas, seguem a 
organização de mundo pequeno para limiares maiores ou iguais a 0,2 e menores ou iguais a 0,5, o maior limiar usado para esse cálculo, como se vê claramente nas figuras 14 e 15, dado que o comprimento de caminho característico das redes cerebrais foi aproximadamente igual ao das redes aleatórias (ou $\lambda \approx 1$ ) para todos os limiares calculados até 0,5 e o coeficiente de clusterização global das redes cerebrais é maior que a das redes aleatórias (ou $\gamma \gg 1$ ) para limiares superiores ou iguais a 0,2 . Isso foi verificado através de um teste-t de dupla amostragem para os valores de $\lambda$ e $\gamma$, para um valor de significância de 0,05 .

Van den Heuvel e colaboradores, em 2008 e 2009 (para análises de conectividade voxel-avoxel), observaram esse comportamento para limiares entre 0,3 e 0,5 para uma rede cerebral cujos nodos foram definidos por cada um dos voxels que representavam a substância cinzenta (van den Heuvel et al., 2008; van den Heuvel et al., 2009). A discrepância no limite inferior poderia ser atribuída à metodologia diferente de construção das redes adotada, enquanto que o limite superior não é encontrado em nosso estudo devido à indefinição no cálculo do comprimento de caminho característico para redes muito esparsas.

Com as figuras 16 e 17, que mostram, para os dados de van den Heuvel et al. (2009) e para os nossos dados coletados, respectivamente, como se diferenciaram as relações entre comprimento de caminho característico normalizado (lambda)/coeficiente de clusterização normalizado (gama) e pontuações de QIT para os dois estudos. A primeira observação que se pode fazer, é de que se encontra uma correlação negativa significante para o estudo de van den Heuvel et al. e nenhuma correlação para o nosso estudo, referindo-se aos gráficos lambda versus pontuações de QIT. Algumas explicações surgem imediatamente ao se considerar que, no estudo de van den Heuvel et al., os nodos das redes binárias eram cada um dos voxels das imagens funcionais processadas dos participantes, enquanto que no nosso estudo os nodos eram as noventa regiões do atlas AAL. No entanto, pode-se notar, nos dados que foram usados para o nosso estudo, que há uma tendência de lambda diminuir em função do aumento do QIT, embora sem significância estatística. Pela sua magnitude, porém, sugere-se que usando-se um maior número de participantes poderia haver concordância com o que foi encontrado por van den Heuvel et al. No que se refere à relação entre gama e o QIT, nenhum dos dois estudos encontrou correlação significante. 
Posto que a eficiência global é o inverso do comprimento de caminho característico e como se encontrou que, para uma análise de grafos cujos nodos são cada um dos voxels da imagem funcional processada, indivíduos com maior QIT também possuem menores comprimentos de caminho característico e, por conseguinte, maior eficiência global de rede cerebral (van den Heuvel et al., 2009), postula-se que cérebros de indivíduos com maiores pontuações de inteligência são otimizadas para promover um uso mais eficiente do córtex (ou mesmo do cérebro).

Um estudo pioneiro em inteligência e conectividade funcional encontrou intensidades de conectividade funcional significantemente correlacionadas com pontuações de inteligência distribuídas nos lobos frontal, parietal, occipital e límbico, além de conectividades funcionais dentro do lobo frontal e entre regiões frontais e posteriores são importantes para as diferenças de inteligência (Song et al., 2008). Outro trabalho encontrou que as intensidades de algumas conectividades funcionais e a eficiência global da DMN foram diferentes para um grupo de inteligência média e um grupo de inteligência superior (Song et al., 2009). No entanto, nesses dois estudos só o QI de larga-escala (ou QIT) foi medido. Também foi encontrada uma correlação negativa significativa entre QIT e comprimento de caminho característico normalizado $(\lambda)$, além de correlações com o QIE e com o IOP (van den Heuvel et al., 2009). Contudo, deve-se ressaltar que nesse trabalho há diferenças metodológicas às feitas aqui, como a definição de nodos ao nível dos voxels, o que poderia trazer informações mais específicas de cada região, mas poderia introduzir também mais falsos positivos, já que é mais difícil sobrepor regiões com a mesma funcionalidade no nível de um voxel, devido às diferenças anatômicas individuais. Talvez a análise entre regiões maiores e que conservem características similares sejam mais consistentes.

Como visto nos resultados, não são encontradas correlações entre nenhum dos parâmetros globais de rede e as pontuações de inteligência. São estudadas aqui duas medidas de segregação funcional (coeficiente de clusterização e, sua variante clássica, transitividade) e duas medidas de integração funcional (comprimento de caminho característico e, seu inverso, eficiência global). As medidas de segregação funcional no cérebro estão relacionadas com a habilidade do processamento especializado ocorrer dentro de grupos de regiões cerebrais interconectados densamente, enquanto que medidas de integração 
funcional relacionam-se com a habilidade de combinar eficientemente informação especializada de regiões cerebrais distribuídas (Rubinov e Sporns, 2009).

O achado de não associação linear entre uma medida de desempenho intelectual e os parâmetros globais da rede cerebral pode ser um reflexo de alta complexidade do sistema em estudo. Ou ainda, esta não associação pode ser resultado das métricas indiretas ou de algumas fontes de erros utilizadas para avaliar o funcionamento cerebral, seja via fMRI ou testes psicométricos. Por último, o número de participantes poderia ser uma limitação do estudo, mas foi considerado como sendo um valor médio entre os 19 de van den Heuvel et al. (2009) e os 59 de Song et al. (2008). Acredita-se que as informações possam ser, ainda assim, úteis para estudos posteriores.

Pela complexidade e grau de especialização de determinadas regiões do cérebro decidiu-se avaliar as correlações entre parâmetros locais de rede e estimativas de desempenho intelectual, procurando associações a um nível regional.

Uma lista das medidas de parâmetros de rede locais associadas a cada um dos índices de inteligência, ordenadas pelo valor de correlação entre eles e apenas mostradas para um pvalor não corrigido menor que 0,1 estão mostradas nas tabelas 5 a 10 e nas figuras 18 a 23 . Como QIT, QIE e QIV são calculados através dos outros quatro índices fundamentais, um olhar para as regiões que aparecem somente nesses últimos seriam suficientes. Desse modo, nota-se que duas regiões se destacam mais nessas medidas, em incidência, grau de correlação e significância estatística (os p-valores mostrados são os não-corrigidos para múltiplas comparações). São elas: giro frontal superior direito, parte orbital medial (associações entre coeficiente de clusterização local/eficiência local e IOP e entre coeficiente de clusterização local/eficiência local e IVP) e giro fusiforme esquerdo (associações entre coeficiente de clusterização local e ICV e entre coeficiente de clusterização local/eficiência local e IVP). Falar da concordância com van den Heuvel, 2009.

Embora o p-valor não-corrigido não tenha sido estatisticamente significante, a região do giro frontal inferior esquerdo, parte opercular, também foi colocada na tabela 9 para associação de parâmetros de rede locais e IMT, pois foi também encontrada por Cole e colaboradores (2012) e foi a segunda maior correlação dos dois parâmetros medidos para esse índice em 
nosso trabalho. $\mathrm{O}$ achado sugere que essa região tem papel central com influência em todo o cérebro que facilitaria o controle de processos cognitivos (Cole et al., 2012).

Pode-se ver claramente nos resultados que coeficiente de clusterização local e eficiência local estão relacionados. Isso vem diretamente da similaridade matemática dessas duas medidas de segregação: pois quanto maior o número de interconexões com seus vizinhos, e consequente maior coeficiente de clusterização, maior a facilidade na comunicação entre eles e, logo, maior a eficiência local.

Finalmente, ainda para o estudo da inteligência, são analisadas as conectividades funcionais do cérebro e suas associações com os índices intelectuais para obter dados ainda mais específicos às regiões. Listas das quinze maiores medidas de conectividade funcional associadas a cada um dos índices de inteligência, ordenadas pelo valor de correlação em ordem decrescente, são mostradas nas tabelas 11 a 17 e nas figuras 24 a 29 e o p-valor não corrigido para todas elas não chegou a 0,006. Também para esse caso, apenas os quatro índices fundamentais são considerados para listar algumas regiões de destaque. Essas regiões e suas conexões são mostradas a seguir:

- Núcleo caudado direito (associam com ICV as conexões com giro frontal superior esquerdo (parte dorsolateral), giro frontal superior esquerdo (parte medial) e PCC esquerdo);

- Núcleo caudado esquerdo (associam-se com ICV as conexões com giro frontal superior esquerdo (parte dorsolateral) e giro frontal superior esquerdo (parte medial));

- Giro pré-central direito (associam-se com ICV as conexões com giro occipital médio esquerdo, giro lingual esquerdo e fissura calcarina direita);

- Giro pré-central esquerdo (associam-se com IOP as conexões com giro occipital inferior esquerdo, giro occipital inferior direito, giro parietal superior direito e giro occipital superior direito);

- Giro parietal superior direito (associam-se com IOP as conexões com lóbulo paracentral esquerdo e giro pré-central esquerdo (já citada); associam-se com IMT as conexões com giro frontal superior esquerdo (parte orbital medial) e giro frontal superior direito (parte orbital medial)); 
- Giro occipital inferior direito (associam-se com IOP as conexões com giro pós-central esquerdo, giro pré-central esquerdo (já citada) e giro pós-central direito);

- Giro frontal médio direito (parte orbital) (associam-se com IMT as conexões com giro frontal médio direito, e cingulado mediano direito);

- Giro supramarginal esquerdo (associam-se com IVP as conexões com cingulado mediano esquerdo e tálamo esquerdo).

Não são encontradas correspondências entre os achados aqui mostrados e os de Song et al. (2008), Song et al. (2009) e van den Heuvel et al. (2009), todos os estudos tratando-se de associações entre índices de inteligência e intensidades de conectividade funcional ou parâmetros de rede. É evidente que há diferenças metodológicas entre os estudos e também na atribuição das coordenadas das regiões significantes encontradas por esses artigos às regiões correspondentes do atlas AAL para comparação dos resultados. As regiões encontradas por eles podem abranger mais de uma região do atlas AAL ao mesmo tempo ou ser diluídas pelo sinal de uma região inteira do AAL. Além disso, regiões do nosso estudo (definidas no atlas AAL) e da literatura (definidas no atlas de Brodmann) mostram diferenças entre elas e foram comparadas através do website do OBART - The Online Brain Atlas Reconciliation Tool (http://qnl.bu.edu/obart). O aplicativo disponível nessa página propõe uma solução para o problema da nomenclatura comparando relações entre regiões sobrepostas em diferentes atlas cerebrais humanos (Bohland et al., 2009). No entanto, esse método diz qual região de um atlas está mais contida e/ou contém mais uma região de outro atlas, de modo que nessa conversão entre atlas é feita uma aproximação, podendo levar a uma comparação errônea dos resultados encontrados.

No estudo de Gläscher e colaboradores (2009), cérebros de 241 sujeitos com algum dano cerebral focalizado foram mapeados a fim de investigar as bases neurais para a sustentação dos quatro índices de inteligência fundamentais. Basicamente, relações estatisticamente significantes entre lesão e déficit de inteligência foram encontradas no córtex frontal inferior esquerdo para ICV, no córtex frontal e parietal esquerdo para IMT, córtex parietal direito para IOP, mas nenhuma localização única confiável para IVP. Algumas concordâncias entre o estudo citado e o presente estudo são mostradas, com um sinal de asterisco, nas tabelas 14 a 17. 
Radulescu e colaboradores (2013) mediram a conectividade funcional entre núcleo caudado e córtex durante um estudo de neuroimagem funcional de geração de linguagem (ou fluência verbal) para investigar por diferenças atribuíveis a heterogeneidade da substância cinzenta em participantes com síndrome de Asperger. A propósito, conexões com o núcleo caudado foram frequentemente relacionadas com ICV no presente estudo. O núcleo caudado, na verdade, é uma região cuja ativação é associada a processos narrativos em relação a não-narrativos e pode contribuir para maior precisão no sequenciamento de narrativas (Price, 2010).

Como nesse estudo muitas possibilidades de análise podem ser realizadas (noventa regiões cerebrais ao quadrado correlacionando-se com sete índices de inteligência para a análise de conectividade, noventa regiões correlacionando-se com sete índices de inteligência para a análise de parâmetros de rede locais), em algum momento seria possível achar alguma associação por mero acaso. Assim, por um lado, considerar apenas o p-valor não corrigido para afirmar significância estatística inseriria muitos falsos positivos na análise. Por outro lado, p-valores corrigidos pelo FDR positivo (False Discovery Rate) para toda a análise feita no estudo de inteligência, exterminaria a significância estatística de todos os valores, inclusive verdadeiros positivos. Logo, aqui foi considerada a correção pelo FDR positivo por regiões, o que seria um equilíbrio entre análises permissivas ou rigorosas demais. $\mathrm{O}$ valor do p-corrigido aqui tem a função de mostrar a robustez dos resultados, mesmo que ele não tenha assumido valores tão baixos.

Algumas evidências sugerem que haja verdadeiros positivos nos resultados e que alguns deles não surgiram por acaso, como o aparecimento da mesma região várias vezes ou de sua correspondente simétrica na lista de correlações mais importantes. Embora admita-se que alguns resultados listados possam ser, na realidade, falso-positivos, a forma com que eles são listados, com as maiores correlações no topo, seus correspondentes p-valores nãocorrigidos e corrigidos e intervalos de confiança, pode ser útil e informativo para futuros estudos e corroboração de quais associações são verdadeiro-positivos.

Os resultados significativos para associação entre conectividade e índices de inteligência tiveram correlação moderada e para associação entre parâmetros de rede locais e índices de 
inteligência tiveram correlação entre fraca e moderada. Possivelmente, um aumento do número de sujeitos levaria a resultados mais conclusivos.

Em suma, não foram encontradas correlações entre nenhum dos parâmetros globais de rede calculados e as pontuações de inteligência obtidas pelos teste WAIS-III. Alguns parâmetros de rede locais, destacando-se o giro frontal superior direito e giro fusiforme esquerdo, quando avaliados de forma individual, evidenciaram correlações com os índices de inteligência. Diversas associações estatisticamente significantes entre conectividades funcionais do cérebro e os quatro índices de inteligência fundamentais foram encontrados, principalmente no núcleo caudado e giro pré-central direito (associando-se com ICV); giro pré-central esquerdo, giro parietal superior direito e giro occipital inferior direito (associando-se com IOP); giro frontal médio direito (associando-se com IMT); e giro supramarginal esquerdo (associando-se com IVP).

\section{2. Diferenças de conectividade funcional entre atenção sustentada e estado de repouso}

Ao analisar como as conectividades funcionais variam entre um estado de repouso e um estado de atenção sustentada, não foram encontrados resultados de diferenças significativas para um teste-t de dupla-amostragem com nível de significância de 0,05. A hipótese inicial era de que haveria uma maior anti-correlação entre a $\mathrm{DMN}$ e redes positivas à tarefa no estado de atenção sustentada, posto que o cérebro em divagação está associado com maior atividade na DMN (Mason et al., 2007) e medidas de conectividade funcional no estado de repouso exibem um forte acoplamento entre a $D M N$ e redes positivas à tarefa em forma de anti-correlações (Fox et al., 2005). Logo, ao requerer que o participante evitasse o exercício da divagação durante o estado de atenção sustentada, uma rede positiva à tarefa de atenção exibiria ativação enquanto que a DMN exibiria desativação. Por outro lado, permitir que o indivíduo divagasse livremente no estado de repouso ativaria a DMN e desativaria a rede positiva à tarefa de atenção sustentada. Newton et al. reportou uma maior anticorrelação entre rede positiva à tarefa e DMN durante o desempenho de uma tarefa de memória de trabalho (Newton et al., 2011) e em nosso trabalho foi lançada a hipótese de que o mesmo aconteceria para um estado de atenção sustentada. Entretanto, não foram encontradas diferenças significativas entre correlações em redes positivas à tarefa e redes 
negativas à tarefa entre os dois estados aqui estudados para um nível de significância de 0,05. Portanto, a hipótese de maior anti-correlação para o estado de atenção não pode ser validada conforme a metodologia adotada.

Constata-se, pela figura 30, que a intensidade de correlação média dentro das redes estudadas e entre elas não mostram diferença significante entre repouso e atenção. Newton et al. (2011), porém, encontrou uma maior correlação dentro da rede positiva e da rede negativa à tarefa de memória de trabalho para a tarefa em relação ao repouso. Os mesmos achados não foram encontrados em nosso trabalho, ao contrário, as correlações dentro da rede positiva e da rede negativa à tarefa de atenção sustentada parecem mostrar uma tendência a diminuírem com a tarefa. No entanto, os resultados não possuem força estatística para discordar dos achados de Newton et al. Embora a definição de ROIs e análise de conectividade nos dois trabalhos seja bem semelhante nos dois trabalhos, a tarefa utilizada foi diferente e poderia se especular que o aumento na conectividade média dentro das redes depende da tarefa utilizada.

A intensidade média de correlação entre a $\mathrm{DMN}$ e a rede negativa à tarefa de atenção sustentada, além de não mostrar diferença significante entre os dois estados, se mostrou mais correlacionada que as outras redes. Isso se deve ao fato de que as duas redes são negativas à tarefa e mostraram desativações correlacionadas. Vale lembrar que a rede negativa à tarefa não é tão específica à tarefa requisitada, geralmente mostram desativação como um todo e não localmente (Shulman et al., 1997).

As ROls positivas e negativas à tarefa de atenção consideradas para esse estudo foram definidas de um estudo anterior (Lawrence et al., 2003), que, embora também trate do assunto da atenção sustentada, há diferenças no tipo de tarefa utilizada (o estudo de Lawrence et al. faz uso do teste RVIP e nosso estudo, a tarefa de concentração). Um estudo das diferenças de ativação entre estados que envolvem concentração e divagação poderia ser mais específico e preciso para as análises de conectividade propostas aqui.

Como não foram encontradas diferenças significativas entre correlações médias no nível das redes, a correlação média entre as 23 regiões definidas na tabela 2 foram examinadas em busca de variações de conectividade funcional suportando a concentração em um objeto. Apenas as nove conexões que evidenciaram diferenças estatisticamente significantes são 
mostradas na figura 31 para um nível de significância de 0,05. O p-valor mostrado para cada um dos testes estatísticos realizados é o não-corrigido. Para p-valores corrigidos para o FDR nenhuma correlação se mostraria significante. Todavia, assim como discutido para o estudo de inteligência, isso mostra a força dos achados e não necessariamente uma segregação entre verdadeiros e falsos positivos.

Nota-se um aumento na magnitude das correlações positivas durante a atenção sustentada para duas conexões: giro frontal médio/inferior esquerdo conectado com giro occipital esquerdo (P15-P4) e giro fusiforme direito (P15-P5). Essas regiões responderam positivamente à tarefa de Lawrence et al. (2003) e o aumento da correlação para a tarefa achado aqui condiz com Newton et al. (2011). Também foram encontradas regiões que se tornaram mais anti-correlacionadas durante a atenção sustentada quando durante o repouso não havia correlação entre elas ou mesmo anti-correlação relativamente menor. Esse é o caso das correlações ínsula anterior esquerda e giro occipital esquerdo (P10-P4), giro frontal médio/superior direito e giro occipital esquerdo (P17-P4), giro frontal médio/superior direito e giro fusiforme direito (P17-P5) e pré-SMA (área motora suplementar) e giro frontal médio/inferior direito (P19-P16). Não foram encontrados estudos que dessem respaldo a esses achados. A conexão entre as regiões da rede negativa à tarefa, córtex frontal medial esquerdo e giro temporal médio esquerdo (N9-N18), tornouse mais positivamente correlacionada com a tarefa, concordando com Newton et al., 2011.

Para conexões entre regiões positivas à tarefa e regiões negativas à tarefa, nota-se que elas se tendem a se dirigir para uma anti-correlação para a tarefa de atenção. Isso condiz com Newton et al. (2011). Isso aconteceu com as conexões entre ínsula média esquerda e giro occipital esquerdo (N11-P4) e giro parahipocampal esquerdo e ínsula anterior esquerda (N6P10). Isso endossa a ideia de que as anti-correlações podem ser importantes para a organização cerebral, atuando como papel diferenciador ao segregar processos neurais que se baseiam em objetivos opostos ou representações competitivas (Fox et al., 2005).

Criticamente, como nenhum objeto de fixação visual foi mostrado para a condição de repouso e uma pequena cruz foi mostrada para a condição de atenção, admite-se que variações de conectividade associadas com a atenção podem estar relacionadas também com o estímulo visual. $\mathrm{O}$ giro occipital aparece em quatro das nove diferenças significantes. 
Embora não tenham sido encontrados resultados que confirmassem a hipótese de que haveria uma maior anti-correlação de redes extrínsecas e intrínsecas como um todo para o estado de atenção focada em relação ao estado de repouso, foram encontradas algumas diferenças estatisticamente significantes para conexões locais dentro das redes positivas e negativas à tarefa. Notou-se que há uma tendência à anti-correlação durante o estado de atenção para conexões entre regiões positivas e regiões negativas à tarefa. 


\section{Capítulo 6}

\section{Conclusões}

As redes cerebrais funcionais, para nodos definidos como as diversas regiões definidas pelo atlas AAL e para arestas definidas como as estimativas de conectividade funcional entre eles, seguem a organização de mundo pequeno para limiares maiores ou iguais a 0,2 e pelo menos menores ou iguais a 0,5 , posto que o limite superior foi definido pelo maior limiar usado para o cálculo nesse estudo.

Não foram encontradas correlações entre nenhum dos parâmetros globais de rede calculados (comprimento de caminho característico, eficiência global, coeficiente de clusterização médio e transitividade) e as pontuações de inteligência obtidas pelos teste WAIS-III.

Alguns parâmetros de rede locais, destacando-se o giro frontal superior direito e giro fusiforme esquerdo, quando avaliados de forma individual, evidenciaram correlações com os índices de inteligência. Ao ser considerado o efeito de múltiplas comparações, não foram encontradas associações estatisticamente significativas ( $p$-valor corrigido pelo FDR<0.05), embora o p-valor não-corrigido seja bem pequeno.

Diversas associações estatisticamente significantes entre conectividades funcionais do cérebro e os quatro índices de inteligência fundamentais foram encontrados, principalmente no núcleo caudado e giro pré-central direito (associando-se com ICV); giro pré-central esquerdo, giro parietal superior direito e giro occipital inferior direito (associando-se com IOP); giro frontal médio direito (associando-se com IMT); e giro supramarginal esquerdo (associando-se com IVP).

Não foram encontrados resultados que confirmassem a hipótese de que, para indivíduos normais, sem experiência em sustentação de concentração, haveria uma maior anticorrelação de redes extrínsecas e intrínsecas como um todo para o estado de atenção 
focada em relação ao estado de repouso. Entretanto, foram encontradas algumas diferenças estatisticamente significantes para conexões locais dentro das redes positivas e negativas à tarefa, evidenciadas por um aumento na magnitude das correlações positivas ou negativas durante a atenção sustentada. Para conexões entre regiões positivas e regiões negativas à tarefa, nota-se que elas tendem a se anti-correlacionar durante o estado de atenção, endossando a ideia de que as anti-correlações atuam segregando processos neurais que se baseiam em objetivos antagônicos. 


\section{Capítulo 7}

\section{Referências}

ANDREWS-HANNA, J. R. et al. Disruption of large-scale brain systems in advanced aging. Neuron, Riverport Lane, v. 56, p. 924-935, 2007.

BECKMANN, C. F. et al. Investigations into resting-state connectivity using independent component analysis. Philosophical Transactions of the Royal Society, London, v. 360, p. 10011013, 2005.

BISWAL, B. et al. Functional connectivity in the motor cortex of resting human brain using echoplanar MRI. Magnetic Resonance in Medicine, Malden, v. 34, p. 537-541, 1995.

BOHLAND, J. W. et al. The brain atlas concordance problem: quantitative comparison of anatomical parcellations. PLOS ONE, San Francisco, v. 4, n. 9, p. 1-18, 2009.

BREFCZYNSKI-LEWIS, J. A. et al. Neural correlates of attentional expertise in long-term meditation practitioners. PNAS, Washington, v. 104, n. 27, p. 11483-11488, 2007.

BREWER, J. A. et al. Meditation experience is associated with differences in default mode network activity and connectivity. PNAS, Washington, v. 108, n. 50, p. 20254-20259, 2011.

BULLMORE, E.; SPORNS, O. Complex brain networks: graph theoretical analysis of structural and functional systems. Nature Reviews, London, v. 10, p. 186-198, 2009.

CABEZA, R.; NYBERG, L. Imaging cognition II - An empirical review of 275 PET and fMRI studies. Journal of Cognitive Neuroscience, Cambridge, v. 12, n. 1, p. 1-47, 2000.

CASTELLANOS, F. X. et al. Cingulate-precuneus interactions: a new locus of dysfunction in adult attention-deficit/hyperactivity disorder. Biological Psychiatry, Philadelphia, v. 63, n. 3, p. 332337, 2008.

COLE, M. W. et al. Global connectivity of prefrontal cortex predicts cognitive control and intelligence. The Journal of Neuroscience, Washington, v. 32, n. 26, p. 8988-8999, 2012.

CHKLOVSKII, D. B.; SCHIKORSKI, T.; STEVENS, C. F. Wiring optimization in cortical circuits. Neuron, Riverport Lane, v. 34, p. 341-347, 2002.

DAMOISEAUX, J. S. et al. Consistent resting-state networks across healthy subjects. PNAS, Washington, v. 103, n. 37, p. 13848-13853, 2006. 
FARB, N. A. S. et al. Attending to the present: mindfulness meditation reveals distinct neural modes of self-reference. SCAN, Oxford, v. 2, p. 313-322, 2007.

FONTES, F. Alterações da default mode network provocadas pela ingestão de Ayahuasca investigadas por ressonância magnética funcional. Natal: UFRN, 2012. 112 p.

FOX, M. D. et al. The human brain is intrinsically organized into dynamic, anticorrelated functional networks. PNAS, Washington, v. 102, n. 27, p. 9673-9678, 2005.

FOX, M. D. et al. The global signal and observed anticorrelated resting state brain networks. Journal of Neurophysiology, Bethesda, v. 101, p. 3270-3283, 2009.

GLÄSCHER, J. et al. Lesion mapping of cognitive abilities linked to intelligence. Neuron, Riverport Lane, v. 61, p. 681-691, 2009.

GONG, G. et al. Age- and gender-related differences in the cortical anatomical network. The Journal of Neuroscience, Washington, v. 29, n. 50, p. 15684-15693, 2009.

GREICIUS, M. D. et al. Default-mode network activity distinguishes Alzheimer's disease from healthy aging: evidence from functional MRIA default mode of brain function. PNAS, Washington, v. 101, n. 13, p. 4637-4642, 2004.

GUSNARD, D.; RAICHLE, M. E. Searching for a baseline: functional imaging and the resting human brain. Nature Reviews, London, v. 2, p. 685-694, 2001.

HASENKAMP, W.; BARSALOU, L. W. Effects of meditation experience on functional connectivity of distributed brain networks. Frontiers in Human Neuroscience, Lausanne, v. 6, n. 38, p. 1-14, 2012.

JANG, J. H. et al. Increased default mode network connectivity associated with meditation. Neuroscience Letters, Philadelphia, v. 10, n. 56, p. 1-5, 2010.

JOSIPOVIC, Z. et al. Influence of meditation on anti-correlated networks in the brain. Frontiers in Human Neuroscience, Lausanne, v. 5, n. 183, p. 1-11, 2012.

KILPATRICK, L. A. et al. Impact of mindfulness-based stress reduction training on intrinsic brain connectivity. Neurolmage, Philadelphia, v. 56, p. 290-298, 2011.

KLYACHKO, V. A.; STEVENS, C. F. Connectivity optimization and the positioning of cortical areas. PNAS, Washington, v. 100, p. 7937-7941, 2003.

LAWRENCE, N. S. et al. Multiple neuronal networks mediate sustained attention. Journal of Cognitive Neuroscience, Cambridge, v. 15, n. 7, p. 1028-1038, 2003.

MANNA, A. et al. Neural correlates of focused attention and cognitive monitoring in meditation. Brain Research Bulletin, Philadelphia, v. 82, p. 46-56, 2010. 
MASON, M. F. et al. Wandering minds: the default network and stimulus-independent thought. Science, Washington, v. 315, p. 393-395, 2007.

MORGAN, V. L.; ABOU-KHALIL, B. (2011). Investigations of Brain Network Alterations in Epilepsy Using Functional Magnetic Resonance Imaging. In: GUNEL, M. K. Management of Epilepsy Research, Results and Treatment. New York: InTech, 2011. cap. X, p. 1-27.

NEWTON, A. T. et al. Modulation of steady state functional connectivity in the default mode and working memory networks by cognitive load. Human Brain Mapping, Malden, v. 32, p. 16491659, 2011.

PAGNONI, G. Dynamical properties of BOLD activity from the ventral posteromedial cortex associated with meditation and attentional skills. The Journal of Neuroscience, Washington, $v$. 32, n. 15, p. 5242-5249, 2012.

POWER, J. D. et al. Evidence for hubs in human functional brain networks. Neuron, Riverport Lane, v. 79, p. 798-813, 2013.

PRICE, C. J. The anatomy of language: a review of $100 \mathrm{fMRI}$ studies published in 2009. Annals of the New York Academy of Sciences, v. 1191, p. 62-88, 2010.

RADULESCU, E. et al. Abnormalities in fronto-striatal connectivity within language networks relate to differences in grey-matter heterogeneity in Asperger syndrome. Neurolmage: Clinical, Philadelphia, v. 2, p. 716-726, 2013.

RAICHLE, M. E. et al. A default mode of brain function. PNAS, Washington, v. 98, n. 2, p. 676-682, 2001.

RUBINOV, M.; SPORNS, O. Complex network measures of brain connectivity: uses and interpretations. Neurolmage, Philadelphia, v. 52, p. 1059-1069, 2010.

SHULMAN, G. L. et al. Common blood flow changes across visual tasks: II. Decreases in cerebral cortex. Journal of Cognitive Neuroscience, Cambridge, v. 9, n. 5, p. 648-663, 1997.

SONG, M. et al. Brain spontaneous functional connectivity and intelligence. Neurolmage, Philadelphia, v. 41, p. 1168-1176, 2008.

SONG, M. et al. Default network and intelligence difference. IEEE Transactions on Autonomous Mental Development, Piscataway Township, v. 1, n. 2, p. 101-109, 2009.

SPORNS, O; Zwi, J. D. The small world of the cerebral cortex. Neuroinformatics, New York, v. 2, p. 145-162, 2004.

TAKEUCHI, $\mathrm{H}$. et al. Cerebral blood flow during rest associates with general intelligence and creativity. PLOS ONE, San Francisco, v. 6, n. 9, p. 1-9, 2011. 
TIAN, L. et al. Altered resting-state functional connectivity patterns of anterior cingulate cortex in adolescents with attention deficit hyperactivity disorder. Neuroscience Letters, Philadelphia, v. 400, p. 39-43, 2006.

TIAN, L. et al. Hemisphere- and gender-related differences in small-world brain networks: A resting-state functional MRI study. Neurolmage, Philadelphia, v. 54, p. 191-202, 2011.

TZOURIO-MAZOYER, $\mathrm{N}$. et al. Automated anatomical labeling of activations in SPM using a macroscopic anatomical parcellation of the MNI MRI single-subject brain. Neurolmage, Philadelphia, v. 15, p. 273-289, 2002.

UDDIN, L. et al. Functional Connectivity of Default Mode Network Components: Correlation, Anticorrelation, and Causality. Human Brain Mapping, Malden, v. 30, p. 625-637, 2009.

VAIDYA, C. J.; GORDON, E. M. Phenotypic variability in resting state functional connectivity: current status. Brain Connectivity, New Rochelle, v. 3, n. 2, p. 99-120, 2013.

VAN DEN HEUVEL, M. P. et al. Small-world and scale-free organization of voxel-based restingstate functional connectivity in the human brain. Neurolmage, Philadelphia, v. 43, p. 528-539, 2008.

VAN DEN HEUVEL, M. P. et al. Efficiency of functional brain networks and intellectual performance. The Journal of Neuroscience, Washington, v. 29, n. 23, p. 7619-7624, 2009.

VAN DEN HEUVEL, M. P.; HULSHOFF POL, H. E. Exploring the brain network: A review on restingstate fMRI functional connectivity. European Neuropsychopharmacology, Philadelphia, v. 20, p. 519-534, 2010.

VAN DIJK, K. R. A. et al. Intrinsic Functional Connectivity As a Tool For Human Connectomics: Theory, Properties, and Optimization. Journal of Neurophysiology, Bethesda, v. 103, p. 297-321, 2010.

VIEIRA, G. Modelagem matemática-computacional da conectividade cerebral em ressonância magnética funcional para o estudo do estado de repouso. São Paulo: USP, 2011. 95 p.

WANG, L. et al. Gender effect on functional networks in resting brain. LNCS, New York, v. 4987, p. 160-168, 2008.

WATTS, D. J.; STROGATZ, S. H. Collective dynamics of 'small-world' networks. Nature, London, v. 393, p. 440-442, 1998.

WECHSLER, D. The measurement of adult intelligence. Williams \& Wilkins Co., Baltimore, 1939.

WEISSENBACHER, A. et al. Correlation and anticorrelations in resting-state functional connectivity MRI - A quantitative comparison of preprocessing strategies. Neurolmage, Philadelphia, v. 47, p. 1408-1416, 2009. 
WHITFIELD-GABRIELI, S.; NIETO-CASTANON, A. Conn: a functional connectivity toolbox for correlated and anticorrelated brain networks. Brain Connectivity, New Rochelle, v. 2, n. 3, p. 125-141, 2012.

WU,K. et al. A longitudinal study of structural brain network changes with normal aging. Frontiers in Human Neuroscience, Lausanne, v. 7, n. 113, p. 1-12, 2013.

YAN, C. et al. Sex- and brain size-related small-world structural cortical networks in young adults: A DTI tractography study. Cerebral cortex, Oxford, v. 21, p. 449-458, 2011. 